2002

\title{
Evaluations of concrete overlays for bridge deck applications
}

Shiwei Luo

West Virginia University

Follow this and additional works at: https://researchrepository.wvu.edu/etd

\section{Recommended Citation}

Luo, Shiwei, "Evaluations of concrete overlays for bridge deck applications" (2002). Graduate Theses, Dissertations, and Problem Reports. 1284.

https://researchrepository.wvu.edu/etd/1284 


\title{
Evaluations of Concrete Overlays for Bridge Deck Applications
}

\author{
Shiwei Luo
}

Thesis submitted to the

College of Engineering and Mineral Resources

at West Virginia University

in partial fulfillment of the requirements

for the degree of

Master of Science
in

Julio F. Davalos, Ph.D., Chair

Indrajit Ray, Ph.D., Co-Chair

Karl E. Barth, Ph.D.

Department of Civil and Environmental Engineering

Morgantown, West Virginia

2002

Keywords: Latex, Silica Fume, Fiber, Concrete Overlays, Interface, Bond Strength 


\section{ABSTRACT \\ Evaluations of Concrete Overlays for Bridge Deck Applications}

\section{Shiwei Luo}

Protective concrete deck overlays have been successfully used by WVDOH in a number of old and new concrete bridge decks to extend their service life, but in several cases delamination and failures have been observed. A comprehensive study has been recently defined to investigate overlays performance and delamination, culminating eventually in the development of specifications in collaboration with WVDOH and the Contractors and Building Supplies Associations of WV.

The present study is an exploratory research concerned with evaluations of four types of overlays for bridge deck applications, and include: latex modified concrete (LMC), microsilica modified concrete (MMC), microsilica modified concrete with flyash (MMC-FA) and polypropylene fiber-reinforced concrete (FRC). The laboratory mixtures were developed using local aggregates, Type-I cement and commercial admixtures and fibers. Mixtures were evaluated by several tests in both fresh and hardened states, including compressive, tensile, and flexural strengths, shrinkage and chloride-ion permeability. To evaluate the performance of overlay-substrate interface behavior, a new compression loading block shear apparatus was developed, and for each type of overlay, double wedge-type bi-layer specimens of overlay-substrate were tested for two different substrate surface preparation conditions: Mechanical abrasion and chemical etching.

The results show that FRC had the highest compressive and split tensile strengths, and MMC and MMC-FA had very low chloride permeability values, while LMC exhibited extremely high interface bond strength. The surface preparation differences indicated that mechanical abrasion performed marginally better than chemical etching for most of the bi-layer specimens. This study provides the bases for streamlining the largescale efforts to be undertaken on development and characterization of overlays for West Virginia. 


\section{Dedication}

To

My Husband

My Parents

And

My Daughter 


\section{ACKNOWLEDGEMENT}

I would like to take this opportunity to express my gratitude to Dr. Julio F. Davalos, an excellent teacher and advisor, for giving me the opportunity to work on this interesting project, and for providing me with the guidance, brilliant ideas, support and resources necessary for accomplishing my research objectives.

My sincere appreciation goes to Dr. Indrajit Ray, who was my co-advisor and research supervisor, for his tremendous support in every step of this research, whose wise advice, valuable suggestions, and guidance in writing the thesis helped significantly to complete my work.

I would like to convey my sincere thanks to Dr. Karl E. Barth who served as the member of my committee and provided me with valuable technical suggestions.

Also I would like to thank Raabal El-Amine, Justin Robinson, Jennifer Morris, Wenbo Zhang, David Boyajian, Haiyong $\mathrm{Wu}$ and Srinivas Thurumella for their friendship and great help in doing laboratory work.

I gratefully acknowledge the financial support provided by West Virginia Department of Transportation -Division of Highways and WVU Res. Corp. Incentive Grant Program. I also acknowledge Arrow Concrete Company, Hoy Concrete, Master Builders Inc., Dow Chemicals and Columbian Fibers for generously supplying the materials.

I would like to dedicate this work to my husband Qiang and my parents, Zixian Luo and Yihe Shi, whose love and whole-hearted support helped me to bring this work and my degree to completion; also my newborn daughter Jennifer, who has brought great joy into my life. I would like to give special thanks to my sister for encouraging me in pursuing my education. My love to you all! 


\section{Table of Contents}

$\begin{array}{lc}\text { Abstract } & \text { ii } \\ \text { Acknowledgement } & \text { iv } \\ \text { Table of Contents } & \text { v } \\ \text { List of Figures } & \text { ix } \\ \text { List of Tables } & \text { xi }\end{array}$

Chapter 1 Introduction 1

1.1 Research Background 1

1.2 Global Research Objective and Scope 5

1.3 Present Research Plan and Tasks 6

$\begin{array}{lll}1.4 & \text { Thesis Organization } & 7\end{array}$

Chapter 2 Description of Overlay Systems and Review of Literature $\begin{array}{lr}\text { and Specifications } & 8\end{array}$

2.1 Overview of Overlay Systems 8

2.1.1 Low-slump, high-density concrete (LSDC) 8

2.1.2 Latex-modified concrete (LMC) 9

2.1.3 Silica-fume (microsilica) modified concrete (MMC) 9

2.1.4 Fiber reinforced concrete (FRC) 10

$\begin{array}{ll}2.1 .5 & \text { Polymer concrete (PC) } \\ & 11\end{array}$

$\begin{array}{lll}2.2 & \text { Review of Literature } & 11\end{array}$

2.2.1 Summary of Reviewed Paper 12

2.2.2 Overlay-Substrate Interface Evaluations 17

2.3 Specifications of Various States 22

2.3.1 Specification of West Virginia 22

2.3.2 Specifications of 14 Other States 23

$\begin{array}{ll}\text { 2.3.2.1 Indiana } & 23\end{array}$ 
2.3.2.2 Iowa 25

2.3.2.3 Kentucky 25

2.3.2.4 Maryland 26

2.3.2.5 Minnesota 27

2.3.2.6 New Jersey 27

2.3.2.7 New York 28

2.3.2.8 North Dakota 30

2.3.2.9 Oregon 33

2.3.2.10 Ohio 33

2.3.2.11 Pennsylvania 35

2.3.2.12 Rhode Island 36

2.3.2.13 Texas 38

2.3.2.14 Washington $\quad 39$

2.4 Limitation of Previous Works and Significance of

Current Research $\quad 40$

Chapter $3 \quad$ Materials and Mixture Proportioning 42

3.1 Types of Mixtures $\quad 42$

3.2 Materials 42

3.2.1 Portland Cement 42

3.2.2 Fine Aggregate 43

3.2.3 Coarse Aggregate 44

3.2.4 Microsilica (Silica Fume) 44

3.2.5 Fly Ash 44

3.2.6 Fiber 45

$\begin{array}{lll}3.2 .7 & \text { Latex } & 46\end{array}$

3.2.8 Antifoam 47

3.2.9 High-range Water-reducing Admixtures 47

3.2.10 Air-entraining Admixtures 47

$\begin{array}{ll}\text { 3.2.11 Mixing Water } & 47\end{array}$ 
3.3 Mixture Proportioning 48

3.4 Mixing Procedure 49

3.5 Preparation of Specimens 51

3.5.1 Specimens for Compressive Strength and Splitting Tensile Strength Tests 51

3.5.2 Specimens for Flexural Strength Test 51

3.5.3 Specimens for Free Shrinkage Test 52

3.5.4 Specimens for Chloride Permeability Test 52

Chapter 4 Characterization of Properties of Overlay Mixtures and Substrate $\quad 54$

4.1 Testing of Fresh Concrete $\quad 54$

4.2 Testing of Hardened Concrete 55

4.2.1 Compressive Strength 55

4.2.2 Splitting Tensile Strength 56

4.2.3 Flexural Strength $\quad 57$

4.2.4 Free Shrinkage 58

4.2.5 Rapid Chloride Permeability 59

4.3 Discussions of Test Results $\quad 62$

4.3.1 Fresh Concrete 62

4.3.2 Compressive and Splitting Tensile Strength 62

4.3.3 Flexural Strength 65

4.3.4 Free Shrinkage $\quad 66$

$\begin{array}{lll}\text { 4.3.5 Rapid Chloride Permeability } & 75\end{array}$

Chapter 5 Evaluations of Interface of Bi-layer Specimens $\begin{array}{ll}\text { by Direct Shear Test } & 77\end{array}$

5.1 Design and Fabrication of Shear Testing Apparatus 77

5.2 Manufacturing of Bi-layer Specimens 80

5.3 Testing of Specimens in Direct Shear 87 
5.4 Discussions of Shear Test Results $\quad 91$

5.4.1 Evaluation of LMC 91

5.4.2 Evaluation of MMC 91

5.4.3 Evaluation of MMC-FA 92

5.4.4 Evaluation of FRC 93

$\begin{array}{ll}\text { 5.4.5 General Comparisons } & 95\end{array}$

$\begin{array}{lll}\text { Chapter } 6 & \text { Conclusions } & 97\end{array}$

$\begin{array}{lll}\text { 6.1 Material Characterizations } & 97\end{array}$

$\begin{array}{lll}6.2 & \text { Interface Evaluations } & 99\end{array}$

$\begin{array}{lll}6.3 & \text { Recommendations for Future Work } & 100\end{array}$

$\begin{array}{ll}\text { Bibliography } & 102\end{array}$

$\begin{array}{lll}\text { Appendix A } & \text { Detailed Literature Review } & 109\end{array}$

$\begin{array}{lll}\text { Appendix B Experimental Data } & 165\end{array}$ 


\section{List of Figures}

Figure 3.1 Fibrillated Polypropylene Fiber 45

Figure 4.1 Flexural Strength Test of A Typical Specimen 57

Figure 4.2 Specimen After Typical Failure 58

Figure 4.3 Free Shrinkage Test in Progress 59

$\begin{array}{lll}\text { Figure } 4.4 \text { Rapid Chloride Permeability Test Specimen } & 60\end{array}$

Figure 4.5 Vacuum System and Charge-Passed Measurement Apparatus 61

Figure 4.6 Chloride Permeability Test in Progress 61

Figure 4.7 Compressive Strength at Different Age 63

Figure 4.8 Splitting Tensile Strength at Different Age 64

Figure 4.9 Load vs. Deflection Diagram under 4-Point Bending (Flexure) 66

$\begin{array}{lll}\text { Figure 4.10 Drying Shrinkage at } 75 \text { days } & 67\end{array}$

Figure 4.11 Best-Fit Linear Equation for LMC Free Shrinkage Strain 70

Figure 4.12 Best-Fit Linear Equation for MMC Free Shrinkage Strain 70

Figure 4.13 Best-Fit Linear Equation for MMC-FA Free Shrinkage Strain 71

Figure 4.14 Best-Fit Linear Equation for FRC Free Shrinkage Strain 71

Figure 4.15 Predictions for Free Shrinkage Strain in LMC 72

Figure 4.16 Predictions for Free Shrinkage Strain in MMC 73

Figure 4.17 Predictions for Free Shrinkage Strain in MMC-FA 73

Figure 4.18 Predictions for Free Shrinkage Strain in FRC 74

Figure 4.19 Chloride Permeability with Time 76

Figure 4.20 Comparison of Chloride Permeability Values 76

$\begin{array}{lll}\text { Figure 5.1 Shear Testing Apparatus } & 78\end{array}$

$\begin{array}{lll}\text { Figure 5.2 Shear Testing Apparatus-A Closer View } & 79\end{array}$

$\begin{array}{lll}\text { Figure 5.3 The Steel Apparatus Fixed on MTS } & 79\end{array}$

$\begin{array}{lll}\text { Figure 5.4 Detail View of The Steel Apparatus } & 79\end{array}$

$\begin{array}{lll}\text { Figure 5.5 Specimen Geometry with Dimensions } & 80\end{array}$

Figure 5.6 Substrate Specimens Cast in Partitioned Wooden Molds 82

Figure 5.7 Substrate Surface after Casting (closer view) 82 
Figure 5.8 Mechanically Scarified Substrate Surface Within Mold 83

Figure 5.9 Closer View of Mechanically Scarified Surface 83

Figure 5.10 Acid Etched Substrate Surface within Mold 84

Figure 5.11 Closer View of Acid Etched Concrete Surface 84

Figure 5.12 Waterproof Tape to Form 1/4 -in. Notch 85

Figure 5.13 Second Layer of Wooden Molds for Overlay Casting 85

Figure 5.14(a) A Typical Butterfly Notched Specimen for Direct Shear Test 86

Figure 5.14(b) Another View of The Specimen 86

Figure 5.15 Specimen Fitted Within The Shearing Apparatus 87

Figure 5.16(a) LMC-Substrate: Substrate Failure-Interface Intact 88

Figure 5.16(b) MMC-Substrate: Interface Failure $\quad 88$

Figure 5.16(c) MMC-FA-Substrate: Interface Failure $\quad 89$

Figure 5.16(d) FRC-Substrate: Interface Failure 89 


\section{List of Tables}

Table 2.1 Summary of Literature Review 12

Table 2.2 Requirement of LMC in WV 22

Table 2.3 Requirement of MMC in WV 23

Table 3.1 Material Composition of Type I Portland Cement 43

Table 3.2 Sieve Analysis of Fine Aggregate 43

Table 3.3 Sieve Analysis of Coarse Aggregate 44

Table 3.4 Physical Properties of Fibrillated Polypropylene Fiber 45

Table 3.5 Typical Properties of Dow Latex 46

Table 3.6 Typical Properties of Antifoam 47

Table 3.7 Mixture Proportioning in US Customary Units 48

Table 4.1 Properties of Fresh Concrete 55

Table 4.2 Compressive Strength of Different Mixtures 56

Table 4.3 Splitting Tensile Strength of Different Mixtures 56

Table 4.4 Flexural Strength of 60-day Beam Specimens 58

Table 4.5 Relationship of Splitting Tensile Strength and Compressive Strength (ACI 363) 65

Table 4.6 Correction Factors for Each Mixture 68

Table 4.7 Constants Used in Free Shrinkage Strain Prediction 72

Table $5.1 \quad$ Number of Specimen Tests 88

Table 5.2 Direct Shear Test Results 90

Table 5.3 Comparison of Interface Bonding Strength of Current Research with Other Published Data 94 


\section{Chapter 1}

\section{Introduction}

\subsection{Research Background}

Deterioration of reinforced concrete decks is one of the single most costly items in lifecycle maintenance of highway bridges. For this reason, many states use overlay systems, which are less permeable than the reinforced concrete deck itself, as an added measure of protection against deck deterioration. Concrete deck overlay systems are routinely used by the West Virginia Division of Highways (WVDOH) at different environmental conditions. Normally in new-deck construction a two-layer system is typically incorporated (ACI 224-90, 1990). Details of the overlay system are defined by the WVDOH Standard Specifications for Roads and Bridges (WVDOH, 2000). Normally, a $6 \frac{1}{2}$ in. reinforced concrete deck is placed and then a 1 to 2 in. overlay is applied. The top portion of the primary reinforcing steel has a cover of about $2 \mathrm{in}$. The overlay portion acts as a protective layer to the base reinforced concrete layer. There has been a significant amount of research that has shown that these overlay systems may be useful in extending the life of the reinforced concrete deck, thus reducing overall maintenance costs for the bridge structure (Sprinkle, 1984; Ozyldirum, 1988; Ozyldirum, 1994).

Additionally, the overlay system must act compositely with the regular reinforced concrete deck in supporting flexural loading. Therefore, the interface bond between the 
two layers is critical in the overall performance of the deck. The characteristics of the base concrete change with time as the concrete matures. The surface porosity, strength, shrinkage and humidity change with the maturity of the deck; these changes in turn affect the surface roughness, a crucial factor for both the overlay-new concrete bond and the integral behavior of deck-overlay system. Also the temperature of concrete and curing conditions affect the deck characteristics and hence the deck-overlay performance.

A protective concrete overlay can extend concrete bridge deck life for several years. For repairing of old decks, the quality of removal of surface concrete, type of surface preparation, selection of overlay materials and reconstruction practices have great influence on the life of the overlays. For new construction, the surface preparation and overlay materials selection and application are important in determining long-term performance of overlays. There are several techniques followed for surface preparations depending on the size of the area to be covered. For small areas, the decks are normally scrabbled, sandblasted, or shot-blasted; whilst for large areas, concrete milling machine or hydrodemolition is used. Surface preparations also include the pretreatments of surfaces using different kinds of bonding agents (Wells et al. 1999). The overlay is exposed to moisture, temperature changes, and aggressive fluids such as chloride, sulfate, carbon dioxide, de-icing salts and freeze-thaw in addition to the traffic load. The failure occurs either within the overlay material or at the interface or at both places depending on the conditions. The failure may take place as spalling and in extreme cases as delamination. The WVDOH uses overlay systems in both repairs of existing structures and construction of new bridge decks. These systems typically incorporate latex-modified concrete (LMC) or microsilica modified concrete (MMC) overlays. Concrete overlay 
spalling and delamination have been observed in both cases of old and new construction. Information from the WVDOH and discussion with the concerned personnel show that in rehabilitation projects the overlay failure can be mostly eliminated by proper hydrodemolition of the surface and using regular surface treatments. However, the problems for newly constructed bridges, where the overlays are applied soon after construction or even after a certain interval of time, are severe and continue to increase. The apparent random pattern of the problem of overlay failures emphasizes the need for the development of specifications for proper applications of the technology. There have been many cases in West Virginia bridges where the overlay experienced some amount of delamination at the overlay-reinforced concrete deck interface for newly constructed bridge decks.

The primary goal of an ongoing effort at WVU is to investigate deck-overlay performance and subsequent construction practices in West Virginia in an effort to develop guidelines that will eliminate the potential for overlay delamination and improve the system performance.

Several types of overlays are possible, and the most commonly used types are as follows:

- Latex modified concrete (LMC),

- Silica fume or microsilica modified concrete (MMC),

- Low slump dense concrete (LSDC),

- Fiber reinforced concrete (FRC), and

- Polymer concrete (PC) 
Each overlay has its both advantages and limitations. Proper selection depends on many factors such as substrate concrete, local aggregate availability, construction practices, construction costs, and others. The MMC overlays are used as an alternative to LMC (ACI 234-R-96) for better protection to penetration of chloride ions into the deck reinforcement, higher amount of abrasion-resistant in the surface, higher early and ultimate strength and lower cost (Luther, 1988; Ozyldirum, 1988). Reports show that the concrete incorporating Type III Portland cement, large quantities of slag and microsilica in a well-proportioned mixture has many beneficial effects (Ozyldirum 1994). A recent report by the FHWA shows that concrete repair mixes for slabs produced with microsilica and fly ash mineral admixtures performed exceptionally well for rebar corrosion protection (FHWA-RD-99-096, 1999). LMC needs only 48-hour moist curing which is advantageous for the construction. LMC is also less prone to plastic shrinkage than MMC, but it is more expensive. FRC needs specialized construction methods for its implementation in the field.

The WVDOH typically uses either LMC or MMC, and general mix requirements for both are provided in their specifications (WVDOH, 2000). There is a standard specification (ACI 548.4-93, 1993) for LMC overlays reported by ACI committee 548. Each of these standards specifies a particular type of surface preparation for the decks, but considering the fact that there may be different types of deck-overlay combinations and deck-maturity condition, it is necessary to have more specific information on the suitability of a particular overlay on a concrete deck with certain maturity and surface condition. The LMC and MMC overlays that are commonly used in new decks are showing premature cracks; spalling and delaminations due to surface shrinkage; cohesive 
and adhesive strength failure at interfaces due to moisture change, temperature change and mechanical stresses, all of which need to be addressed.

The surface preparation of substrate deck concrete, placement and curing are extremely important for a successful application of overlays in both new construction and deck retrofits. There are some guidelines for surface preparations in reports by ACI committee 345 (ACI 345R-91, 1991) and by the WVDOH; however, both of them are very general. The ACI 548.4-93 is a guideline for LMC overlays only. More specific construction standards are required on practices such as surface preparation, placement, curing condition to ensure better bonding between overlays and the reinforced concrete deck concrete, elimination of crack development, better resistance against chloride ion permeability and freeze-thaw durability.

The needs discussed above, therefore, indicate that the characterizations of overlay materials and evaluations of performance of two-layer system (overlay and deck) under different constructional and environmental condition are extremely important for developing modifications to current specifications and suggestions for improved construction practices.

The present study, which is an initial part of a comprehensive program on concrete overlays, is designed as an exploratory effort focusing on the development and evaluations of a number of overlays and the laboratory characterization of overlaysubstrate interface performance. 


\subsection{Global Research Objective and Scope}

Concrete overlay delaminations have been observed in WV in both old and new bridge deck construction, and the apparent random pattern of this problem emphasizes the need for the development of specifications for proper applications of the technology. A review of the literature, including state-of-the-art and surveys experiences of other states and knowledge of product manufacturers, is the first step to identify problem areas, conduct research to resolve uncertainties, and finally develop specifications in collaboration with contractors and material suppliers and producers. The overall project recently sponsored by the WVDOH will be organized into the following three major tasks:

- Review of the current state-of-knowledge, including technical literature, experience of other departments of transportation, and survey of concrete overlay projects in $\mathrm{WV}$ and identification of problem areas.

- Investigation of delamination issues related to materials and construction methods of particular interest to the WVDOH.

- Development of specifications for concrete overlays for old and new bridge decks in WV.

\subsection{Present Research Plan and Tasks}

This study is conceived with the intention of providing basic knowledge and background to later undertake the global research program described above. The objectives are as follows: 
(1) Reviews of literature including published research articles, manuals and specifications from various departments of transportation (including WVDOH).

(2) Characterization of properties of four commonly used types of overlay mixtures and also of substrate.

(3) Evaluation of interface performance for bi-layer overlay-substrate specimens using a newly developed shear apparatus.

\subsection{Thesis Organization}

A description of overlay systems, summary of literature review of material properties and detailed literature review of overlay-substrate interface, limitations of previous works, and research significance, are presented in Chapter 2. Chapter 3 presents the materials and mixture proportioning. Chapter 4 presents the characterization of overlay mixtures and substrate. Chapter 5 presents the evaluations of interface of bi-layer specimens by a direct shear test including sample preparation, testing programs, and results and discussions. Chapter 6 draws conclusions on the entire study and recommendations for future work. Appendices A and B furnish the detailed literature review and experimental data (shrinkage, permeability and direct shear test) respectively. 


\section{Chapter 2}

\section{Description of Overlay Systems and}

\section{Review of Literature and Specifications}

\subsection{Overview of Overlay Systems}

Concrete bridge deck overlays serve many purposes: protecting bridge deck substrate, restoring riding quality, providing added cover as protection for reinforcement, and modifying existing roadway alignment or deck drainage.

Most overlays in the United States are bonded to the original bridge deck. In some cases unbonded overlays are placed to protect waterproofing membranes.

Construction of bridge deck overlays is an important part of public-sector transportation work. Materials and other construction requirements are generally given in the standard specifications or special provisions of the specifying agency. Preferences for overlay materials vary by region and state. Different types of overlays are manufactured and used. Out of them the most commonly used types are discussed in this section, to highlight their various advantages. A brief description of these common overlays is mentioned below.

\subsubsection{Low-slump, high-density concrete (LSDC)}

Concrete overlays with zero or very low slump were an early remedy for concrete bridge deck deterioration. With some modifications, similar mixes are still widely used. The mixes typically contain relatively high cement contents and low water-cement ratios. 
The high cement content and low water content lead to reduced permeability as long as the concrete is well consolidated. This type of concrete bridge deck overlay is commonly called the "Iowa mix" because of extensive use in that state of a low-slump, high-density overlay mix since 1965 . Though these mixes use conventional materials and construction equipment, their low slump can make placement and consolidation difficult.

\subsubsection{Latex-modified concrete (LMC)}

Latex-modified mortar was first used as a bridge deck overlay material in 1956. ACI developed a standard specification (ACI 548.4-93) for latex-modified concrete overlays in 1993. A material called "styrene-butadiene latex" normally is used to modify the properties of Portland cement concrete. Usually supplied as a milky-white liquid, this material changes the concrete pore structure favorably and reduces its permeability significantly. Compressive strengths may be about the same or slightly less than concretes with similar materials and water-cement ratios. However flexural and tensile strengths are higher compared to conventional concrete. It is known that the polymer films inhibit the propagation of micro cracks because of their high tensile strength. Besides being highly impermeable, latex-modified concrete is noted for bonding tenaciously to the concrete substrate and failure generally occurs through the substrate, not through the interface.

\subsubsection{Silica-fume or Microsilica modified concrete (MMC)}

Concrete with silica fume has been used worldwide in highway bridge applications since the 1970s. The first U.S. bridge deck overlay with MMC was built in 1984. Silica fume, reclaimed from the manufacture of ferro-silicon or silicon industries, can be added to a concrete mix in densified (compacted) or slurry form. For typical 
concrete bridge deck overlays, silica fume in the range of $5 \%$ to $10 \%$ of the weight of Portland cement is added. Silica-fume particles are much finer than Portland cement, so the material can help fill the microscopic spaces inside the concrete. Also, silica fume reacts with lime produced by the hydration of Portland cement to form compounds with cementitious properties. Concrete with silica fume has several advantages for bridge deck overlays. It tends to have a high strength, which leads to good abrasion resistance. It is less permeable than conventional concretes, and helps protect reinforcement from the penetration of chloride ions that promote corrosion. The electrical resistance of concrete containing silica fume also is higher than is found in conventional concretes, which reduces the chance of reinforcement corrosion.

\subsubsection{Fiber reinforced concrete (FRC)}

Since the 1960s, fiber-reinforced concrete has been used to increase the durability of transportation structures. The Virginia Department of Transportation (VDOT) used steel fibers in 1974 for a bridge deck overlay and recently used steel and plastic fibers in bridge deck and pavement overlays on an experimental basis. FRC has also been used in overlays in some other states to minimize cracking. Fibers are expected to improve the properties of concrete both in the unhardened and hardened states. In the unhardened state, fibers increase resistance to plastic shrinkage. In the hardened state, fibers improve the strength (impact, tensile, and flexural) and toughness of concrete, depending on fiber type, shape, size, and amount. The most frequently used fibers for bridge deck overlays

are steel fibers (hooked-end), polypropylene fibers (monofilament and fibrillated), and polyolefin fibers (monofilament). 


\subsubsection{Polymer concrete (PC)}

Polymer concrete was used as early as 1958 in the United States to produce building cladding. Polymer concrete overlays have been installed on Portland cement concrete bridge decks in many states during the past 25 years. PC consists of aggregate with a polymer binder and contains no Portland cement or water. The most frequently used binders are epoxy, polyester styrene, and methacrylate. The binders are usually twocomponent systems: one component contains the resin and the second contains the curing agent or initiator. The aggregates are usually silica and basalt. Typically, uniformly graded aggregates are used with slurry and premixed overlays, and gap-graded aggregates are used with multiple-layer overlays and are broadcast on the top of slurry and some premixed overlays. Quick curing, high early compressive strength and excellent bond strength are the advantages of PC overlays.

Excellent performance can be expected from bridge deck overlays if materials and construction are carefully selected and executed. They can prolong the life of bridge decks for 25 to 35 years.

\subsection{Review of Literature}

A detailed literature review of 43 published articles has been compiled, and a concise summary of the review is furnished in section 2.2.1 (Table 2.1) in chronological order. The detailed review of papers discussing the material properties are furnished in Appendix A. However, considering the relevance of the topic to the present study, a detailed information of evaluations of overlay-substrate bi-layer systems is provided in this chapter in section 2.2.3. 


\subsubsection{Summary of Reviewed Papers}

Table 2.1 Summary of Reviewed Papers

\begin{tabular}{|c|c|c|c|c|c|c|}
\hline No. & Authors & Year & Overlay Type & Evaluations & $\begin{array}{l}\text { Laboratory } \\
\quad / \text { Field }\end{array}$ & Important Conclusions \\
\hline 1 & Steele \& Judy & 1977 & LMC & Freeze-thaw test & Field & LMC shows the best performance. \\
\hline 2 & Cady et al. & 1984 & $\begin{array}{l}\text { LMC, LSDC, } \\
\text { PC }\end{array}$ & $\begin{array}{c}\text { Durability \& compatibility by freeze-thaw } \\
\text { test }\end{array}$ & Laboratory & MMA impregnated substrate is good. \\
\hline 3 & Dhir & 1984 & Regular & Direct shear test & $\begin{array}{l}\text { Laboratory } \\
\text { \& Field }\end{array}$ & $\begin{array}{l}\text { Interface strength from interior of slab } \\
\text { is better. }\end{array}$ \\
\hline 4 & Christensen et al. & 1984 & $\begin{array}{l}\text { MMC, LMC, } \\
\quad \text { LSDC }\end{array}$ & $\begin{array}{l}\text { Compressive strength, flexural strength, } \\
\text { shear-bond strength, freeze-thaw, } \\
\text { permeability, and abrasion tests }\end{array}$ & Laboratory & MMC shows the best performance. \\
\hline 5 & $\begin{array}{l}\text { Kaufman \& } \\
\text { Keeling }\end{array}$ & 1987 & $\begin{array}{c}\text { Asphalt } \\
\text { overlay }(\mathrm{AC})\end{array}$ & Cracking and seating evaluation & Field & Expected 8 to 10 years of service. \\
\hline 6 & Ozyildirim & 1987 & MMC & $\begin{array}{l}\text { Compressive, flexural, and bond strength, } \\
\text { permeability, freeze-thaw, thermal } \\
\text { expansion and dry shrinkage }\end{array}$ & Laboratory & MMC exhibited good performance. \\
\hline 7 & Wallace & 1987 & LMC & $\begin{array}{l}\text { Placing method of overlays at different } \\
\text { temperature \& wind velocity }\end{array}$ & Field & $\begin{array}{l}\text { LMC overlay should no be placed less } \\
\text { than } 11 / 4 \text { in. thick, at temperature lower } \\
\text { than } 40^{\circ} \mathrm{F} \text { or when the surface } \\
\text { evaporation rate is more than } 0.15 \mathrm{lb} / \mathrm{ft}^{2} \\
\text { per hour. }\end{array}$ \\
\hline 8 & Berke & 1988 & MMC & $\begin{array}{l}\text { Compressive strength, freeze-thaw test, } \\
\text { permeability test, electrochemical tests }\end{array}$ & Laboratory & $\begin{array}{l}\text { Silica fume improves the overall } \\
\text { performance of concrete. }\end{array}$ \\
\hline 9 & Bunke & 1988 & MMC & $\begin{array}{l}\text { Compressive and flexural strengths, freeze- } \\
\text { thaw test, permeability test }\end{array}$ & Field & $\begin{array}{c}\text { The silica-fume content should be } 10 \% \text {. } \\
\text { MMC shows a good performance for } \\
\text { overlay. }\end{array}$ \\
\hline 10 & Luther & 1988 & MMC & $\begin{array}{l}\text { Strengths, abrasion resistance, permeability, } \\
\text { freeze-thaw test, plastic shrinkage }\end{array}$ & Field & $\begin{array}{l}\text { MMC at dosages between } 5 \text { and } 15.5 \% \\
\text { can provide a good performance. }\end{array}$ \\
\hline
\end{tabular}




\begin{tabular}{|c|c|c|c|c|c|c|}
\hline 11 & Holland & 1988 & MMC & Field work evaluation & Field & $\begin{array}{l}\text { Silica fume offers significant potential } \\
\text { for improvements in some properties of } \\
\text { concrete. }\end{array}$ \\
\hline 12 & Ozyildirim & 1988 & $\mathrm{MMC}$ & $\begin{array}{c}\text { Freshly mixed concrete properties, } \\
\text { compressive, flexural, and bond strengths, } \\
\text { chloride permeability, freeze-thaw test, } \\
\text { petrographic examination }\end{array}$ & Field & $\begin{array}{l}\text { Concrete containing } 7-10 \% \text { Silica-fume } \\
\text { exhibited good performance. MMC can } \\
\text { be a cost-effective alternative to LMC. }\end{array}$ \\
\hline 13 & Sprinkel & $1988_{(1)}$ & LMC & $\begin{array}{l}\text { Compressive and shear bond strengths, } \\
\text { permeability test, freeze-thaw test, } \\
\text { shrinkage, skid resistant }\end{array}$ & $\begin{array}{l}\text { Laboratory } \\
\& \text { Field }\end{array}$ & $\begin{array}{l}\text { High-early strength LMC (LMC-HE) } \\
\text { provided the better performance than } \\
\text { LMC. It can be opened to traffic within } \\
24 \text { hours. }\end{array}$ \\
\hline 14 & Sprinkel & $1988_{(2)}$ & LMC & $\begin{array}{c}\text { Compressive and shear bond strengths, } \\
\text { permeability test }\end{array}$ & $\begin{array}{c}\text { Field \& } \\
\text { Laboratory }\end{array}$ & $\begin{array}{l}\text { It is practical to accelerate LMC } \\
\text { overlay construction by using Type III } \\
\text { cement and a higher cement content. }\end{array}$ \\
\hline 15 & Walters & 1988 & LMC & $\begin{array}{l}\text { Evaluation of latex hydraulic cement } \\
\text { additive by tension bond and shear bond } \\
\text { strengths, flexural and splitting tensile } \\
\text { strengths, abrasion resistance, permeability } \\
\text { resistance }\end{array}$ & Laboratory & $\begin{array}{l}\text { The use of latex with hydraulic cements } \\
\text { results in a co-matrix that gives } \\
\text { improvements in adhesion, resistance } \\
\text { to transmission of fluids, and some } \\
\text { strength properties. }\end{array}$ \\
\hline 16 & Weil & 1988 & MMC & $\begin{array}{c}\text { Field work evaluation and lab certification } \\
\text { by compressive strength and permeability } \\
\text { test }\end{array}$ & $\begin{array}{c}\text { Field \& } \\
\text { Laboratory }\end{array}$ & $\begin{array}{l}\text { MMC is a good type of overlay for } \\
\text { parking garage. }\end{array}$ \\
\hline 17 & Knab \& Spring & 1989 & LMC & $\begin{array}{l}\text { Bond strength evaluation by friction grips } \\
\text { tension test, pipe nipple grips tension test } \\
\text { and ASTM slant shear bond strength test }\end{array}$ & Laboratory & $\begin{array}{l}\text { The effects of surface preparation and } \\
\text { the environment should be investigated } \\
\text { thoroughly. }\end{array}$ \\
\hline 18 & $\begin{array}{l}\text { Ramakrishnan et } \\
\text { al. }\end{array}$ & 1989 & FRC & $\begin{array}{l}\text { Static flexural strength and pulse velocity } \\
\text { tests, including toughness calculation }\end{array}$ & Laboratory & $\begin{array}{l}\text { FRC has higher first-crack strength, } \\
\text { static flexural strength, toughness } \\
\text { index, ductility, post-crack energy and } \\
\text { absorption capacity. }\end{array}$ \\
\hline 19 & $\begin{array}{l}\text { Whiting \& } \\
\text { Dziedzic }\end{array}$ & 1989 & $\begin{array}{l}\text { LMC, MMC, } \\
\text { LSDC }\end{array}$ & Chloride permeability test & Field & $\begin{array}{l}\text { The rapid chloride permeability test } \\
\text { showed good potential for use as a } \\
\text { means of establishing relative } \\
\text { effectiveness of rigid overlay materials. }\end{array}$ \\
\hline 20 & $\begin{array}{l}\text { Babaeie \& } \\
\text { Hawkins }\end{array}$ & 1990 & LMC, LSDC & $\begin{array}{l}\text { Freeze-thaw sealing, wheel track wear, skid } \\
\text { resistance, surface cracking, overlay bond, } \\
\text { chloride permeability, water permeability, } \\
\text { abrasion resistance }\end{array}$ & Field & $\begin{array}{c}\text { LMC and LSDC are resistant but not } \\
\text { impermeable to salt intrusion, and can } \\
\text { protect reinforcement from moisture } \\
\text { and oxygen. }\end{array}$ \\
\hline
\end{tabular}




\begin{tabular}{|c|c|c|c|c|c|c|}
\hline 21 & Hindo & 1990 & - & In-place direct tensile test & $\begin{array}{l}\text { Field \& } \\
\text { Laboratory }\end{array}$ & $\begin{array}{l}\text { In-place bond test is a valuable tool to } \\
\text { determine directly the bond strength } \\
\text { and the quality of the prepared surface. }\end{array}$ \\
\hline 22 & Kuhlman & 1990 & LMC & Pipe-nipple grips test & Laboratory & $\begin{array}{l}\text { The effect of overlay thickness on the } \\
\text { failure load and mode of failure, the } \\
\text { effect of water submersion at various } \\
\text { curing times, and the surface } \\
\text { preparation needs to be thoroughly } \\
\text { studied. }\end{array}$ \\
\hline 23 & Calvo \& Meyers & 1991 & $\mathrm{PC}, \mathrm{MMC}, \mathrm{AC}$ & General evaluation of overlay system & Laboratory & $\begin{array}{l}\text { The epoxy overlays have been } \\
\text { successfully used for structural } \\
\text { repairing systems. }\end{array}$ \\
\hline 24 & Kuhlmann & 1991 & LMC & Chloride permeability test & Laboratory & $\begin{array}{l}\text { Cracks in LMC were not always } \\
\text { detrimental to the long-term } \\
\text { performance of the material, and can be } \\
\text { controlled by proper attention to the } \\
\text { quality of the materials used in the mix. }\end{array}$ \\
\hline 25 & Walters & 1991 & $\begin{array}{l}\text { MMC, LMC, } \\
\text { LMC + silica- } \\
\quad \text { fume }\end{array}$ & $\begin{array}{l}\text { Compressive and flexural strengths, } \\
\text { permeability, pipe-nipple grips tension test, }\end{array}$ & Laboratory & $\begin{array}{l}\text { The combined use of silica fume and } \\
\text { Latex dispersions can yield a concrete } \\
\text { that is suitable for overlay applications. }\end{array}$ \\
\hline 26 & $\begin{array}{l}\text { Babaeie \& } \\
\text { Hawkins }\end{array}$ & 1992 & $\begin{array}{l}\text { LMC, LSDC, } \\
\text { cathodic } \\
\text { protection } \\
(\mathrm{CP}) \\
\end{array}$ & $\begin{array}{l}\text { Corrosion and durability evaluation by half- } \\
\text { cell corrosion detection test }\end{array}$ & Field & $\begin{array}{l}\text { A selection of proper concrete overlay } \\
\text { strategy is more cost effective than } \\
\text { cathodic protection systems. }\end{array}$ \\
\hline 27 & Sprinkel & 1992 & LMC & $\begin{array}{l}\text { Rapid permeability test, bond and } \\
\text { compressive strength tests, chloride ion } \\
\text { content test, half-cell potential test }\end{array}$ & Field & $\begin{array}{l}\text { The shear and tensile rupture strengths } \\
\text { at the bond interface between the LMC } \\
\text { overlay and the base concretes were } \\
\text { typically as good as or better than the } \\
\text { shear and tensile strengths of the base } \\
\text { concrete. }\end{array}$ \\
\hline 28 & Halvorsen & 1993 & $\begin{array}{l}\text { LMC, MMC, } \\
\text { LSDC }\end{array}$ & Introduction of bridge deck overlays & Field & $\begin{array}{c}\text { Excellent performance can be expected } \\
\text { from bridge deck overlays if materials } \\
\text { and construction methods are carefully } \\
\text { selected and executed. }\end{array}$ \\
\hline
\end{tabular}




\begin{tabular}{|c|c|c|c|c|c|c|}
\hline 29 & Northcott & 1993 & - & Introduction of bridge deck overlays & Field & $\begin{array}{l}\text { Overlays are a more economical } \\
\text { method of strengthening and } \\
\text { maintaining existing concrete and } \\
\text { bituminous roads and restore high- } \\
\text { speed skid resistance. }\end{array}$ \\
\hline 30 & Deming et al. & 1994 & $\mathrm{PC}$ & Interface tension test & Laboratory & $\begin{array}{l}\text { This study successfully developed a } \\
\text { direct tensile testing procedure for PCC } \\
\text { to PC interface. }\end{array}$ \\
\hline 31 & Ozyildirim & 1994 & MMC & Compressive strength, chloride permeability & Laboratory & $\begin{array}{l}\text { The use of slag as a portion of the } \\
\text { cementitious material in concrete } \\
\text { results in a product with an appreciably } \\
\text { lower chloride permeability than PCC. }\end{array}$ \\
\hline 32 & Glauz & 1995 & LMC & Pull-off tensile test (California test 420) & Field & $\begin{array}{c}\text { A LMC overlay would bond well to a } \\
\text { dry clean substrate without wetting or } \\
\text { buttering the substrate. }\end{array}$ \\
\hline 33 & Banthia et al. & 1996 & FRC & Restrained shrinkage cracking & Laboratory & $\begin{array}{l}\text { Steel fibers not only reduced the } \\
\text { maximum crack widths but also caused } \\
\text { multiple cracking in the composite up } \\
\text { to a fiber volume fraction of } 0.5 \% \text {. }\end{array}$ \\
\hline 34 & Fitch \& Abdulshafi & 1996 & MMC & $\begin{array}{l}\text { Ground-penetrating radar (GPR) test, } \\
\text { permeability test, bond strength test }\end{array}$ & $\begin{array}{l}\text { Field \& } \\
\text { Laboratory }\end{array}$ & $\begin{array}{l}\text { The use of bonding grout with MMC } \\
\text { overlays may be unnecessary. }\end{array}$ \\
\hline 35 & Ozyildirim et al. & 1996 & FRC & $\begin{array}{l}\text { Fresh concrete test, compressive and } \\
\text { splitting tensile strength, drop-weight test, } \\
\text { first-crack strength and flexural toughness }\end{array}$ & Laboratory & $\begin{array}{l}\text { The impact resistance of concretes is } \\
\text { greatly improved with increases in fiber } \\
\text { volume and length. The toughness of } \\
\text { concretes improves with increases in } \\
\text { fiber volume. }\end{array}$ \\
\hline 36 & Detwiler et al. & 1997 & MMC, LSDC & Chloride permeability test & Field & $\begin{array}{l}\text { MMC and LSDC overlay repairs are } \\
\text { generally of high quality. }\end{array}$ \\
\hline 37 & Warner et al. & 1998 & $\mathrm{LMC}, \mathrm{MMC}$ & Interface tension test & Field & $\begin{array}{l}\text { The overlay bond required proper } \\
\text { surface preparations. }\end{array}$ \\
\hline 38 & Sprinkel & 1998 & LMC & Compressive strength, chloride permeability & Field & $\begin{array}{l}\text { Very-early strength LMC (LMC-VE) } \\
\text { could be placed and opened to traffic } \\
\text { with as little as } 3 \text { hours curing time. }\end{array}$ \\
\hline 39 & $\begin{array}{l}\text { Sprinkel \& } \\
\text { Ozyildirim }\end{array}$ & 1998 & MMC, FRC & $\begin{array}{c}\text { Fresh concrete test, compressive, flexural, } \\
\text { and tensile bond strength, permeability test, } \\
\text { shrinkage }\end{array}$ & Field & $\begin{array}{c}\text { MMC has low permeability to chloride } \\
\text { penetration and satisfactory } \\
\text { compressive, flexural, and bond }\end{array}$ \\
\hline
\end{tabular}




\begin{tabular}{|c|c|c|c|c|c|c|}
\hline 40 & Fowler & 1999 & $\begin{array}{c}\text { stymer- } \\
\text { impregnated } \\
\text { concrete (PIC) }\end{array}$ & Introduction of polymers used in concrete & $\begin{array}{c}\text { Field } \\
\text { Limitations of PIC, PC, and LMC } \\
\text { include cost, odor, toxicity, and } \\
\text { flammability. }\end{array}$ \\
\hline 41 & Wells et al. & 1999 & LMC, MMC & Interface tension test & $\begin{array}{c}\text { Laboratory discernable advantage exists in } \\
\text { using polymer-modified bonding } \\
\text { agents over conventional cement-sand } \\
\text { slurry to obtain high bond strengths } \\
\text { between the substrate and the overlay. }\end{array}$ \\
\hline 42 & Gillum et al. & 1998 & $\begin{array}{c}\text { Overlays \& } \\
\text { Substrate }\end{array}$ & Guillotine shear test & $\begin{array}{c}\text { Field \& } \\
\text { Laboratory }\end{array}$ & $\begin{array}{c}\text { Bond strength was measured through a } \\
\text { load deliberately at interface. }\end{array}$ \\
\hline 43 & $\begin{array}{c}\text { SHRP Product } \\
2025\end{array}$ & -- & $\begin{array}{c}\text { Overlays \& } \\
\text { Substrate }\end{array}$ & Interface shear test & Laboratory & Measure the shear strength of interface \\
\hline
\end{tabular}




\subsubsection{Overlay-Substrate Interface Evaluations}

An important property of concrete and mortar materials used to repair concrete is the ability to adhere to the substrate being repaired. The question of how to measure this bond property has been the subject of numerous studies, but no test has been adopted as a standard. Also there are only few published articles on overlay-substrate interface evaluations are available currently. These are as follows:

Dhir, 1984 used direct shear test to evaluate the effect of temperature variations on the bonding of concrete overlays. He subjected the concrete overlays to five kinds of different environments and tested the samples in direct shear. He found overlaying done in extreme hot weather with large temperature variations inhibits the development of bond along panel peripheries. The solutions to this problem are suggested in the form of measures such as use of shear pegs, epoxy bonding, or concreting in temperate weather. There is also the measure of preventing large temperature variations through the use of a lightweight and inexpensive insulation covering. He recommended use of an insulation covering which is indicated for preventing temperature variations so that adequate bond strength is developed along panel peripheries. He also observed that interface bond strengths of samples collected from edge and corner were lower than those from the interior.

Knab and Spring, 1989 evaluated test methods for measuring the bond strength of LMC to concrete substrate. They used three kinds of test methods to evaluate the bond strength of specimens. These are: Friction Grips Tension Test and Pipe Nipple Grips Tension Test to perform the uniaxial tensile strength test, and ASTM Slant Shear Bond Strength Test. After comparing the results of the three different test methods, they 
concluded that the nature of the two test methods investigated (slant shear and uniaxial tension), which had different geometry and loading conditions, resulted in substantially different failure stresses. Thus, the failure pattern needs to be considered when analyzing the failure stresses. The relative precision of the three test methods was good. The pipe nipple grips tension test method was considered to be the more promising of the two uniaxial tension test methods investigated, because of its higher average failure stress and possibly better relative precision as compared to the friction grips test method. A potentially useful criterion in establishing the minimum strength for the slant shear test method is the fraction of the strength of the slant shear composite specimen relative to the base concrete control specimen. They recommended that: 1) The minimum strength levels related to field performance should be developed; 2) The effects of the environment on the bond strength of the repair material to its base concrete should be investigated; 3) The feasibility of using the test methods to determine the bond strength of different types of repair materials should be investigated, especially at early age; 4) The effects of surface preparation and surface conditions of the base concrete on the bond strength of the repair material should be investigated; and 5) Analytical analyses, such as finite-element analysis, of the interface bond strength should be considered.

Kuhlmann, 1990 used the pipe-nipple grip test to measure the bond strength of latex-modified concrete and mortar, using four series of LMC laboratory specimens. He concluded that the weakest component of two concretes bonded together is easily determined by visual observation of the failure surfaces of the sample. The pipe-nipple grip test method can be used to measure the bond of LMC at curing times as early as 1 day. The bond of LMC exceeds 70 psi at 1 day, 340 psi at 28 days, and 450 psi at 90 days 
of curing at room temperature. He recommended to study the effect of overlay thickness on the failure load and mode of failure. He also suggested that the effect of water submersion at various curing times and the surface preparation should be studied.

Hindo, 1990 described a new method to determine the strength and quality of bond directly, using the LOK-Test pullout device, which is a field test. The procedure calls for a partial depth core to be drilled in the test area. The depth of the test cut extended beyond the bonded interface into the original concrete material. Hs observed that when hydrodemolition was used, bond strength has generally increased to almost twice the strength achieved when surfaces are prepared by pneumatic hammers. $\mathrm{He}$ concluded that the in-place bond test is a valuable tool to determine the direct bond strength and the quality of the prepared surface. Two important advantages are that the test is performed in-situ and represents actual field conditions and it is a useful tool for quality control during construction repairs.

Deming et al., 1994 evaluated the interface strength of polymer overlay to Portland cement concrete substrate. They introduced four kinds of test methods. These are: ACI field test, ASTM slant shear test, pipe nipple grip test, and friction grip test. They modified the test methods to define proper conditions to minimize variability of results. The basic testing apparatus consisted of steel pull plates uniformly attached to the top and bottom of the specimen with structural adhesive. Thus, the interface between PC and Portland cement concrete (PCC) is transverse to the loading direction. The apparatus was connected to the testing machine with clevises at top and bottom to prevent any overturning moment on the interface during load application. The test was conducted 
under strain control. They observed that most failure occurred within the PCC and the stress at failure ranged from 300 psi to 500 psi.

Warner et al., 1998 studied the surface preparation of overlays. They introduced three typical test methods used for the interface test. They observed that the failure of bilayer specimens occurred in one of three places: above the bond line in the new concrete, at the bond line, or in the parent concrete below the bond line. In practice, failures in the new concrete are rare, and when the failure is in the original concrete, it is often very near the bond surface. Based on some experiments from field work, they concluded that the overlay bond required proper surface preparations. The development of appropriate surface preparation methods is extremely important. Damage in the parent concrete should be carefully identified, and the damaged area should be properly prepared by abrasion, shotblasting, or hydroblasting.

Wells et al., 1999 evaluated the surface preparation methods used for concrete overlays bonding. They evaluated the bond strength of concrete overlays utilizing four different methods of surface preparations and six different methods/materials for bonding agents. The four different methods of surface preparation were: light brooming and vacuuming, vigorous hand wire brushing and vacuuming, waterblasting at $4000 \mathrm{psi}$, and shotblasting using medium-heavy blast. The six pretreatments were: (1) none (dry), (2) saturated surface dry (SSD), (3) cement-sand slurry at water-cement ratio of 0.42 , (4) cement-sand-acrylic latex slurry, (5) proprietary cement-silica fume modified styrene butadiene paste (SBR), and (6) a proprietary structural grade two-component, moistureinsensitive epoxy conforming to ASTM C 881. They used the uniaxial tension test to measure the bond strength between the base slab and the overlay. Based on the data 
obtained in the test program, they concluded that some degree of surface preparation is required to clean and texture the concrete substrate to affect a strong bond with the new concrete overlay. An aggressive method of surface preparation such as shotblasting, which provided a course profile, removed the dependency on the use of a bonding agent. For less aggressive methods of surface preparation such as wire brushing or waterblasting at $4000 \mathrm{psi}$, the use of a bonding agent to obtain a satisfactory bond strength greater than $130 \mathrm{psi}$ between the substrate and the overlay is required. The results presented suggested that no discernable advantage exists in using polymer-modified bonding agents including a structural grade epoxy, over conventional cement-sand slurry to obtain high bond strengths between the substrate and the overlay.

Gillum et al., 1998 examined and reported the influence of guillotine direct shear test on the interfacial bond strength. The test apparatus consisted of a base that holds a core or cylinder, and a sliding head. The test specimen is positioned such that the load is applied at the overlay and base-concrete interface. The bond strength is calculated by dividing the ultimate load by the bond area. The nature of failure was influenced by the positioning of the loads during testing.

Strategic Highway Research Program (SHRP), Product 2025, described interfacial bond strength test of concrete to concrete. The test apparatus consisted of two L-shaped segments with dimensions of $15 \times 12 \times 6$ in. each. Two companion $4 \times 8$ in. cylinder specimens for each segment were also tested for compressive strength. The nominal bond stress was computed by dividing the maximum debonding load by the nominal bonding area of 36 square inches. The manufacturing method is such that even 
for the same surface preparation, the specimens are to be fabricated separately. However, the bond strength is a measure of direct shear strength at the interface.

\subsection{Specifications of Various States}

This section describes the overlay types, mixture proportions and requirements of West Virginia and 14 other states.

\subsubsection{Specifications of West Virginia}

\section{Latex Modified Concrete}

Table 2.2 shows the cement and latex content and other properties of LMC.

Table 2.2 Requirement of LMC in WV

\begin{tabular}{|l|l|}
\hline Chloride Permeability & $\begin{array}{l}1000 \text { coulombs @ 90 days, maximum } \\
\text { (per AASHTO T277) }\end{array}$ \\
\hline Compressive Strength (a) & $\begin{array}{l}\text { not less than } 80 \% \text { of } 28 \text {-day } \\
\text { compressive strength of the approved test mix }\end{array}$ \\
\hline Water/(Cement + fly ash) Ratio & 0.40 by weight, maximum \\
\hline Portland Cement Content (b) & $658 \mathrm{lb} / \mathrm{cu}$. yd., minimum $\left(390 \mathrm{~kg} / \mathrm{m}^{3}\right.$, minimum) \\
\hline Latex Admixture Content & $24.5 \mathrm{gal} / \mathrm{cu}$. yd., minimum $\left(121 \mathrm{liters} / \mathrm{m}^{3}\right.$, minimum) \\
\hline Air Content (c) & $6.5 \%$ maximum (Per AASHTO T152) \\
\hline Slump & 4.0 inches \pm 2.0 inches $(100 \mathrm{~mm} \pm 50 \mathrm{~mm})$ \\
\hline
\end{tabular}

(a) The minimum 28 -day compressive strength shall be 4,000 psi (28 MPa).

(b) An equal volume of fly ash may be substituted for cement to a maximum of $1 \frac{1 / 4}{4}$ bags per cubic yard (meter). When fly ash is used, equivalent volumes of fly ash shall be considered as cement for purposes of determining the proportioning ratios.

(c) The initial mix design shall be based on an expected air content range of 3\% to $6 \%$. 


\section{Microsilica Concrete}

Table 2.3 shows the cement and microsilica content and other properties of MMC.

Table 2.3 Requirement of MMC in WV

\begin{tabular}{|l|l|}
\hline Chloride Permeability & $\begin{array}{l}1000 \text { coulombs @ 90 days, } \\
\text { maximum (per AASHTO T277) }\end{array}$ \\
\hline Compressive Strength,(a) & $\begin{array}{l}\text { not less than } 80 \% \text { of 28-day } \\
\text { compressive strength of the approved test mix }\end{array}$ \\
\hline $\begin{array}{l}\text { Water/(Cement + microsilica + } \\
\text { fly ash) Ratio }\end{array}$ & 0.37 by weight, maximum \\
\hline Portland Cement Content & $680 \mathrm{lb} / \mathrm{cu} . y d .$, minimum $\left(404 \mathrm{~kg} / \mathrm{m}^{3}\right.$, minimum) \\
\hline Microsilica Content (b)(Dry Weight) & $50 \mathrm{lb} . / \mathrm{cu}$. Yd., minimum $\left(30 \mathrm{~kg} / \mathrm{m}^{3}\right.$, minimum) \\
\hline Air Content & $7.0 \%$ (plus or minus $1.5 \%)(\mathrm{Per}$ AASHTO T152) \\
\hline Slump & 6.5 inches \pm 1.5 inches $(165 \mathrm{~mm} \pm 40 \mathrm{~mm})$ \\
\hline $\begin{array}{l}\text { High } \\
\text { Reducer(Superplasticizers) (c) }\end{array}$ & $\begin{array}{l}\text { As needed for workability, slump and } \\
\text { water/cementitious ratios }\end{array}$ \\
\hline
\end{tabular}

(a) The minimum 28-day compressive strength shall be 4,000 psi (28 MPa).

(b) Microsilica sampling shall be in accordance with AASHTO M 307.

(c) A high range water-reducing admixture is required to improve workability. No more than two additions of the admixture shall be made, and the total quantity shall not exceed the maximum dosage rate prescribed by the manufacturer.

\subsubsection{Specifications of 14 Other States}

\subsubsection{Indiana:}

\section{$\underline{\text { Latex Modified Concrete }}$}

Physical properties of the latex modifier:

Polymer Type Styrene Butadiene

Stabilizers. Anionic and Nonionic Surfactants

Antifoaming Agent Polydimethyl Siloxane

Percent Solids, $\%$ by mass 46.0 Minimum 170 
Mass Per Liter (gallon) $1.0 \mathrm{~kg}(8.4 \mathrm{lb})$ at Minimum

$\mathrm{Ph}$ (as shipped) $9.0-11.0$

Freeze--Thaw Stability Five Cycles, $-15 \mathrm{E}$ to $25 \mathrm{EC}$

Shelf Life Two Years, Minimum

Color. White

- The amount of fine aggregate shall be $60 \% \pm 5 \%$ by dry weight of the total aggregate and shall be considered as the amount of aggregate blend passing the $4.75 \mathrm{~mm}$ (No. 4) sieve. The coarse aggregate shall be size No. 11, class A crushed stone. The cement content shall be a minimum of $391 \mathrm{~kg} / \mathrm{m}^{3}(658 \mathrm{lb} / \mathrm{cu} \mathrm{yd})$ of concrete. The same brand of cement shall be used throughout a bridge structure. The amount of latex modifier shall be $13.3 \mathrm{~L}$ per $43 \mathrm{~kg}$ (3.5 gal. per $94 \mathrm{lb})$ of cement. The net water added shall produce a slump of $125 \mathrm{~mm}(5$ in. $) \pm 25 \mathrm{~mm}(1$ in.) at 4 to 5 min after discharge from the mixer. The moisture content of the aggregates shall be controlled such that the slump is within the specified limits. The air content shall be a maximum of $6 \%$, by volume, of the plastic mix.

- Class F or class C fly ash may be used in the latex modified Portland cement concrete. The maximum cement reduction shall be $15 \%$ and the minimum replacement ratio by weight of fly ash to cement shall be $1.25: 1$. If Portland pozzolan cement, Type IP is to be used in the concrete mix design, the cement content shall be increased by a multiplier of 1.06 times the specified cement content. 


\subsubsection{Iowa:}

Bonded Portland Cement Concrete Overlay

- Fly Ash and GGBFS substitution

- When fly ash or GGBFS is substituted for the cement, the replacement shall be on a kilogram-for-kilogram (pound-for-pound) basis.

- When both fly ash and GGBFS are substituted for the cement in ready-mixed concrete, the replacement shall be on a kg-for-kg (pound-for-pound) basis.

\subsubsection{Kentucky:}

\section{Latex Concrete Overlays}

When mix is adjusted, ensure that the mixture contains no less than 658 pounds per cubic yard of cement or less than 24.5 gallons per cubic yard of latex admixture.

\begin{tabular}{|l|l|}
\hline Material & Quantity \\
\hline Type I or Type III Cement & $94 \mathrm{lbs}$ \\
\hline Latex Admixture & $3.5 \mathrm{gal}$ \\
\hline Fine Aggregate & 215 to $245 \mathrm{lbs}^{(1)}$ \\
\hline Coarse Aggregate & 165 to $195 \mathrm{lbs}^{(1)}$ \\
\hline Water $^{(2)}$ & $22 \mathrm{lbs}^{(1)}$ \\
\hline
\end{tabular}

(1) Actual quantities are determined and submitted to the Engineer for approval.

(2) Includes free moisture on the fine and coarse aggregates.

\section{Property}

Slump ${ }^{(1)}$

Maximum Air Content

Maximum w/c ratio $^{(2)}$

\section{Value}

$4-6$ in

$7 \%$

0.40 
7 - day compressive strength ${ }^{(3)}$

3000 psi

(1) The Department will perform the slump test 4 to 5 minutes after discharging from continuous type mixers.

${ }^{(2)}$ Consider all the non-solids in the latex admixture as part of the total water.

(3) Attain a 28-day compressive strength of 4000 psi when compressive strength is tested at 28 days or later due to unusual circumstances.

\section{Low Slump Concrete}

Proportion low slump concrete to contain 8.75 bags of cement and no more than 35 gallons per cubic yard of water, including free moisture on the aggregates. Use enough water to maintain the required slump except do no use more than 35 gallons per cubic yard. Attain a 7-day compressive strength of 5,000 psi. Use an approximate percent fine to total aggregate of 50. Use the amount of air-entraining admixture necessary to achieve $5.5 \%+1.5 \%$ or $5.5 \%-1.5 \%$. Maintain a slump close to $3 / 4$ inch. The Department will perform the slump test 4 to 5 minutes after discharge from the mixer. The Department may allow a slump tolerance of $\pm 1 / 4$ in.

\subsubsection{Maryland:}

\section{$\underline{\text { Latex Modified Concrete }}$}

Not much information is available. However, the specified concrete is similar to other latex-modified concrete or latex concrete overlays. 


\subsubsection{Minnesota:}

Low Slump Concrete

\begin{tabular}{|l|l|}
\hline Strength & $39 \mathrm{MPa}$ concrete at 28 days \\
\hline Water & $160 \mathrm{~kg}$ \\
\hline Air & $6.5 \%$ \\
\hline Cement $(\mathrm{C} / \mathrm{V}=0.70)$ & $496 \mathrm{~kg}$ \\
\hline FA & $815 \mathrm{~kg}$, Concrete Sand \\
\hline CA ${ }^{*}$ & $\mathrm{CA}$, Class A \\
\hline Water Reducer & Maximum amount authorized by the Concrete Manual \\
\hline Slump & $20 \mathrm{~mm} \pm 5 \mathrm{~mm}$ \\
\hline
\end{tabular}

* New Ulm Quartzite - $810 \mathrm{~kg}$

* Meridian Granite $\quad-822 \mathrm{~kg}$

* Dresser Trap Rock - 914 kg

\subsubsection{New Jersey:}

$\underline{\text { Latex Modified Concrete Overlay }}$

\begin{tabular}{|c|c|c|}
\hline \multicolumn{2}{|c|}{ Cement, bags per cubic meter (42.7 kilogram bag) } & 9.16 \\
\hline \multicolumn{2}{|c|}{ Latex emulsion admixture, liters per bag } & 13.2 \\
\hline \multicolumn{2}{|l|}{ Water, liters per bag } & $10.2 \max$ \\
\hline \multicolumn{2}{|c|}{ Air content, $\%$ according to AASHTO T 152} & $6.5 \max$ \\
\hline \multicolumn{2}{|l|}{ Slump, (mm) } & 75 to $150 \max$ \\
\hline \multicolumn{2}{|c|}{ Percent fine aggregate as percent of total aggregate, by weight } & 55 to 70 \\
\hline \multirow[t]{3}{*}{ Weight ratio range (dry basis): } & Cement & 1.0 \\
\hline & Sand & 2.5 to 3.1 \\
\hline & Coarse aggregate & 1.4 to 2.0 \\
\hline \multicolumn{2}{|c|}{ LMC 28-day compressive strength, $\mathrm{MPa}$} & 28 \\
\hline
\end{tabular}




\subsubsection{New York:}

\section{High Density Concrete}

\begin{tabular}{|l|l|}
\hline Cement Content $\left(\mathrm{kg} / \mathrm{m}^{3}\right)$ & 490 \\
\hline $\begin{array}{l}\text { Sand content ( \% total aggregate by } \\
\text { volume) }(\mathrm{a})\end{array}$ & 50.0 \\
\hline Desired Slump $(\mathrm{mm})(\mathrm{d})$ & 20 \\
\hline Allowable air content \%(c) & $5.0-8.0$ \\
\hline Water $\left(\mathrm{kg} / \mathrm{m}^{3}\right)(\mathrm{b})$ & 122 \\
\hline Allowable slump range $(\mathrm{mm})(\mathrm{d})$ & $13-25$ \\
\hline
\end{tabular}

a. Fine aggregate fineness modulus: 2.80 .

b. Water/cement ratio (by weight): 0.327 .

c. Desired air content: $6.5 \%$.

d. Slump shall be measured 5 minutes after discharge from the mobile mixer. The sample shall not be disturbed during the waiting period

\section{Latex Modified Concrete}

\begin{tabular}{|l|l|l|l|}
\hline Cement content $\left(\mathrm{kg} / \mathrm{m}^{3}\right)$ & 390 & Water $\left(1 / \mathrm{m}^{3}\right)(\mathrm{b})$ & 50.7 \\
\hline Sand content $(\%$ total aggregate by volume) & 60 & Slump Desired $(\mathrm{mm})(\mathrm{c})$ & $50-100$ \\
\hline Latex Admixture $\left(1 / \mathrm{m}^{3}\right)$ & 71 & Slump Maximum $(\mathrm{mm})(\mathrm{c})$ & 150 \\
\cline { 1 - 2 } Air Content $($ Maximum \%) & 6.5 & \multicolumn{2}{|l}{} \\
\cline { 1 - 3 } & &
\end{tabular}

(a) The criteria are given for design information and the data is based on a fine aggregate modulus of 2.80 and a CA1 coarse aggregate gradation. The initial mix design shall be based on an expected air content range of 3 to 6 percent. The mixture proportions shall be determined using actual conditions for fineness modulus and bulk specific gravities 
(saturated surface dry for aggregates). The proportions shall be computed according to Department written instructions.

(b) The amount of added water shall be adjusted to provide slump at or below the prescribed limit.

(c) Concrete for the slump test shall be deposited in a clean container and allowed to stand covered without disturbance for 5 minutes prior to performing the slump test. Care shall be taken during the test to exclude the effects of vibrations caused by traffic and concrete placement operations.

\section{Microsilica Concrete}

\begin{tabular}{|l|l|l|l|}
\hline Cement content $\left(\mathrm{kg} / \mathrm{m}^{3}\right)$ & 390 & Allowable air content range $(\%)$ & $5.0-8.0$ \\
\hline $\begin{array}{l}\text { Sand content }(\% \text { total aggregate } \\
\text { by volume) (a) }\end{array}$ & 53.0 & Water $\left(\mathrm{kg} / \mathrm{m}^{3}\right)(\mathrm{b})$ & 156 \\
\hline Microsilica Admixture $\left(\mathrm{kg} / \mathrm{m}^{3}\right)$ & 36 & Desired slump $(\mathrm{mm})(\mathrm{c}, \mathrm{d})$ & 150 \\
\hline Desired air content $(\%)$ & 6.5 & Allowable slump range $(\mathrm{mm})(\mathrm{c}, \mathrm{d})$ & $125-200$ \\
\hline
\end{tabular}

(a) The criteria are given for design information and the data is based on a fine aggregate modulus of 2.80 and a CA1 coarse aggregate gradation. The mixture proportions shall be determined using actual conditions for fineness modulus and bulk specific gravities (saturated surface dry for aggregates). The proportions shall be computed according to written instructions, by department of transportation.

(b) This is the total quantity of mix water required. This total quantity shall be added at the batch plant. If a microsilica slurry is used, the slurry water shall be included in the calculations as mix water. The free moisture content of both the fine and coarse aggregates shall be included in the calculation as mix water. Retempering with water shall not be allowed. 
(c) A high range water reducing admixture shall be added to provide slump within the allowable range. It shall be added at the concrete batching plant to assist mixing, using a method approved by Engineer may permit the addition of high range water reducing admixture at the work site to adjust/maintain slump within the allowable range. Additions of admixture at the work site shall not exceed two in number and the total quantity from all additions shall not exceed the maximum recommended dosage by manufacture. Each time the admixture is added at the work site, the concrete shall be mixed an additional minimum of 30 revolutions. Regardless of where the high range water reducing admixture is added, the total number of revolutions shall not exceed 190.

(d) When using a mobile mixer, the concrete for the slump test shall be deposited in a clean container and allowed to stand without disturbance for 5 minutes prior to performing the slump test.

\subsubsection{North Dakota:}

\section{Low-Slump Concrete}

- Cement: Type I or IA

- Basic absolute volume per unit volume of concrete:

\begin{tabular}{|l|l|}
\hline Coarse Aggregate (Size 5) & 0.3121 \\
\hline Fine Aggregate & 0.3121 \\
\hline Air & 0.0600 \\
\hline Water & 0.1603 \\
\hline Cement (Type I or IA) & 0.1555 \\
\hline & 1.0000 \\
\cline { 2 - 2 }
\end{tabular}

- Approximate quantities of dry materials per cubic yard of concrete: 


\begin{tabular}{|l|l|}
\hline Coarse Aggregate (Size 5) & $1,393 \mathrm{lbs}$ \\
\hline Fine Aggregate & $1,393 \mathrm{lbs}$ \\
\hline Cement (8.75 bags) & $823 \mathrm{lbs}$ \\
\hline
\end{tabular}

These quantities are based on the following assumptions:

\begin{tabular}{|l|l|}
\hline Specific gravity of cement & 3.14 \\
\hline Specific gravity of aggregate & 2.65 \\
\hline Weight of one cubic foot of water & $62.4 \mathrm{lbs}$ \\
\hline
\end{tabular}

- An approved water-reducing admixture shall be used.

- The slump measured using AASHTO T-119 shall not exceed one inch.

- The concrete shall have an entrained air content of $6 \%$ with a tolerance of plus or minus $1 \%$.

- Grout for bonding the overlay to the existing concrete shall consist of equal parts, by weight, of Portland cement and fine aggregate mixed with sufficient water to form stiff slurry. The slurry shall have a consistency that permits application with a stiff brush or broom to a thin even coating that does not run or puddle in low spots. For sealing construction joints, the grout shall be thinned as necessary.

\section{Latex-Modified Concrete}

- Cement: Type I

- Latex Modifier: Formulated latex modifier shall be a nontoxic, film forming, polymeric emulsion to which all stabilizers have been added at the point of manufacture and shall be homogeneous and uniform in 
composition. Qualified technical assistance shall be made available by the latex manufacturer or supplier.

The latex modifier shall meet the following requirements:

\begin{tabular}{|l|l|}
\hline Polymer Type & Styrene butadiene \\
\hline $\begin{array}{l}\text { Stabilizers } \\
\text { (a) Latex } \\
\text { (b) Portland Cement Composition }\end{array}$ & $\begin{array}{l}\text { Nonionic surfactants } \\
\text { Poly Dimethyl Siloxane }\end{array}$ \\
\hline Percent Solids & $46.0-49.0$ \\
\hline Weight per gallon (pounds at 25 0 C.) & 8.4 \\
\hline Shelf Life & 2 years minimum \\
\hline Color & White \\
\hline
\end{tabular}

- Proportioning:

\begin{tabular}{|l|l|}
\hline Cement, sacks/cubic yard & 7 \\
\hline Latex, gallon/sack cement & 3.5 gal. (US) \\
\hline $\begin{array}{l}\text { Weight ratio (dry): } \\
\text { Cement, sand, Coarse Aggregate }=\end{array}$ & $1.0: 2.8: 1.7$ \\
\hline Specific Gravity of Aggregates $=$ & $2.65+$ \\
\hline Water* & \\
\hline
\end{tabular}

*Water may be added as required for a maximum of 6 inches. Testing of the slump shall be delayed from 4 to 5 minutes after the material has been discharged from the mixer. The slump shall be measured using AASHTO T-119.

- Grout for sealing longitudinal construction joints shall consist of 1 part cement, 2 parts fine sand, and a 60/40 latex/water premix added to form a creamy consistency. 


\subsubsection{Oregon:}

1. Latex-Modified Concrete

2. Microsilica Concrete

3. Flexible Polymer Concrete

The details are not available but numbers. (1) and (2) are similar to other latexmodified and microsilica modified concrete.

\subsubsection{Ohio:}

1. Microsilica Modified Concrete

QUANTITIES OF MATERIAL PER CUBIC METER(CUBIC YARD) (DRY WEIGHTS)*

\begin{tabular}{|c|c|c|c|c|c|}
\hline $\begin{array}{c}\text { Type of } \\
\text { Coarse } \\
\text { Aggregate }\end{array}$ & $\begin{array}{c}\text { Coarse } \\
\text { Aggregate } \\
\mathrm{kg}(\mathrm{lbs})^{(\mathrm{a})}\end{array}$ & $\begin{array}{c}\text { Fine } \\
\text { Aggregate } \\
\mathrm{kg}(\mathrm{lbs})^{(\mathrm{a})}\end{array}$ & $\begin{array}{c}\text { Cement kg } \\
(\mathrm{lbs})\end{array}$ & $\begin{array}{c}\text { Microsilica } \\
\mathrm{kg} \mathrm{(lbs)}^{(\mathrm{a})}\end{array}$ & $\begin{array}{c}\text { Max. Water } \\
\text { Cementitious }^{(\mathrm{b})} \\
\text { Ratio }^{(\mathrm{b})}\end{array}$ \\
\hline Gravel & $805(1355)$ & $805(1355)$ & $415(700)$ & $30(50)$ & 0.36 \\
\hline Limestone & $815(1370)$ & $805(1355)$ & $415(700)$ & $30(50)$ & 0.36 \\
\hline Slag & $705(1190)$ & $805(1355)$ & $415(700)$ & $30(50)$ & 0.36 \\
\hline
\end{tabular}

(a) The specific gravities used for determining the above weights are: natural sand 2.62, gravel 2.62, limestone 2.65, slag 2.30 and microsilica 2.20 .

(b )The water-cementitious material ratio shall be calculated based upon the total cementitious material. Cementitious material shall include Portland cement and microsilica (solids). 


\section{Latex Modified Concrete}

QUANTITIES OF MATERIALS PER CUBIC METER (CUBIC YARD) (DRY WEIGHT)

\begin{tabular}{|c|c|c|c|c|c|}
\hline $\begin{array}{c}\text { Type of } \\
\text { Coarse } \\
\text { Aggregate }\end{array}$ & $\begin{array}{c}\text { Fine } \\
\text { Aggregate } \\
\mathrm{kg}(\mathrm{lbs})\end{array}$ & $\begin{array}{c}\text { Coarse } \\
\text { Aggregate } \\
\mathrm{kg}(\mathrm{lbs})\end{array}$ & $\begin{array}{c}\text { Cement kg } \\
(\mathrm{lbs})\end{array}$ & $\begin{array}{c}\text { Latex } \\
\text { Emulsion L } \\
(\mathrm{gal})\end{array}$ & $\begin{array}{c}\text { Maximum } \\
\text { Net Water } \\
\text { L }(\mathrm{gal})\end{array}$ \\
\hline Gravel & $974(1645)$ & $769(1300)$ & $389(658)$ & $121(24.5)$ & $86(17.5)$ \\
\hline Limestone & $974(1645)$ & $778(1315)$ & $389(658)$ & $121(24.5)$ & $86(17.5)$ \\
\hline Slag & $974(1645)$ & $675(1140)$ & $389(658)$ & $121(24.5)$ & $86(17.5)$ \\
\hline
\end{tabular}

(a) Slump: 100 to $150 \mathrm{~mm}$ (4 to 6 inches)

(b) Air content of plastic mix shall not exceed 7 percent.

(c) The specific gravities used for determining the above weights are: natural sand 2.62, gravel 2.62, limestone 2.65 and slag 2.30 .

(d) The dry weights are approximate. This proportion should produce good workability, but due to gradation variability, the fine aggregate content may be increased, with approval by the Engineer, as much as 8 percent by weight if the coarse aggregate is reduced an equal volume.

(e) The slump shall not be measured until after the concrete has been discharged from the mixer and left undisturbed for 4 to 5 minutes. The water content may be adjusted to control the slump within the prescribed limits.

\section{Superplasticized Dense Concrete}

QUANTITIES OF MATERIAL PER CUBIC METER (CUBIC YARD), DRY WEIGHTS

\begin{tabular}{|c|c|c|c|c|}
\hline $\begin{array}{c}\text { Type of Coarse } \\
\text { Aggregate }\end{array}$ & $\begin{array}{c}\text { Coarse } \\
\text { Aggregate kg } \\
(\mathrm{lbs})\end{array}$ & $\begin{array}{c}\text { Fine Aggregate } \\
\text { kg(lbs) }\end{array}$ & Cement kg (lbs) & $\begin{array}{c}\text { Maximum } \\
\text { Water Cement } \\
\text { Ratio }\end{array}$ \\
\hline Gravel & $769(1300)$ & $769(1300)$ & $489(825)$ & 0.36 \\
\hline Limestone & $778(1315)$ & $769(1300)$ & $489(825)$ & 0.36 \\
\hline Slag & $675(1140)$ & $769(1300)$ & $489(825)$ & 0.36 \\
\hline
\end{tabular}


The specific gravities used for determining the above weights are:

natural sand 2.62, gravel 2.62, limestone 2.65 and slag 2.30 .

\subsubsection{Pennsylvania:}

1. Portland Cement Concrete Overlay

- Maximum water-cement mass ratio: 0.40

- When overlay thickness is less than $75 \mathrm{~mm}$ ( 3 inches), use No. 8 Coarse Aggregate

- Cement

- Fine Aggregate, Type A

- Coarse Aggregate, Type A, No. 8, (Stone, Gravel, or Slag)

- Water

- Admixtures

- Pozzolan: fly ash, ground granulated blast furnace slag, and silica fume.

\section{Latex-Modified Mortar or Concrete Wearing Surface}

- Cement. Type I, IP or II

- Fine Aggregate. Type A (Sand)

- Coarse Aggregate. Type A, No. 8

- Water

- Latex Emulsion Admixture. A nontoxic, film forming, polymeric emulsion in water to which all stabilizers have been added at the point of manufacture and homogeneous and uniform in composition. 
- Latex Modified Mortar or Concrete Mix Design. Use Latex Modified Mortar for depths less than $30 \mathrm{~mm}$ (1 1/4 inches). Use Latex-Modified Concrete when the depth is $30 \mathrm{~mm}$ (1 1/4 inches) or more.

\begin{tabular}{|l|l|l|}
\hline & \multicolumn{2}{|l|}{ Requirements } \\
\hline Physical Properties & Mortar & Concrete \\
\hline Cement Content, bags/cu. yd. & 8.0 & 7.0 \\
\hline Latex Emulsion Admixture Modifier, gal/bag & 3.5 & 3.5 \\
\hline Air Content, \% of Plastic Mix (PTM No. 615) & $7 \pm 2$ & $5 \pm 1.5$ \\
\hline Water/Cement Ratio, by Weight & $0.35-0.40$ & $0.30-0.40$ \\
\hline Slump ${ }^{(1)}$ inches (PTM No. 600) & $4-6$ & $2-6$ \\
\hline Percent Fine Aggregate as Percent of Total Aggregate, by Weight & 100 & $60 \pm 5$ \\
\hline Cement/Fine Aggregate/Coarse $^{(2)}$ Aggregate Ratio, by Weight & $1: 3.25$ & $\begin{array}{l}1: 2.5: 2.0 \text { to } \\
1: 2.9: 1.6\end{array}$ \\
\hline
\end{tabular}

(1) Measure the slump 4 to 5 minutes after discharge from the mixer. During this waiting period, deposit it on the deck in a suitable container and do not disturb. (Use care so traffic vibrations do not affect the measurement.)

(2) Aggregate Specific Gravity (on dry basis) $=2.65$. The dry mass (weight) ratios are approximate and should produce good workability, but due to gradation changes, the ratios may be adjusted within limits by the Engineer.

\subsubsection{Rhode Island:}

\section{Latex Modified Concrete}

\begin{tabular}{|l|l|}
\hline Cement content, min. (lbs./cu.yd.) & 658 \\
\hline Latex Emulsion Admixture (gal./cu.yd.)* & 24.5 \\
\hline Water/cement ratio** & 0.4 \\
\hline Air Content (\% of Plastic Mix) & $5.5 \pm 1.5$ \\
\hline Slump (inches) & $3-7$ \\
\hline Strength, 28 day, min. compressive strength (psi) & 3500 \\
\hline
\end{tabular}


* Polymer Type: Styrene Butadiene Stabilizer:

a) Latex: Nonionic Surfactants

b) Portland Cement Composition: Poly Dimethyl Siloxane

Percent Solids: 47.0 - 49.0

Weight per Gallon: 8.4 (lbs. at $25^{\circ} \mathrm{C}$ )

Color: White

** The net water added shall be adjusted to control the slump within the prescribed limits and should produce a maximum net water/cement ratio of 0.40 by weight, including water in latex and aggregate.

2. Microsilica Modified Concrete

\begin{tabular}{|l|l|}
\hline Cement content, min. (lbs./cu.yd.) & 650 \\
\hline Microsilica Admixture (solids) (lbs./cu.yd. of concrete) & 46 \\
\hline Maximum Water/Total Cementitious* & 0.40 \\
\hline Synthetic Polymer Fibers (lbs./cu.yd.)** & $1-2$ \\
\hline Air Content, (\% of Plastic Mix) & $5.5 \pm 1.5$ \\
\hline Slump, (inches) & $3-7$ \\
\hline Strength, 28 day, min. compressive strength (psi) & 5000 \\
\hline
\end{tabular}

* The total cementitious content is equivalent to the combined weight of Portland cement and microsilica in the mixture.

** Quantity to be added per cubic yard of concrete shall be in accordance with the recommendation by manufacture and as approved by the Engineer. 
2.3.2.13 Texas:

\section{Portland Cement Concrete}

(a) Cement. Type I cement shall be used for concrete overlay. Type II cement shall be used for dense concrete overlay.

(b) Coarse Aggregate. The coarse aggregate shall be a crushed or broken aggregate and, unless otherwise shown on plans, shall conform to the gradation Grade No. 6 of Table 1 . Eighty-five percent of the coarse aggregate particles retained on the No. 4 sieve shall have one or more mechanically induced crushed.

(c) Classification and Mix Design:

(i) Concrete Overlay. The concrete shall be Class $\mathrm{CO}$ and shall have a coarse aggregate factor of not less than 0.55 . The entrained air content of the fresh concrete shall be six percent with a tolerance of plus or minus one percent.

(ii) Dense Concrete Overlay. The concrete shall be Class DC and shall have a coarse aggregate factor which will provide equal absolute volume of fine aggregate and absolute volume of coarse aggregate with a tolerance of plus or minus five percent; and the entrained air content of the fresh concrete shall be six percent with a tolerance of plus or minus one percent.

A water reducing admixture will be required for dense concrete overlay. 


\section{CLASSES OF CONCRETE}

\begin{tabular}{|c|c|c|c|c|c|c|}
\hline $\begin{array}{c}\text { Class of } \\
\text { Conc. }\end{array}$ & $\begin{array}{c}\text { Cement } \\
\text { per C.Y. } \\
\text { Minimum } \\
\text { (sacks) }\end{array}$ & $\begin{array}{c}\text { Min. } \\
\text { Comp. } \\
\text { Strength } \\
\text { 28 Day } \\
\text { psi }\end{array}$ & $\begin{array}{c}\text { Min.Flex. } \\
\text { Sgth. } \\
7 \text { day psi }\end{array}$ & $\begin{array}{c}\text { Max. } \\
\text { Water } \\
\text { Cement } \\
\text { Ratio } \\
\text { Gal/sk }\end{array}$ & $\begin{array}{c}\text { Coarse } \\
\text { Aggre. } \\
\text { Grade No. }\end{array}$ & $\begin{array}{c}\text { General } \\
\text { Usage } \\
\text { (informati } \\
\text { on only) }\end{array}$ \\
\hline $\mathrm{DC}$ & 8.75 & 5500 & 720 & 3.6 & 6 & $\begin{array}{c}\text { Dense } \\
\text { Concrete } \\
\text { Overlay }\end{array}$ \\
\hline $\mathrm{CO}$ & 7.0 & 4600 & 640 & 4.5 & 6 & $\begin{array}{c}\text { Concrete } \\
\text { Overlay }\end{array}$ \\
\hline
\end{tabular}

(d) Grout. The grout for bonding new concrete to existing concrete shall consist of equal parts by weight of Portland cement and sand, mixed with sufficient water to form stiff slurry which can be applied with a stiff brush or broom to the existing concrete in a thin, even coating that will not run or puddle in low spots.

\subsubsection{Washington:}

\section{Fly Ash Modified Concrete Overlay}

- Portland Cement: Type III cement is not permitted.

- Coarse Aggregate: No.7 or No.8 are to be used

- Typical mix proportion as follows:

\begin{tabular}{|l|l|}
\hline Portland cement & $363 \mathrm{~kg}$ \\
\hline Fly Ash & $163 \mathrm{~kg}$ \\
\hline Fine aggregate & $38 \%$ of total aggregate \\
\hline Coarse aggregate & $62 \%$ of total aggregate \\
\hline Air & $6 \%$ plus or minus $1 \frac{1}{2} \%$ \\
\hline Maximum water/cement ratio & 0.30 max. \\
\hline
\end{tabular}




\subsection{Limitations of Previous Works and Significance of Current Research}

Based on the above literature review and specifications it is evident that no state has any standard specification by which interface bond of substrate-to-overlays can be evaluated. A review of a number of published papers (section 2.2.2) shows that there are several laboratory and field tests available for measuring interface bond strength. These are: ACI field test, ASTM slant shear test, Pipe nipple grip test, Friction grip test, Guillotine shear test, and SHRP 2025 test. Except for the guillotine shear test and SHRP 2025 test, all other tests do not truly characterize the overlay-substrate interface behavior, where the stress transfer takes place in direct shear. The guillotine shear test applies the load deliberately at the interface, but small variations in load placement influence the results. SHRP 2025 test is a good shear bond strength test, but the fabrication of the specimen is difficult. Consistent fabrication of a large number of SHRP 2025 specimens (L-shape) with a particular type of surface preparation is not possible without variations within batches and among the batches.

The above review further shows that failure of interface occurred mainly due to shear and that failure depended on overlay and substrate concrete properties, age of concrete, surface preparations, bonding agents, test methods, size and shape of specimens, and manufacturing and collection of specimens for bond test. Most of the research work was directed to the development of high quality overlay materials having high strength, low porosity, high freeze-thaw resistance and high abrasion resistance. Little attention was directed to study the compatibility of overlay-substrate assemblies 
through shear-bond tests of bi-layer materials, although most failures occurred due to incompatibility between the two dissimilar materials.

The WVDOH encountered several problems of delaminations of overlays, and such failure need to be addressed more fundamentally. In this current study, therefore, the emphasis has been directed to the characterization of overlay-substrate interfaces through a direct shear test. Two different commonly adopted surface preparations were selected to compare the performance. Different overlays were placed over a common substrate to study the effect of overlay types on interface bond failures. A newly devised shear apparatus was used to measure the direct shear strength and identify nature of bond failures. This new test will be helpful for screening and selection of overlay types and studying the effect of surface preparation on the response. 


\section{Chapter 3}

\section{Materials and Mixture Proportioning}

The overlay types, materials, mixing procedure, and mixing proportions are discussed in this chapter.

\subsection{Types of Mixtures}

A review of the specifications of 15 states shows that almost all of them use latexmodified concrete (LMC) and many of them use microsilica modified concrete (MMC) and low-slump dense concrete (LSDC) as the overlay. Out of MMC and LSDC, the MMC has become more acceptable due to its better performance and less constructional problems. The WVDOH is also interested in using fly ash as substitution of cement. This will serve three purposes, (i) it will reduce the material cost, (ii) it will enhance the durability, and (iii) it will solve partially the disposal problem of fly ash. Therefore the choice of overlay was as follows: (1) LMC, (2) MMC, (3) MMC with fly ash as partial substitution for cement (MMC-FA), and (4) FRC using synthetic fiber. In the present study, commercial fibrillated polypropylene fibers are selected as the synthetic fibers, considering their durability and successful implementation in overlays in other states.

\subsection{Materials}

\subsubsection{Portland Cement}


Commercially available Type I Portland cement conforming to ASTM C 150 (Standard specification for Portland cement) was used in this study. For the purpose of mixture proportioning a specific gravity of 3.15 was assumed. Table 3.1 lists the chemical compound composition of the Type I cement used in this study.

Table 3.1 Material Composition of Type I Portland Cement [Arrow Concrete Company]

\begin{tabular}{|c|c|}
\hline Element & Percentage (mass) \\
\hline Tricalcium Silicate & 49 \\
\hline Dicalcium Silicate & 25 \\
\hline Tricalcium Aluminate & 12 \\
\hline Tetracalcium Aluminoferrite & 8 \\
\hline Calcium Sulfate & 2.9 \\
\hline Calcium Oxide & 0.8 \\
\hline Magnesium Oxide & 2.3 \\
\hline
\end{tabular}

\subsubsection{Fine aggregate}

The fine aggregate used in this experimental program was graded river sand of 3/8 in. nominal size conforming to ASTM C 33 (Standard specification for concrete aggregates). The sieve analysis data is shown in Table 3.2. The specific gravity (saturated surface dry condition) of sand is 2.61 .

Table 3.2 Sieve Analysis of Fine Aggregate [Arrow Concrete company]

\begin{tabular}{|c|c|}
\hline Sieve Size & Percentage Passing \\
\hline $3 / 8^{\prime \prime}$ & 100 \\
\hline$\# 4$ & 97.2 \\
\hline$\# 8$ & 82.3 \\
\hline$\# 16$ & 69 \\
\hline$\# 30$ & 54.6 \\
\hline$\# 50$ & 16.1 \\
\hline$\# 100$ & 2.0 \\
\hline$\# 200$ & 0.7 \\
\hline FM & 2.79 \\
\hline
\end{tabular}




\subsubsection{Coarse Aggregate}

The coarse aggregate used in this study was graded river gravel of $1 / 2 \mathrm{in}$. maximum size conforming to ASTM C 33 (Standard specification for concrete aggregates). The specific gravity (saturated surface dry condition) is 2.71 . Table 3.3 shows the sieve analysis of the coarse aggregate.

Table 3.3 Sieve Analysis of Coarse Aggregate [Arrow Concrete Company]

\begin{tabular}{|c|c|}
\hline Sieve Size & Percentage Passing \\
\hline $1 / 2 "$ & 100 \\
\hline $3 /$ " $^{\prime \prime}$ & 92 \\
\hline$\# 4$ & 20 \\
\hline$\# 8$ & 5 \\
\hline$\# 16$ & 3 \\
\hline
\end{tabular}

\subsubsection{Microsilica (Silica Fume)}

The commercial silica fume used in this study conformed to ASTM C 1240 (Standard specification for use of silica fume as a mineral admixture in hydraulic cement concrete, mortar, and grout). The specific gravity of the silica fume is 2.2. The material was supplied by Masterbuilders Inc.

\subsubsection{Fly Ash}

The Class F fly ash used in this study conforming to ASTM C 618 (Standard specification for coal fly ash and raw or calcined natural pozzolan for use as a mineral admixture in Portland cement concrete) was from Hatfield power station, Pennsylvania. The specific gravity of the fly ash is 2.4 . 


\subsubsection{Fiber}

Commercial fibrillated polypropylene fiber was used in this study. Table 3.4 shows the physical properties of the fiber. Figure 3.1 shows the fiber used, which was supplied by Columbian Concrete Fibers Inc.

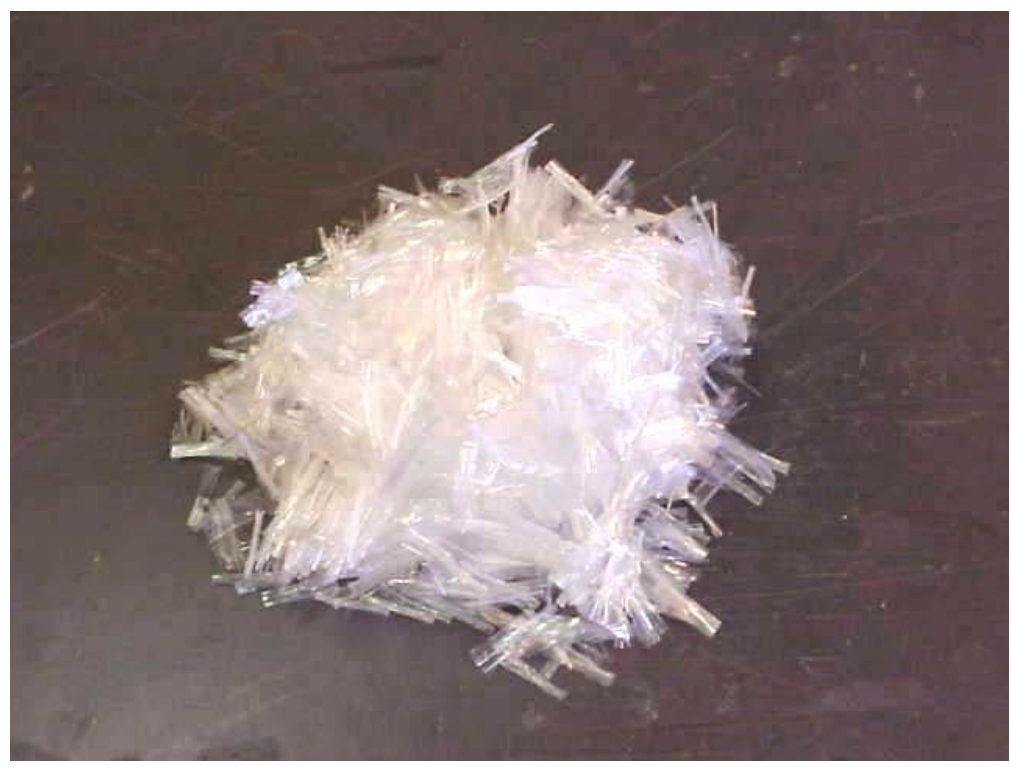

Figure $3.1 \quad$ Fibrillated Polypropylene Fiber

Table 3.4 Physical Properties of Fibrillated Polypropylene Fiber

\begin{tabular}{|c|c|}
\hline Material & $100 \%$ Virgin Polypropylene \\
\hline Tensile Strength & $97 \mathrm{Ksi}$ Avg $\left(0.67 \mathrm{KN} / \mathrm{mm}^{2}\right)$ \\
\hline Modulus (Young's) & $580 \mathrm{Ksi}\left(4.0 \mathrm{KN} / \mathrm{mm}^{2}\right)$ \\
\hline Melt Point & $330 \mathrm{deg}$ F $(165 \mathrm{deg} \mathrm{C})$ \\
\hline Chemical Resistance & Excellent \\
\hline Alkali Resistance & Excellent \\
\hline Acid and Salt Resistance & High \\
\hline Ignition Point & NIL \\
\hline Absorption & 0.91 \\
\hline Specific Gravity & deg F $(600 \mathrm{deg}$ C $)$ \\
\hline
\end{tabular}




\begin{tabular}{|c|c|}
\hline Density, Bulk & $56 \mathrm{lbs} / \mathrm{cu} \mathrm{ft}$ (approx.) \\
\hline Density, Loose & $15-25 \mathrm{lbs} / \mathrm{cu} \mathrm{ft}$ (approx.) \\
\hline Denier & $15-23$ \\
\hline Dosage (Normal) & $1.5 \mathrm{lbs} / \mathrm{cu} \mathrm{yd}$ \\
\hline Fiber Length (Normal) & $3 / 4 "$ \\
\hline Form & Fibrillated Polypropylene \\
\hline Color & White \\
\hline Fiber Count & $8-12$ Million/lb \\
\hline
\end{tabular}

\subsubsection{Latex}

The Dow Latex Modifier A/NA was used in this study. It is a proprietary styrene/butadiene latex supplied as a white liquid with suspended solids. The specific gravity is 1.04 . Table 3.5 shows some properties of latex.

Table 3.5 Typical Properties of Dow Latex [Dow Chemical Company]

\begin{tabular}{|c|c|c|}
\hline Test Item and Condition & Limit & Unit \\
\hline Solids & $47.0-49.0$ & $\%$ \\
\hline $\mathrm{pH}$ & $9.0-11.0$ & \\
\hline 200 Mesh Residue, per $900 \mathrm{ml}$ & $0.50 \mathrm{Max}$ & $\mathrm{G}$ \\
\hline Particle Size, red filter & $1900-2200$ & Angstrom \\
\hline Brookfield Viscosity, \#1 spindle@10 rpm & May-40 & $\mathrm{cps}$ \\
\hline Surface Tension & $22-31$ & $\mathrm{dyn} / \mathrm{cm}$ \\
\hline Freeze Thaw Stability, after 2 cycles & $0.1 \mathrm{Max}$ & $\mathrm{g}$ \\
\hline Butadiene Content & $30-40$ & $\%$ \\
\hline Weight per Gallon & $8.4-8.6$ & $\mathrm{lb} / \mathrm{gal}$ \\
\hline
\end{tabular}




\subsubsection{Antifoam}

Dow Corning Antifoam 2210 was used in this study. It is a water-dilatable, 10 percent active emulsion that is designed to control foam in aqueous systems. Table 3.6 shows its typical properties.

Table 3.6 Typical Properties of Antifoam [Dow Corning Corporation]

\begin{tabular}{|c|c|}
\hline Appearance & White \\
\hline Active Ingredient, percent & 10 \\
\hline Specific Gravity, at $25^{\circ} \mathrm{C}\left(77^{\circ} \mathrm{F}\right)$ & Medium \\
\hline Consistency at $25^{\circ} \mathrm{C}\left(77^{\circ} \mathrm{F}\right)$ & 2,500 \\
\hline Viscosity, cps & 7 \\
\hline $\mathrm{pH}$ & Nonionic \\
\hline Emulsifier Type & Cool water \\
\hline Suitable Diluent &
\end{tabular}

\subsubsection{High-range Water-reducing Admixture}

The high range water-reducing admixture (HRWRA) used in the mixtures was a naphthalene-based superplasticizer conforming to ASTM C 494 Type F.

\subsubsection{Air-entraining Admixture}

The air-entraining admixture (AEA) used in the mixtures was based on neutralized vinsol resin meeting the requirements of ASTM C 260. 


\subsubsection{Mixing Water}

The mixing water used in this study was tap water from the Morgantown city water supply and was assumed to have a density of $62.4 \mathrm{lbs}$ per cubic foot (1000 kg per cubic meter).

\subsection{Mixture Proportioning}

A total of five mixtures were prepared for the study. Normal concrete (NC) was the substrate; LMC, MMC, MMC-FA and FRC were the overlay mixtures. The mixture proportions are provided in Table 3.7.

Table 3.7 Mixture Proportions of Substrate and Overlay Concrete

\begin{tabular}{|c|c|c|c|c|c|}
\hline Mixture Type & NC & LMC & МMC & MMC-FA & FRC \\
\hline Cement (lbs) & 568 & 700 & 635 & 517 & 635 \\
\hline Silica Fume (lbs) & & & 55 & 55 & 55 \\
\hline Fly Ash (lbs) & & & & 90 & \\
\hline Latex (lbs) & & 212.6 & & & \\
\hline Defoamer (oz.) & & 31 & & & \\
\hline Fiber (lbs) & & & & & 3.06 \\
\hline Water (lbs) & 284 & 134.4 & 276 & 265 & 276 \\
\hline Gravel (lbs) & 1750 & 1206 & 1206 & 1206 & 1206 \\
\hline Sand (lbs) & 1206 & 1750 & 1750 & 1750 & 1750 \\
\hline HRWRA (oz.) & 34 & & 187 & 187 & 200 \\
\hline AEA (oz.) & 22 & & 20 & 20 & 16 \\
\hline $\mathrm{w} / \mathrm{cm}^{\mathrm{a}}$ & 0.5 & $0.35^{\mathrm{b}}$ & $0.4^{\mathrm{c}}$ & $0.4^{\mathrm{d}}$ & $0.4^{\mathrm{e}}$ \\
\hline
\end{tabular}

Note: All values are based on one cubic yard of concrete.

${ }^{a} w / \mathrm{cm}=$ Water-Cementitious Materials Ratio

${ }^{b} w=$ Water from latex + Mixing Water $=110.6+134.4=24.5 \mathrm{lb}$.

${ }^{c} \mathrm{~cm}=$ Cement + Silica Fume.

${ }^{d} \mathrm{~cm}=$ Cement + Silica Fume + Fly Ash.

${ }^{e} \mathrm{~cm}=$ Cement + Silica Fume. 


\subsection{Mixing Procedure}

All mixing was done in a standard laboratory rotary drum mixer. The mixing sequences of different mixtures were as follows:

Normal Concrete (NC):

1. AEA agent and mixing water were mixed together as the liquid mixture.

2. All the coarse aggregate, fine aggregate and approximately one third of liquid mixture were added. The mixer was rotated until the aggregate were well mixed.

3. Cement and remaining liquid mixture were added and mixed well for about five minutes or until the mixture was uniform.

4. HRWRA was added while the mixer was kept rotating until the mixture was uniform. The HRWRA dosage was controlled to obtain the desired slump.

Latex-modified concrete (LMC):

1. Latex, Antifoam, AEA and mixing water were mixed together as the liquid mixture.

2. All the coarse aggregate, fine aggregate and approximately one third of liquid mixture were added. The mixer was rotated until the aggregate were well mixed.

3. Cement and remaining liquid mixture were added and mixed well for about five minutes or until the mixture was uniform.

Microsilica modified concrete (MMC):

1. AEA agent and mixing water were mixed together as the liquid mixture. 
2. All the coarse aggregate, fine aggregate and approximately one third of liquid mixture were added. The mixer was rotated until the aggregate were well mixed.

3. All cementitious materials such as cement and silica fume, and remaining mixing water were added and mixed well for about three minutes or until the mixture was uniform.

4. HRWRA was added while the mixer was kept rotating for another three to five minutes or until the mixture was uniform. The HRWRA dosage was controlled to obtain the desired slump.

Microsilica modified concrete with Fly ash (MMC-FA):

1. AEA agent and mixing water were mixed together as the liquid mixture.

2. All the coarse aggregate, fine aggregate and approximately one third of liquid mixture were added. The mixer was rotated until the aggregate were well mixed.

3. All cementitious materials such as cement, silica fume, and fly ash and remaining mixing water were added and mixed well for about three minutes or until the mixture was uniform.

4. HRWRA was added while the mixer was kept rotating for another three to five minutes or until the mixture was uniform. The HRWRA dosage was controlled to obtain the desired slump.

Fiber reinforced concrete (FRC):

1. AEA and mixing water were mixed together as the liquid mixture.

2. Cement, silica fume and fibers were added to make a dry mixture. 
3. All the coarse aggregate and fine aggregate were mixed for a while. The dry mixture as prepared by cement, silica fume and fibers is now added and mixed until the mixture was well mixed.

4. Liquid mixture was added and mixed well for about five minutes or until the mixture was uniform.

5. HRWRA was added while the mixer was kept rotating for another three to five minutes or until the mixture was uniform. The HRWRA dosage was controlled to obtain the desired slump.

As soon as the mixing was completed, slump, temperature, air content and unit weight of concrete were measured according to relevant ASTM and AASHTO standards.

\subsection{Preparation of Specimens}

\subsubsection{Specimens for Compressive Strength and Splitting Tensile Strength Tests}

After mixing, the fresh concrete was cast in 4 in. diameter and 8 in. long plastic cylinder molds in three layers and each layer was compacted by steel rod and plastic hammer. Within few minutes after casting, the specimens were covered with wet burlap and plastic sheet and cured in a curing room for 24 hours before demolding. After demolding, MMC, MMC-FA and FRC specimens were kept under lime water for six days and then air dried in a curing room at $73 \pm 5{ }^{\circ} \mathrm{F}$ until the day of testing. After demolding LMC specimens were moist cured for 24 hours and then air dried in a curing room until the day of testing. 


\subsubsection{Specimens for Flexural Strength Test}

After mixing, the fresh concrete was cast in 2 in. $\mathrm{x} 2$ in. $\mathrm{x} 11$ in. long steel beam molds and vibrated on a vibration table for 45 seconds. Within few minutes after casting, the specimens were covered with wet burlap and plastic sheet and cured in a curing room for 24 hours before demolding. After demolding, MMC, MMC-FA and FRC specimens were kept under lime water for six days and air dried in a curing room at $73 \pm 5{ }^{\circ} \mathrm{F}$ until the day of testing. After demolding LMC specimens were moist cured for 24 hours and then air dried in a curing room until the day of testing.

\subsubsection{Specimens for Free Shrinkage Test}

After mixing, the fresh concrete was cast in 3 in. $x 3$ in. $x 10$ in. long steel beam molds fitted with pins and vibrated on a vibration table for several minutes. Within few minutes after casting, the specimens were covered with wet burlap and plastic sheet and cured in a curing room at $73 \pm 5{ }^{\circ} \mathrm{F}$ for 24 hours before demolding. After demolding, all specimens were immediately transferred to the environmental room at $40 \pm 5 \%$ relative humidity and $73 \pm 5{ }^{\circ} \mathrm{F}$ temperature with the provisions of adequate air circulation through the specimens.

\subsubsection{Specimens for Chloride Permeability Test}

The cylindrical specimens were prepared in a similar manner to the compressive and splitting tensile strength specimens. Then disc specimens were cut with a diamond saw from the top of these cylinder specimens, to obtain samples of size 2 in. thick and 4 
in. diameter. These disc specimens were stored under wet burlap at temperature of $73 \pm 5$ ${ }^{\circ} \mathrm{F}$ until the day of testing between 28 to 38 days. 


\section{Chapter 4}

\section{Characterization of Properties of Overlay Mixtures and}

\section{Substrate}

\subsection{Testing of Fresh Concrete}

These tests include slump, air content, unit weight and temperature. The slump of fresh concrete was measured in accordance with ASTM C 143 (Standard Test Method for Slump of Hydraulic Cement Concrete) and AASHTO T 119. Soon after the mixing was completed, the quality of mixture was also noticed visually. The air content of fresh concrete was determined by the pressure method in accordance with ASTM C 231 (Standard Test Method for Air Content of Freshly Mixed Concrete by the Pressure Method) and AASHTO T 152. The unit weight of fresh concrete was measured per ASTM C 138 (Standard Test Method for Unit Weight, Yield, and Air Content of Concrete) and AASHTO $\mathrm{T}$ 121. The temperature of concrete was measured with a standard thermometer, with an accuracy of $\pm 0.5^{\circ} \mathrm{F}$, soon after mixing was completed, in accordance with ASTM C 1064 (Standard Test Method of Temperature of Freshly Mixed Portland Concrete).

Table 4.1 lists the fresh properties of NC, LMC, MMC, MMC-FA and FRC. 
Table 4.1 Properties of Fresh Concrete

\begin{tabular}{|c|c|c|c|c|}
\hline \multirow{2}{*}{ Mixture } & Air Content & Slump & Unit Weight & Temperature \\
\cline { 2 - 5 } & $(\%)$ & $($ in. $)$ & $(\mathrm{lb} / \mathrm{c} . \mathrm{ft})$ & $\left({ }^{\mathrm{o}} \mathrm{F}\right)$ \\
\hline \hline NC & 7.1 & 6.3 & 142 & 73 \\
\hline LMC & 3.8 & 7.5 & 147 & 64 \\
\hline MMC & 7.0 & 5.5 & 135 & 70 \\
\hline MMC-FA & 8.0 & 7.0 & 134 & 68 \\
\hline FRC & 7.6 & 5.0 & 133 & 70 \\
\hline
\end{tabular}

NC: Substrate Concrete

LMC, MMC, MMC-FA, and FRC: Overlay Concrete

\subsection{Testing of Hardened Concrete}

These tests include compressive strength, splitting tensile strength, toughness, shrinkage and rapid chloride permeability.

\subsubsection{Compressive Strength}

Compressive strength of 4 in. diameter and 8 in. long cylinder specimens was measured in accordance with ASTM C 39 (Standard Test Method for Compressive Strength of Cylindrical Concrete Specimens) and AASHTO T 22, using a 350,000 lbs capacity hydraulic type compression testing machine. Tests were conducted on specimens at 3, 7 and 28 days. For each mixture three specimens were tested and the average was calculated for presentation of data. Table 4.2 shows the average values of compressive strength for NC, LMC, MMC, MMC-FA and FRC. Figure 4.7 shows the bar diagram of compressive strength of all the mixtures for comparison. 
Table 4.2 Compressive Strength of Different Mixtures

\begin{tabular}{|c|c|c|c|c|c|}
\hline \multirow{2}{*}{$\begin{array}{c}\text { Age } \\
\text { (Days) }\end{array}$} & NC & LMC & MMC & MMC-FA & FRC \\
\cline { 2 - 6 } & $(\mathrm{psi})$ & $(\mathrm{psi})$ & $(\mathrm{psi})$ & $(\mathrm{psi})$ & $(\mathrm{psi})$ \\
\hline 3 & 3130 & 4340 & 4870 & 3880 & 4340 \\
\hline 7 & 4230 & 5190 & 5860 & 4830 & 5600 \\
\hline 28 & 6100 & 6950 & 8340 & 7180 & 8860 \\
\hline
\end{tabular}

\subsubsection{Splitting Tensile Strength}

Splitting Tensile strength of 4 in. diameter and 8 in. long cylinder specimens was measured in accordance with ASTM C 496 (Standard Test Method for Splitting Tensile Strength of Cylindrical Concrete Specimens), using a 350,000 lbs capacity hydraulic type compression testing machine. Tests were conducted on specimens at 3, 7 and 28 days. For each mixture three specimens were tested and the average was calculated for presentation of data. Table 4.3 shows the average values of splitting tensile strength for NC, LMC, MMC, MMC-FA and FRC. Figure 4.8 shows the bar diagram of splitting tensile strength of all the mixtures for comparison.

Table 4.3 Splitting Tensile Strength of Different Mixtures

\begin{tabular}{|c|c|c|c|c|c|}
\hline $\begin{array}{c}\text { Age } \\
\text { (Days) }\end{array}$ & NC & LMC & MMC & MMC-FA & FRC \\
\cline { 2 - 6 }$(\mathrm{psi})$ & $(\mathrm{psi})$ & $(\mathrm{psi})$ & $(\mathrm{psi})$ & $(\mathrm{psi})$ \\
\hline 3 & 355 & 480 & 480 & 300 & 525 \\
\hline 7 & 405 & 575 & 545 & 470 & 575 \\
\hline 28 & 580 & 710 & 680 & 560 & 825 \\
\hline
\end{tabular}




\subsubsection{Flexural Strength}

The flexural strength of 2 in. $x 2$ in. $x 11$ in. long concrete beam specimens of overlay mixtures was measured under four-point bending in accordance with ASTM C 78 (Standard test method for flexural strength of concrete) and AASHTO T 97. The span of the beam was 9 in. For each mixture, three specimens were tested and the average was calculated for presentation of data. The 60-day specimens were tested on an MTS machine at a constant displacement rate of $0.004 \mathrm{in.} / \mathrm{min}$ in accordance with ASTM C 1018 (Standard test method for flexural toughness and first-crack strength of fiberreinforced concrete). Two LVDTs, each placed on the apposite face of the specimen, were used to measure the displacement of the center of the beam specimen. A load cell of $2000 \mathrm{lbs}$ capacity was used to measure the loading. Figures 4.1 and 4.2 show the test system and the typical failure respectively. Table 4.4 shows the test results. Figure 4.9 shows the load vs. deflection graph of all the overlay mixtures.

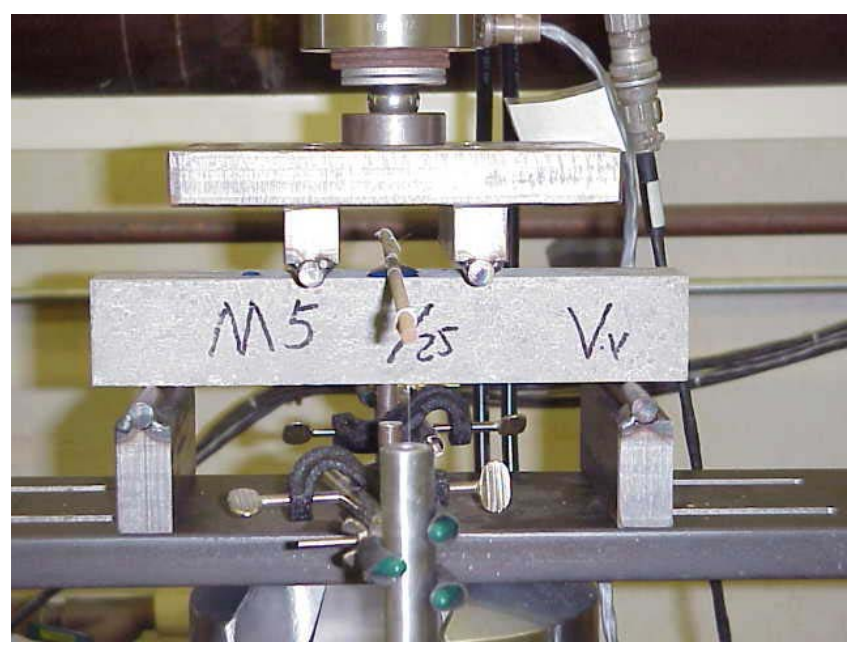

Figure 4.1 Flexural Strength Test of A Typical Specimen 


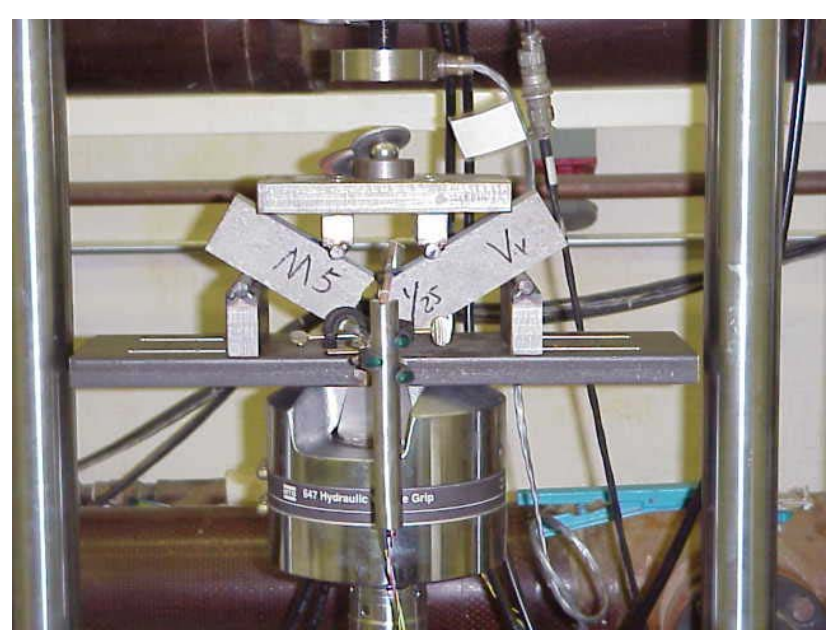

Figure 4.2 Specimen After Typical Failure

Table 4.4 Flexural Strength of 60-day Beam Specimens

\begin{tabular}{|c|c|c|}
\hline Overlay Type & Flexural Strength (psi) & Deflection at Maximum Load (in.) \\
\hline LMC & 1315 & $9.7 \times 10^{-3}$ \\
\hline MMC & 850 & $6.2 \times 10^{-3}$ \\
\hline MMC-FA & 765 & $5.6 \times 10^{-3}$ \\
\hline FRC & 995 & $6.8 \times 10^{-3}$ \\
\hline
\end{tabular}

\subsubsection{Free Shrinkage}

The length change of 3 in. $x 3$ in. $x 10$ in. long concrete prism specimens was measured in accordance with ASTM C 157 (Standard Test Method for Length Change of Hardened Hydraulic-Cement Mortar and Concrete) and AASHTO T 160. The specimens were stored at $40 \pm 5 \%$ relative humidity and $73 \pm 5{ }^{\circ} \mathrm{F}$ temperature with adequate air circulation through the specimens. For each mixture, three specimens were tested. The readings of length change were taken by a standard length change comparator every three days and up to 75 days. From the values of length change, the free shrinkage of prism specimens was calculated in microstrains. Figure 4.3 shows the test in progress using a digital length change comparator. The individual data of all the mixtures are furnished in 
Appendix B. The bar diagram showing the comparisons of shrinkage at 75 days among all the mixtures is provided in Figure 4.10.

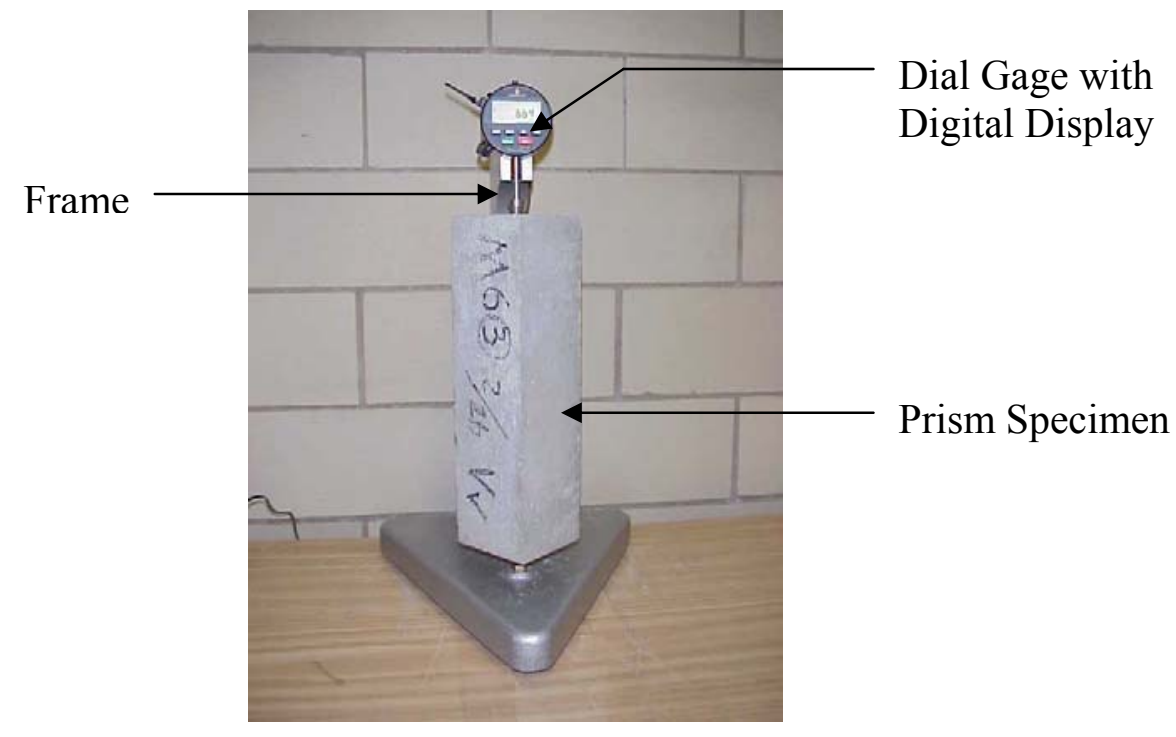

Figure 4.3 Free Shrinkage Test in Progress

\subsubsection{Rapid Chloride Permeability}

The chloride permeability test of disc specimens ( 4 in. diameter and 2 in. thickness) cut from cylinders was conducted in accordance with ASTM C 1202 (Standard Test Method for Electrical Indication of Concrete's Ability to Resist Chloride Ion Penetration) and AASHTO T 277. Figures 4.4 and 4.5 show the test specimens and the apparatus respectively. The circular surfaces of the disc specimens were coated with an epoxy sealant. The specimen was then brought to a standard moisture condition by the following vacuum saturation procedure: vacuum was applied to the dry specimen for 3 hours, and then continued for one more hour with the specimen immersed in de-aerated water; then, the specimen was soaked in the same water for an additional $18 \pm 2$ hours at atmospheric pressure. The ends of the specimen were then sealed into hollow, polymethyl methacrylate (Plexiglas) chambers. The side of the cell containing the top of the sample 
was filled with a $3 \%$ sodium chloride solution, and the other side containing the bottom with a $0.3 \mathrm{~N}$ sodium hydroxide solution. An electric current of 60 volts DC was applied across the specimen between copper screen electrodes contained in each cell. The total charge passed, or the integral of the current with respect to time, during a 6 hours period is a measure of the chloride permeability of the concrete. The test was conducted on properly cured 28 to 35 days old specimens. For each mixture, two specimens were tested and the average was calculated for presentation of data. Figure 4.6 shows the test in progress. The individual data of all the mixtures (NC, LMC, MMC, MMC-FA and FRC) are furnished in Appendix B. Figure 4.20 shows the bar diagram of chloride permeability values of all the mixtures for comparison.

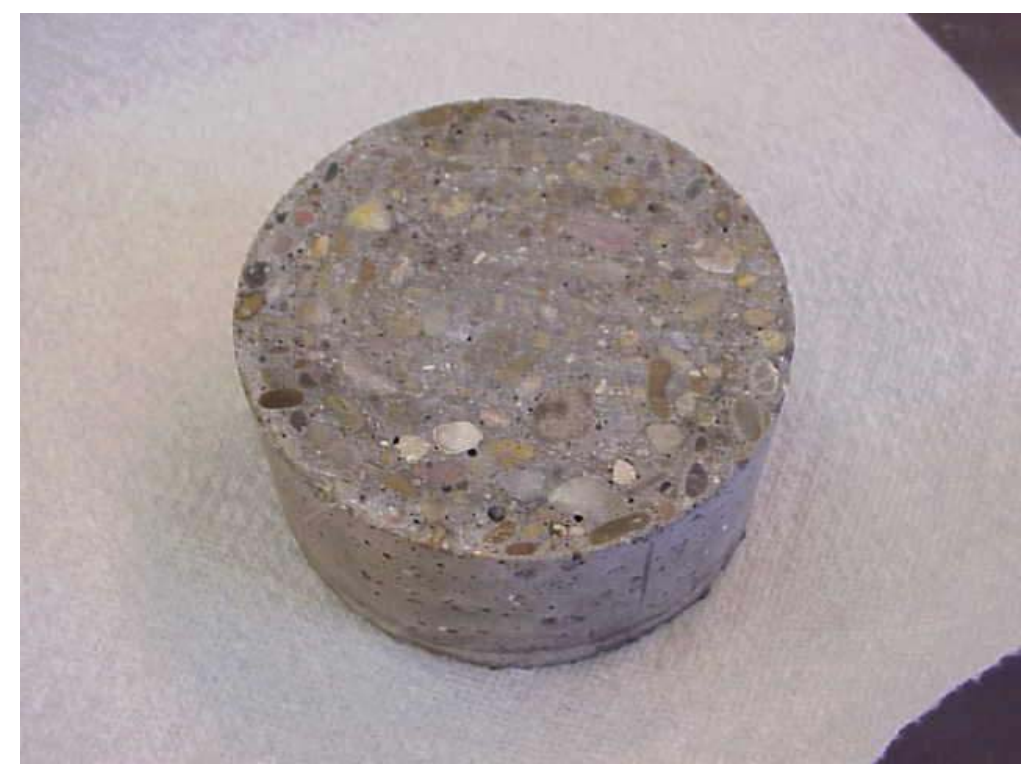

Figure 4.4 Rapid Chloride Permeability Test Specimen ( 2 in. thickness $x 4$ in. diameter) 


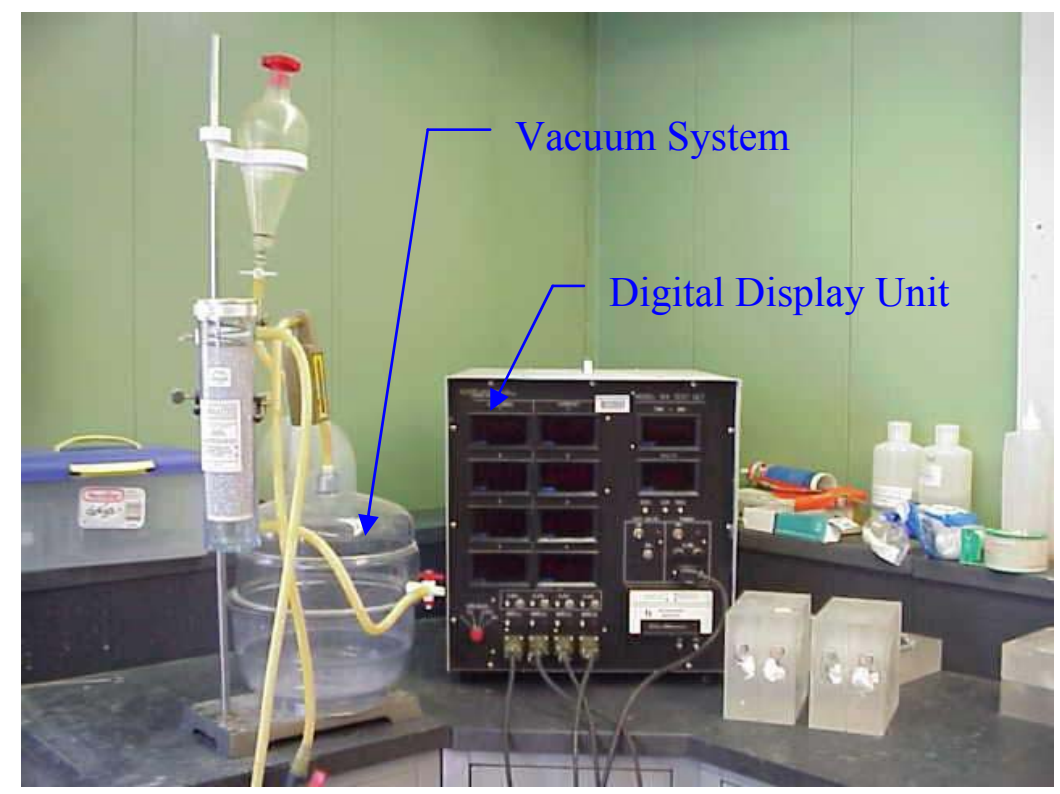

Figure 4.5 Vacuum System and Charge-Passed Measurement Apparatus

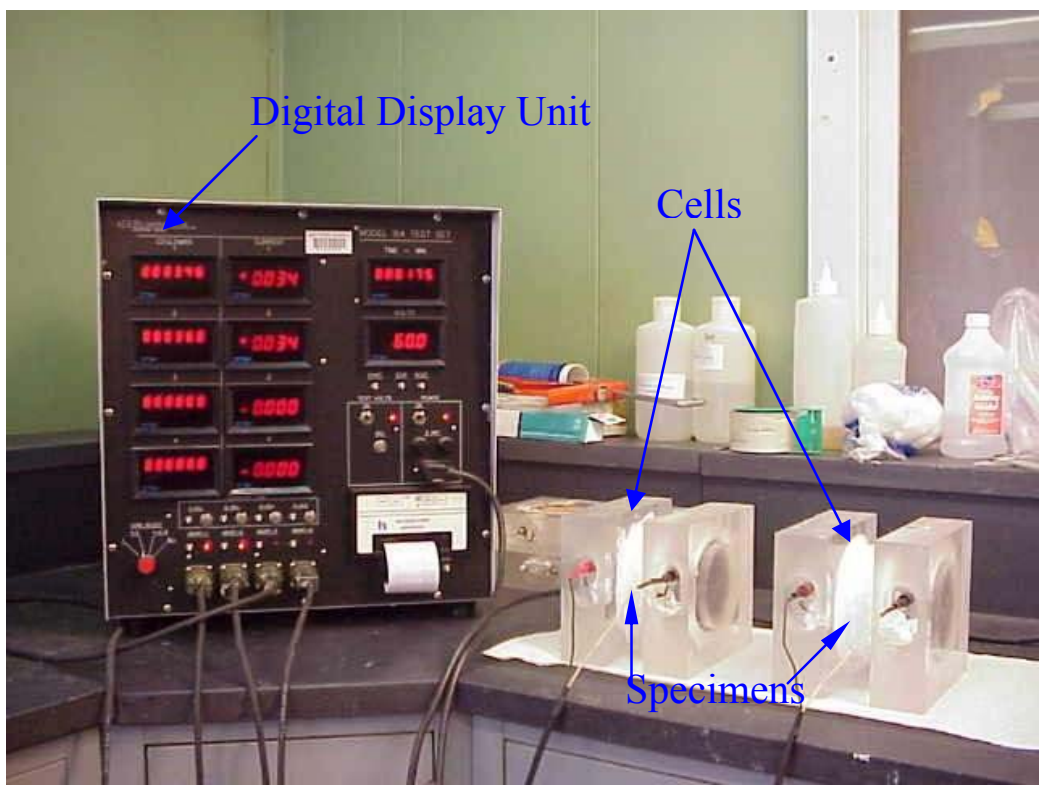

Figure 4.6 Chloride Permeability Test in Progress 


\subsection{Discussion of Test Results}

\subsubsection{Fresh Concrete}

Table 4.1 shows that both air content and slump of all the mixtures were within the range of the WVDOH specifications. Though LMC had relatively lower air content, due to use of antifoam, it still satisfied the specification of WVDOH. The slump of LMC was found to be slightly higher than the specification requirement (4.0 in. $\pm 2.0 \mathrm{in}$.).

The unit weights of MMC, MMC-FA and FRC were within a narrow range of 133 lb/c.ft to $135 \mathrm{lb} / \mathrm{c}$.ft. The values were slightly lighter than the normal weight concrete. This is due to the replacement of cement with relatively lightweight silica fume and fly ash in MMC, MMC-FA and FRC, and the addition of lightweigh synthetic fiber (polypropylene) in FRC. The unit weight of LMC $(147 \mathrm{lb} / \mathrm{c} . \mathrm{ft})$ was close to NC $(142$ lb/c.ft).

The temperatures of all overlay mixtures just before placement were within a reasonable range of $64{ }^{\circ} \mathrm{F}$ to $70{ }^{\circ} \mathrm{F}$, which indicates that these overlay mixtures are suitable for constructions in normal climatic conditions. The concrete temperature is ideal for timely setting of concrete.

\subsubsection{Compressive and Splitting Tensile Strength}

Tables 4.2 and 4.3 and Figures 4.7 and 4.8 show the average values of compressive strength and splitting tensile strength of NC, LMC, MMC, MMC-FA and FRC. All the overlay mixtures had higher compressive strengths compared to the substrate mixture (NC). All the overlay mixtures except MMC-FA achieved higher splitting tensile strengths compared to the substrate mixture (NC). MMC-FA had slightly

lower splitting tensile strength. This may be due to the use of fly ash as a partial 
substitution of cement. LMC had the lowest 28-day compressive strength but second highest splitting tensile strength. FRC had the highest compressive and splitting tensile strength. Fibers improved both the compressive and tensile strengths of concrete. When compared with substrate concrete, the FRC had the maximum overall gain in strength and MMC-FA had the minimum overall increase in strength, for both compression and splitting tension. In general, the difference of tensile strength between overlays and substrate was more than the difference in compressive strengths. All overlay mixtures satisfied the strength requirements of WVDOH, which is 4000 psi at 28 days. Table 4.2 shows that the 3-day strength of LMC, MMC and FRC (4340, 4870 and 4340 psi respectively) was even greater than the 28-day strength requirement of WVDOH. This favorable characteristic will allow the traffic on a bridge deck after only 3 days of curing, which is highly advantageous.

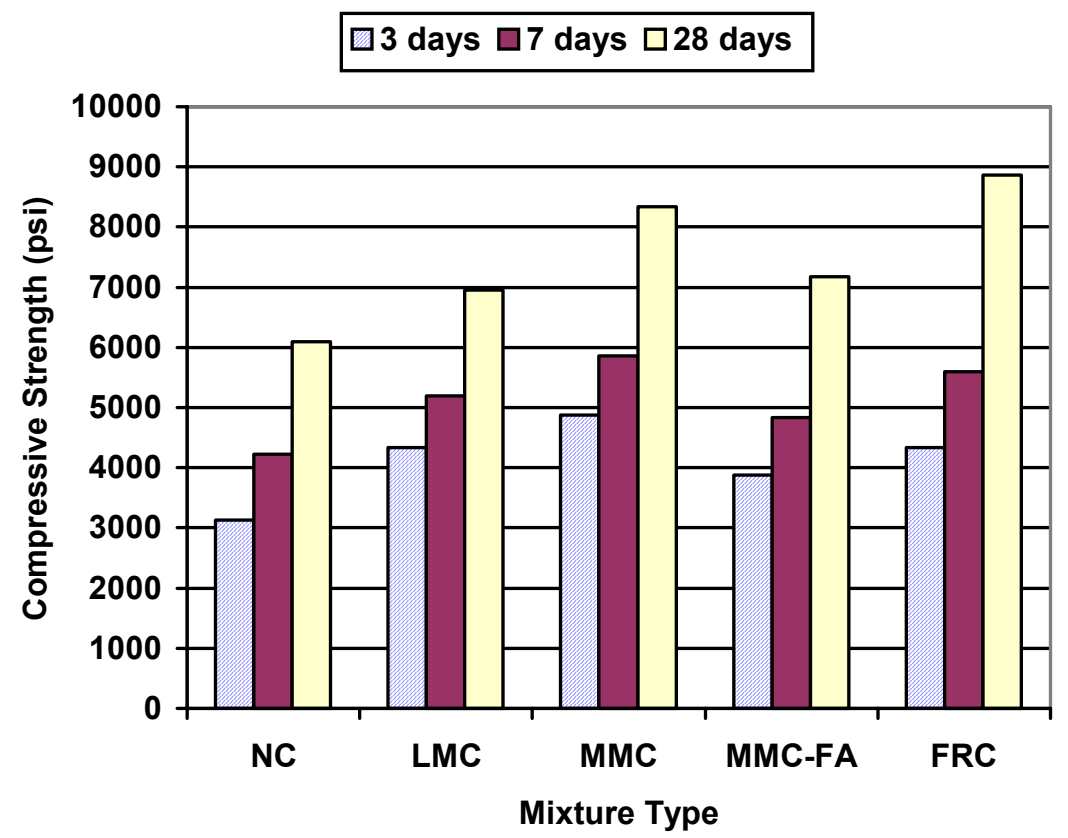

Figure 4.7 Compressive strength at Different Age 


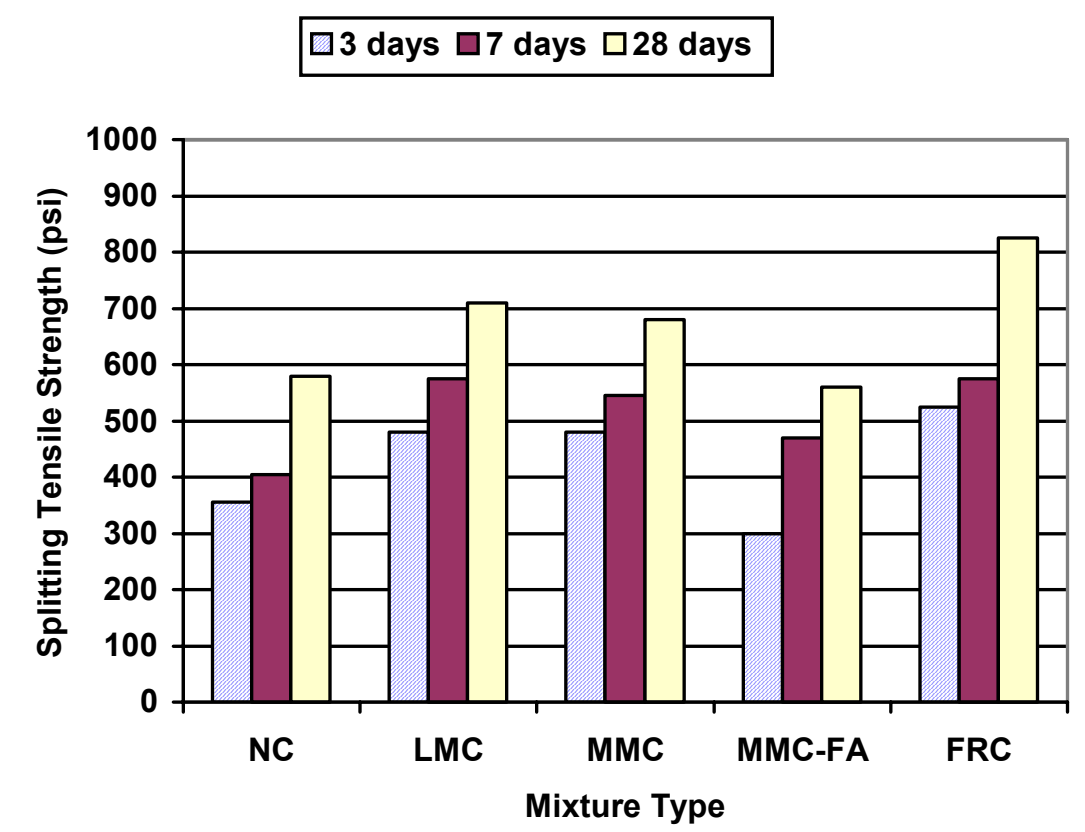

Figure 4.8 Splitting Tensile strength at Different Age

ACI 363R (State-of-the-art report on high-strength concrete) presents a relationship between compressive strength $\left(f_{\mathrm{c}}{ }^{\prime}\right)$ and splitting tensile strength $\left(f_{\mathrm{sp}}{ }^{\prime}\right)$. The slope of the relationship between $f_{\mathrm{sp}}^{\prime}$ and $\left(f_{\mathrm{c}}^{\prime}\right)^{1 / 2}$ may be represented as the brittleness of the material. In Table 4.5, the relative brittleness of overlays with respect to substrate is provided.

It is evident from Table 4.5 that LMC and FRC are less brittle than substrate concrete. Latex and fiber improved the ductility of the concrete. MMC had same order of brittleness as that of the substrate. MMC-FA is more brittle than the substrate though the tensile strength was close to NC. 
Table 4.5 Relationship of Splitting Tensile Strength and Compressive Strength (ACI 363)

\begin{tabular}{|c|c|c|c|c|c|}
\hline $\begin{array}{l}\text { Mixture } \\
\text { Types }\end{array}$ & $\begin{array}{c}\boldsymbol{f}_{\mathbf{c}}^{\prime}(\mathbf{p s i}) \\
(28 \text {-days })\end{array}$ & $\begin{array}{l}f_{\text {sp }}^{\prime}(\mathbf{p s i}) \\
(28 \text {-days })\end{array}$ & $\begin{array}{c}f \mathrm{sp}^{\prime} /\left(f \mathrm{c}^{\prime}\right)^{1 / 2} \\
\text { (Current Study) }\end{array}$ & $\begin{array}{l}f \mathrm{sp}^{\prime} /\left(f \mathrm{c}^{\prime}\right)^{1 / 2} \\
\text { (Substrate) }\end{array}$ & $\begin{array}{c}\text { Comment } \\
\text { (Compare to Substrate) }\end{array}$ \\
\hline LMC & 6950 & 710 & 8.5 & \multirow{4}{*}{7.4} & Less Brittle \\
\hline МMC & 8340 & 680 & 7.4 & & Same \\
\hline MMC-FA & 7180 & 560 & 6.6 & & More Brittle \\
\hline FRC & 8860 & 825 & 8.8 & & Less Brittle \\
\hline
\end{tabular}

\subsubsection{Flexural Strength}

Table 4.4 indicates that LMC had the highest flexural strength among all the overlay mixtures (1315 psi) and MMC-FA had the lowest flexural strength (765 psi). The addition of fibers in FRC increased the flexural strength (995 psi) compared to MMC (850 psi) and MMC-FA (765 psi), but the value was less than for LMC. Figure 4.9 shows that the addition of latex improved the ductility (deflection at maximum load) more than adding fibers. But FRC had higher ductility than both MMC and MMC-FA. The slope of the load-deflection curve represents the initial tangent modulus. Though LMC had significantly higher flexural strength than MMC and MMC-FA, the initial tangent modulus was lower than of MMC and MMC-FA, whereas the initial tangent modulus of FRC was close to those of MMC and MMC-FA. 


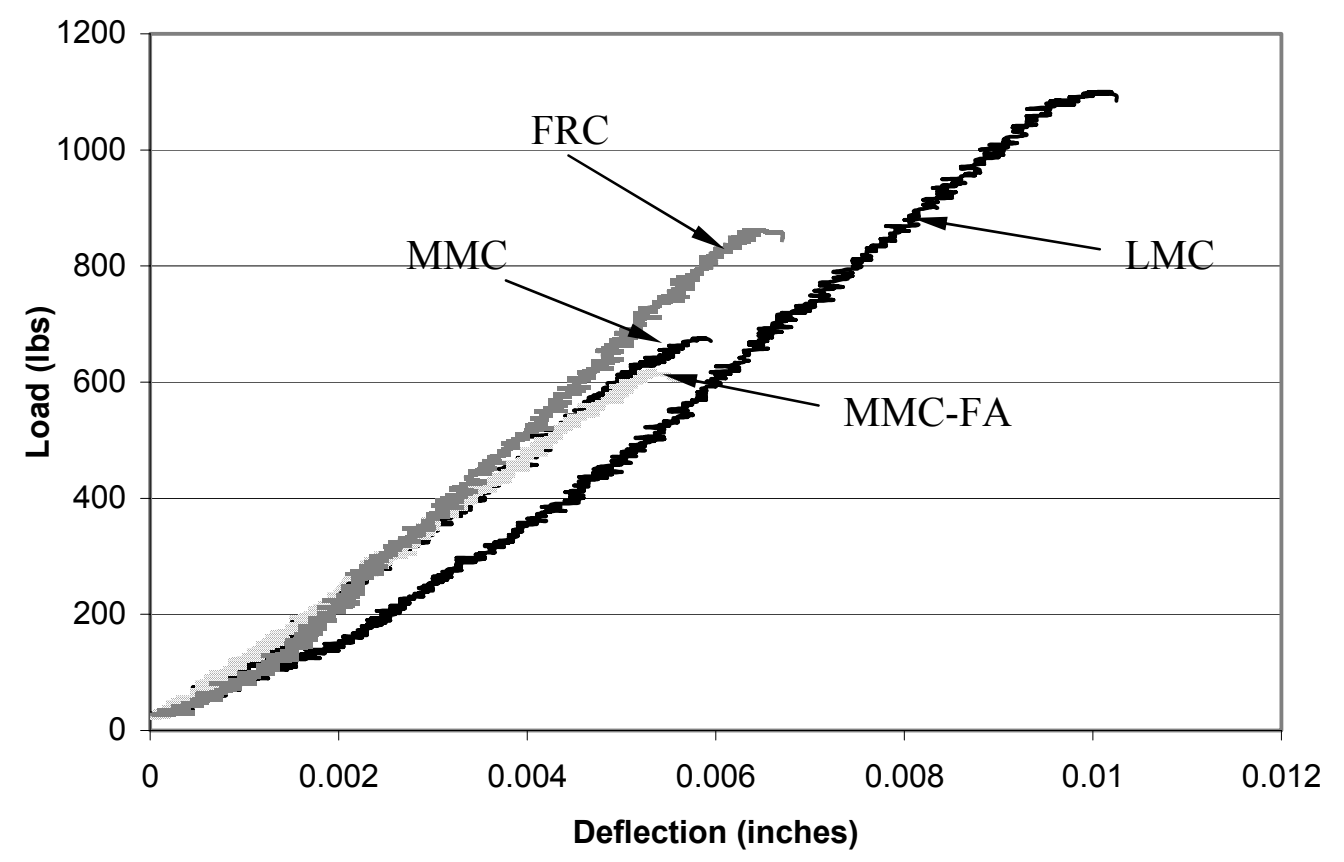

Figure 4.9 Load vs. Deflection Diagram Under 4-Point Bending (Flexure)

\subsubsection{Free Shrinkage}

Figure 4.10 shows the comparisons of 75 days free shrinkage of NC, LMC, MMC, MMC-FA and FRC. The free shrinkage values of MMC, MMC-FA and FRC were very close. All the overlay mixtures had lower free shrinkage values compared to normal concrete. Among the overlays, the value of shrinkage of LMC was the lowest $(615 \mu \varepsilon)$ and of MMC-FA was the highest $(670 \mu \varepsilon)$. Overall, the values of free shrinkage of all the mixtures were within a close range. The difference of shrinkage between substrate and all other overlays was mainly due to the use of higher water-cement ratio for substrate concrete $(w / \mathrm{cm}=0.50)$ compared to the overlays $(w / \mathrm{cm}=0.35$ to 0.40$)$. It is observed that the maximum difference of free shrinkage strain between substrate and overlay was $110 \mu \varepsilon$ which is reasonable. However the values do not provide adequate 
information of differential shrinkage under actual restrained conditions at different humidity and temperature levels in the field.

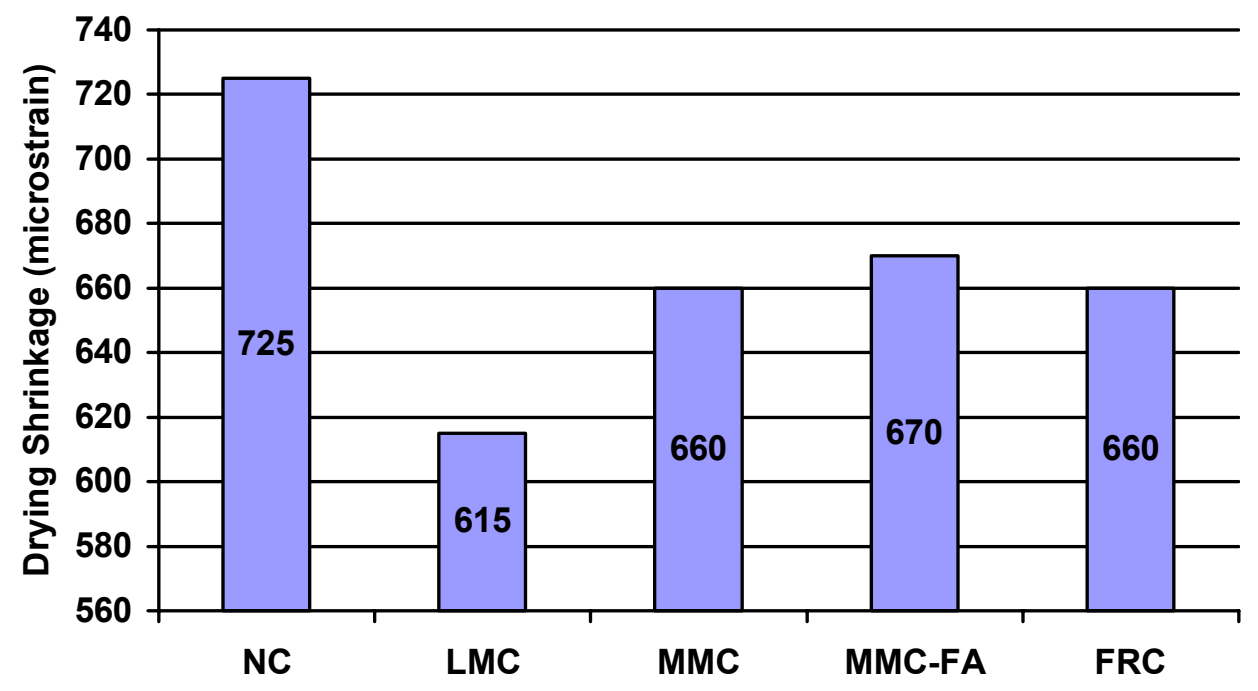

Figure 4.10 Free Shrinkage at 75 days

An empirical shrinkage prediction formula has been proposed by ACI 209R-92. A comparison of the prediction of free shrinkage strain for the concrete mixtures in this study using ACI 209 equations, modified ACI 209 equations by Huo et al. (2001), and equations developed using experimental data collected in this study is made as follows. All of the equations used are of rectangular hyperbolic form as used in ACI 209, which states that the following equation predicts the free shrinkage strain at any time, after age 7 days for moist-cured concrete:

$$
\left(\varepsilon_{s h}\right)_{t}=\frac{t}{f+t}\left(\varepsilon_{s h}\right)_{u}
$$

where

$f=35$ 
$\left(\varepsilon_{s h}\right)_{t}=$ shrinkage strain in./in.

$\left(\varepsilon_{s h}\right)_{u}=780 \gamma_{s h} \times 10^{-6}$ in./in.

$t=$ time after the end of the initial wet curing; and

$\gamma_{s h}=$ applicable correction factor

In this study, the correction factor, $\gamma_{s h}$, for each mixture used in the ACI 209 equation are shown in Table 4.6. The correction factor allows for different size of specimens, onset of drying and variations in mix designs.

Table 4.6 Correction Factor for Each Mixture

\begin{tabular}{|c|c|}
\hline Mixture Type & Correction Factors \\
\hline LMC & 1.93 \\
\hline MMC & 1.70 \\
\hline MMC-FA & 1.81 \\
\hline FRC & 1.70 \\
\hline
\end{tabular}

In a study by Huo et al. (2001), it was found that the ACI 209 prediction for free shrinkage strain was not accurate for high-performance concrete (HPC). Therefore, they modified the ACI equation. They used the rectangular hyperbolic form of the ACI 209 equation with two additional factors $K_{s}$ and $\gamma_{s t, s}$.

$$
\begin{aligned}
& K_{s}=45-2.5 f_{c}^{\prime} \\
& \gamma_{s t, s}=1.20-0.05 f_{c}^{\prime} \leq 1
\end{aligned}
$$

where, $f_{c}^{\prime}=28$-day Compressive Strength (ksi). Then, in ACI 209 Eq. (4.1)

$$
\begin{aligned}
& f=K_{s} \\
& \left(\varepsilon_{s h}\right)_{u}=780 \gamma_{s h} \gamma_{s t, s}
\end{aligned}
$$


The prediction of free shrinkage by ACI 209 using Eq. (4.1) and the modified equation used by Huo et al. (2001) are compared with calculated equations of the same form using the collected free shrinkage data from this study. The results are interpreted using the following equation:

$$
\frac{1}{\varepsilon_{s h}}=\frac{f}{\left(\varepsilon_{s h}\right)_{u} t}+\frac{1}{\left(\varepsilon_{s h}\right)_{u}}
$$

where $t$ is a variable.

$$
\begin{gathered}
\text { Let } \frac{1}{\varepsilon_{s h}}=y ; \frac{1}{t}=x ; \frac{1}{\left(\varepsilon_{s h}\right)_{u}}=b ; \frac{f}{\left(\varepsilon_{s h}\right)_{u}}=a \text {, then Eq. (4.4) can be expressed as } \\
y=a x+b
\end{gathered}
$$

By trial and error the following graphs with best-fit linear equations were obtained and are presented in Figures 4.11 through 4.14. The factor, $f$, and the ultimate free shrinkage strain, $\left(\varepsilon_{s h}\right)_{u}$, for each overlay mixture, were calculated from these figures. Table 4.7 shows the factors, $f$ and the $\left(\varepsilon_{s h}\right)_{u}$ for all the overlay mixtures. The values are calculated on the basis of ACI 209, Huo et al. (2001) and the current experimental data for comparison. 


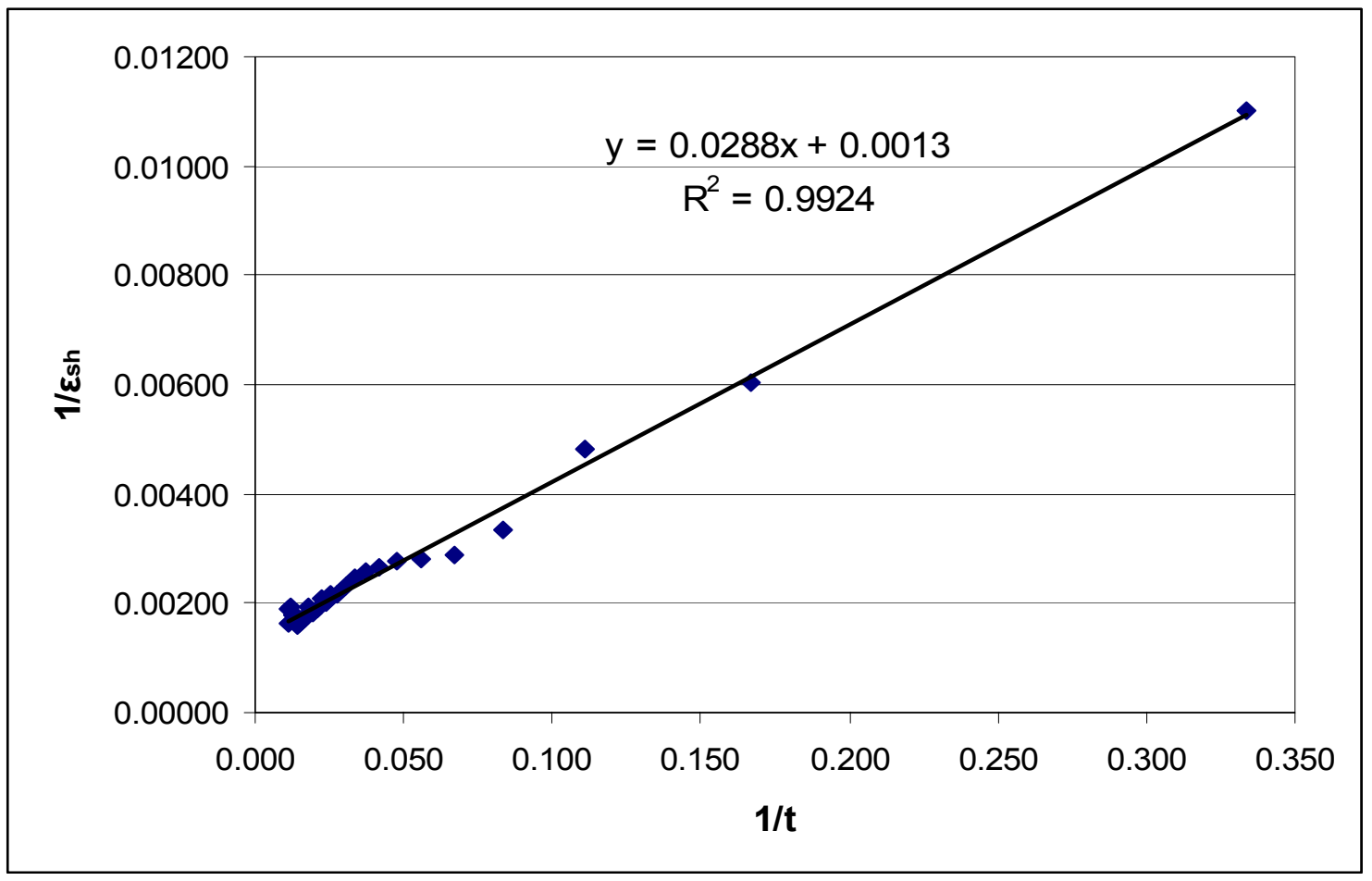

Figure 4.11 Best-Fit Linear Equation for LMC Free Shrinkage Strain

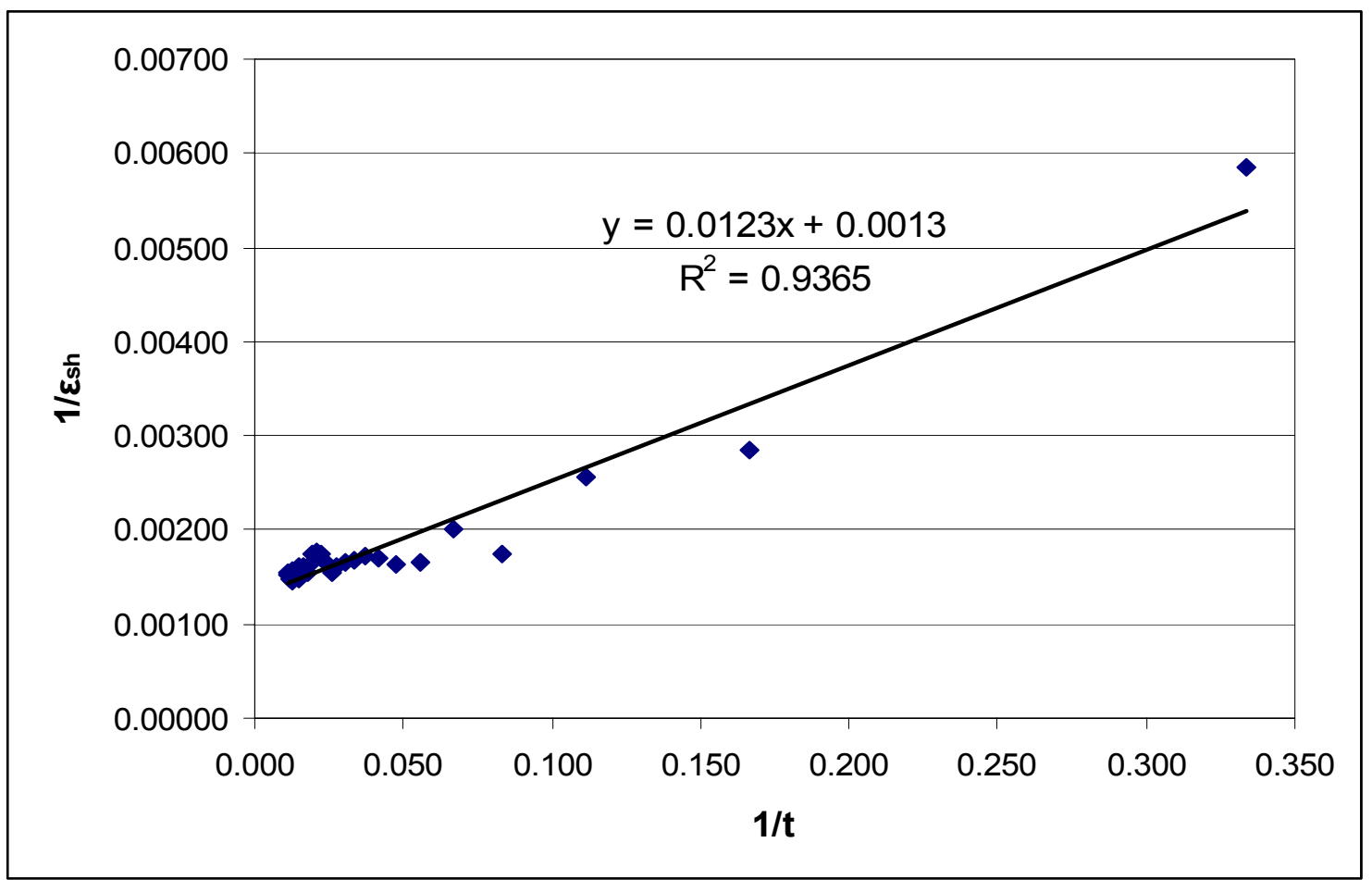

Figure 4.12 Best-Fit Linear Equation for MMC Free Shrinkage Strain 


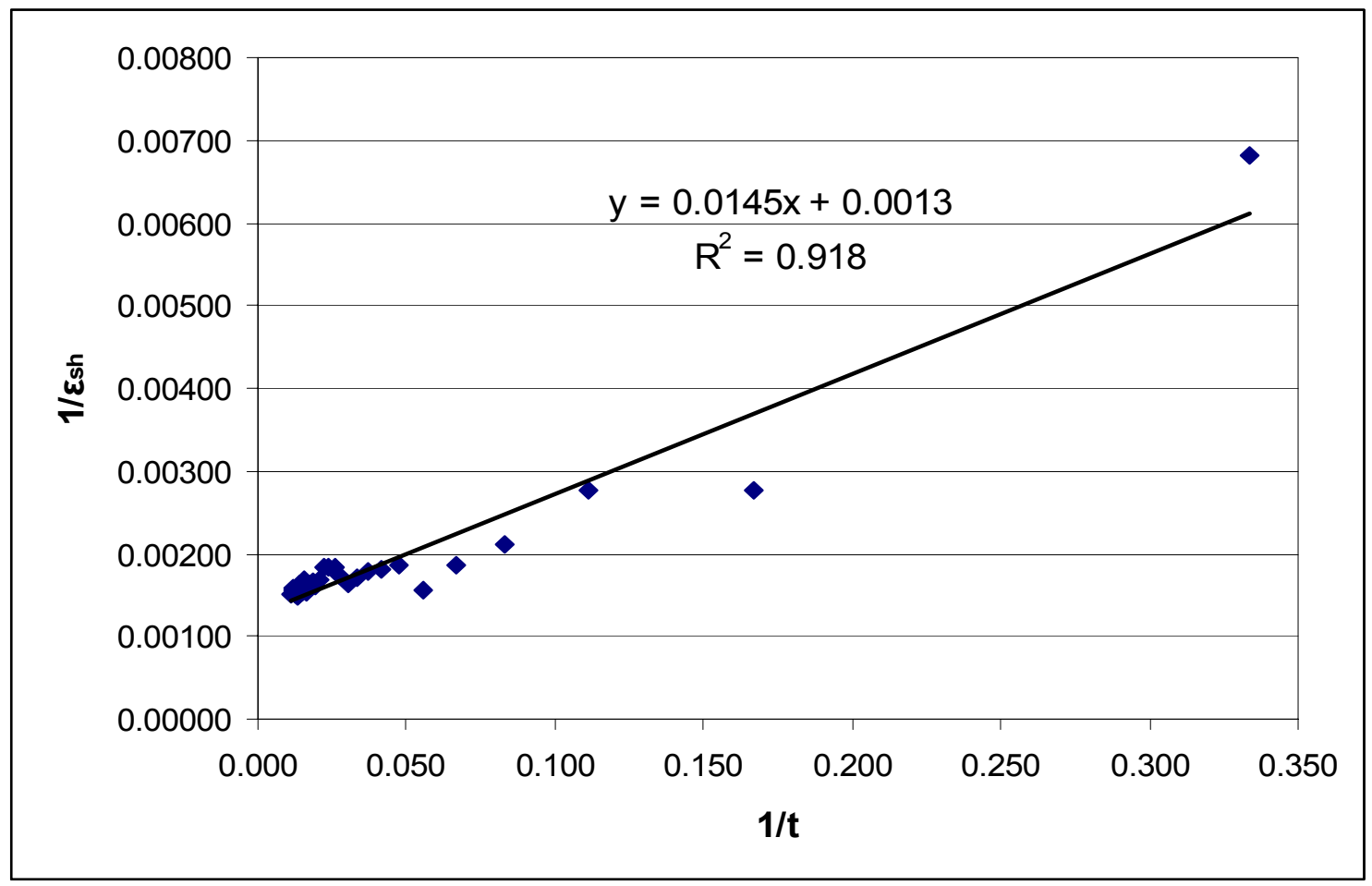

Figure 4.13 Best-Fit Linear Equation for MMC-FA Free Shrinkage Strain

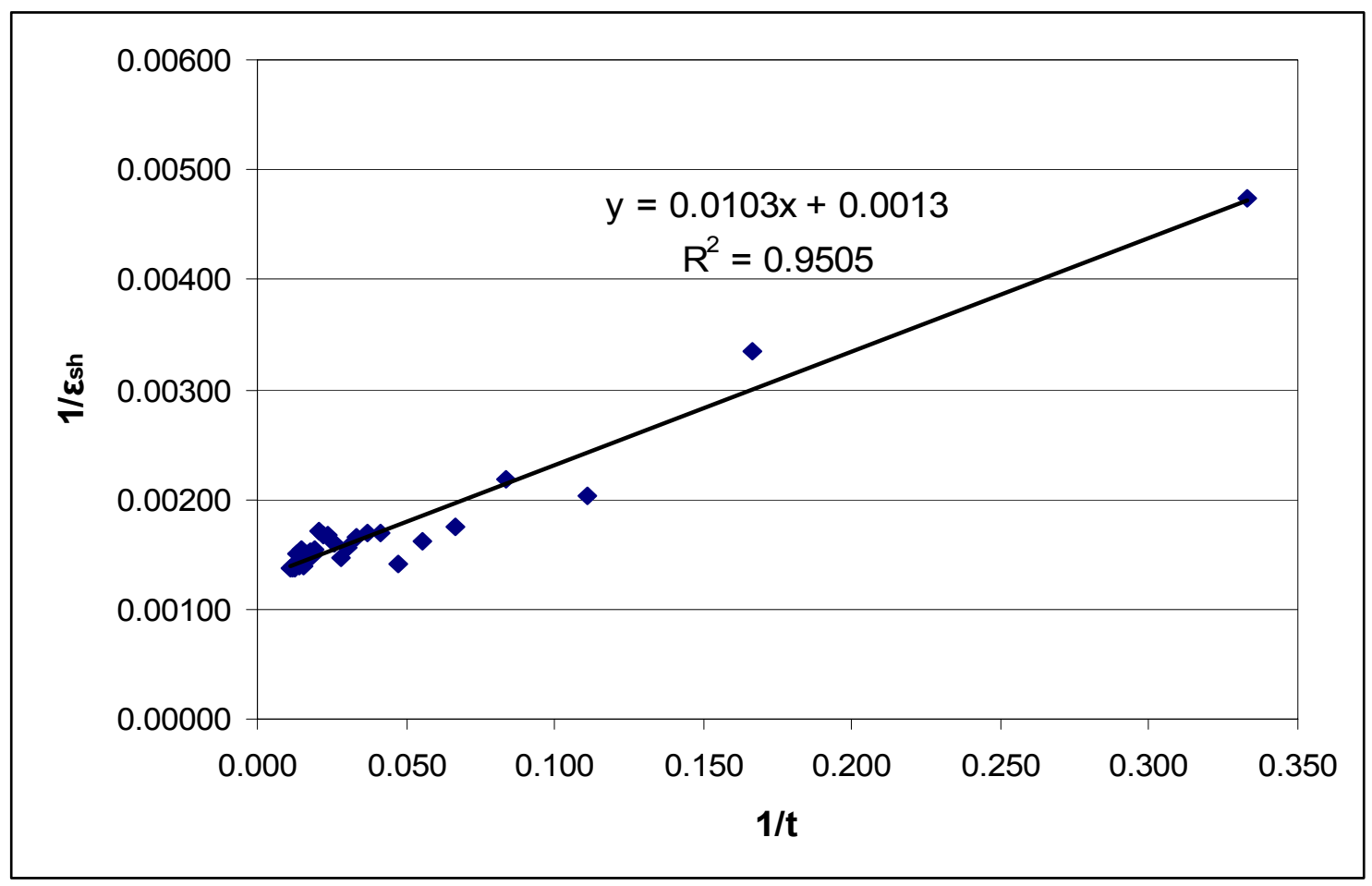

Figure 4.14 Best-Fit Linear Equation for FRC Free Shrinkage Strain 
Table 4.7 Constants Used in Free Shrinkage Strain Prediction

\begin{tabular}{|c|c|c|c|c|c|c|}
\hline & \multicolumn{2}{|c|}{ Experimental } & \multicolumn{2}{c|}{ Huo et al., 2001 } & \multicolumn{2}{c|}{ ACI 209} \\
\hline Mixture Type & $f$ & $\left(\varepsilon_{s h}\right)_{u}$ & $f$ & $\left(\varepsilon_{s h}\right)_{u}$ & $f$ & $\left(\varepsilon_{s h}\right)_{u}$ \\
\hline LMC & 22.15 & $769 \times 10^{-6}$ & 27.63 & $956 \times 10^{-6}$ & 35 & $1506 \times 10^{-6}$ \\
\hline MMC & 9.46 & $769 \times 10^{-6}$ & 24.15 & $1038 \times 10^{-6}$ & 35 & $1326 \times 10^{-6}$ \\
\hline MMC-FA & 11.15 & $769 \times 10^{-6}$ & 27.05 & $1187 \times 10^{-6}$ & 35 & $1411 \times 10^{-6}$ \\
\hline FRC & 7.92 & $769 \times 10^{-6}$ & 22.85 & $1004 \times 10^{-6}$ & 35 & $1326 \times 10^{-6}$ \\
\hline
\end{tabular}

The nonlinear forms were plotted by Eq. (4.1) with the different coefficients from Table 4.7. Figures 4.15 through 4.18 show the nonlinear forms of LMC, MMC, MMCFA and FRC.

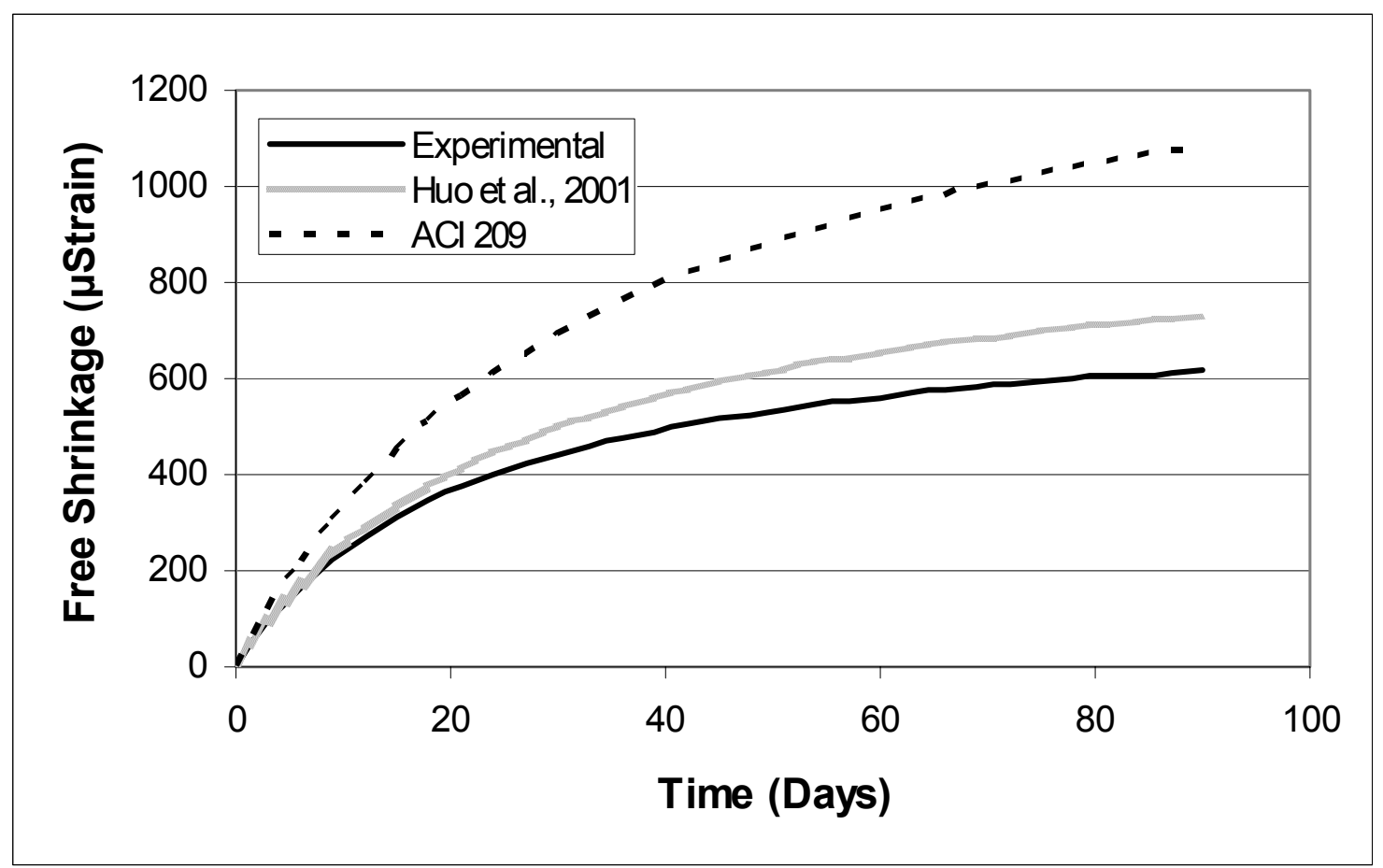

Figure 4.15 Predictions for Free Shrinkage Strain for LMC 


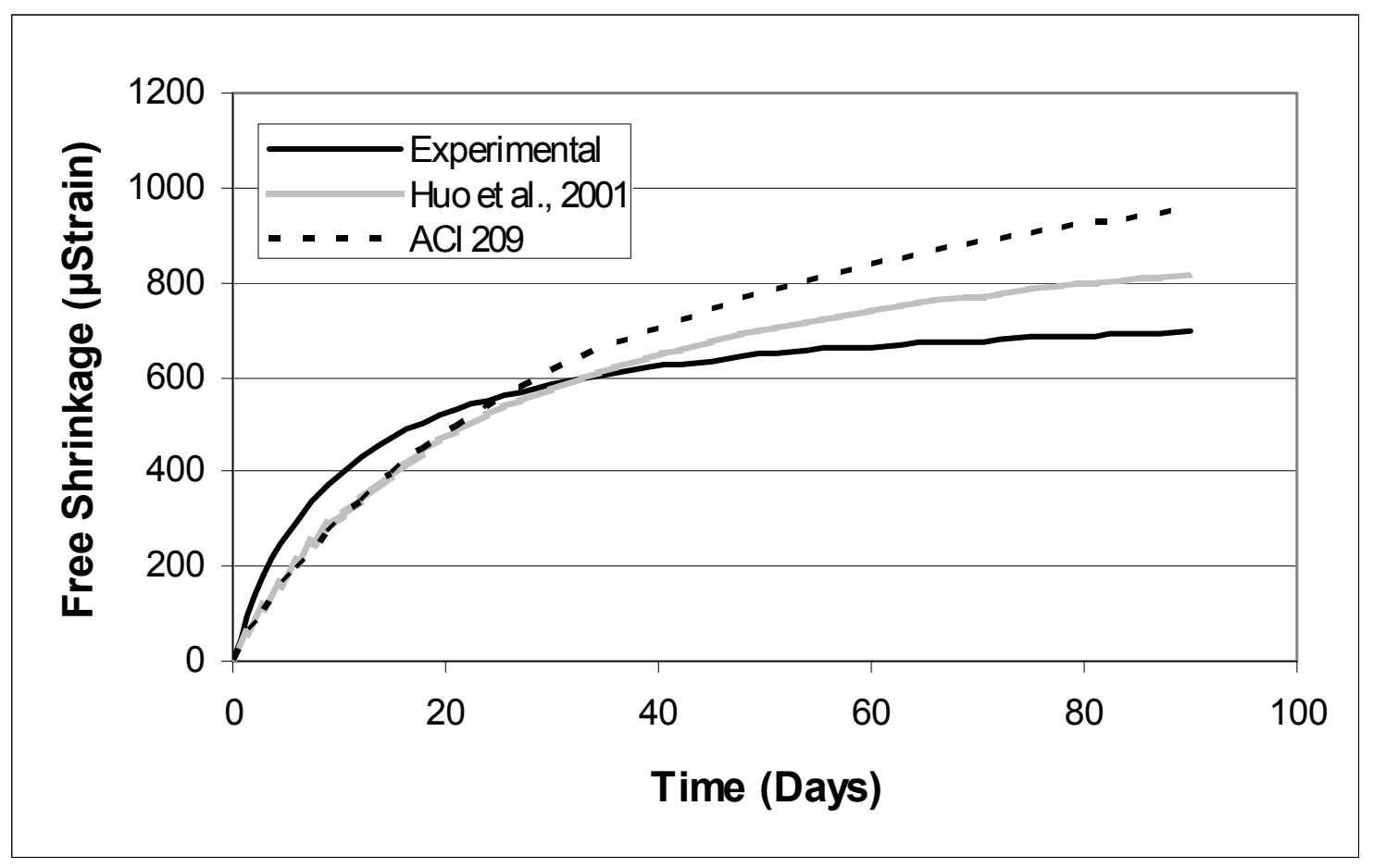

Figure 4.16 Predictions for Free Shrinkage Strain for MMC

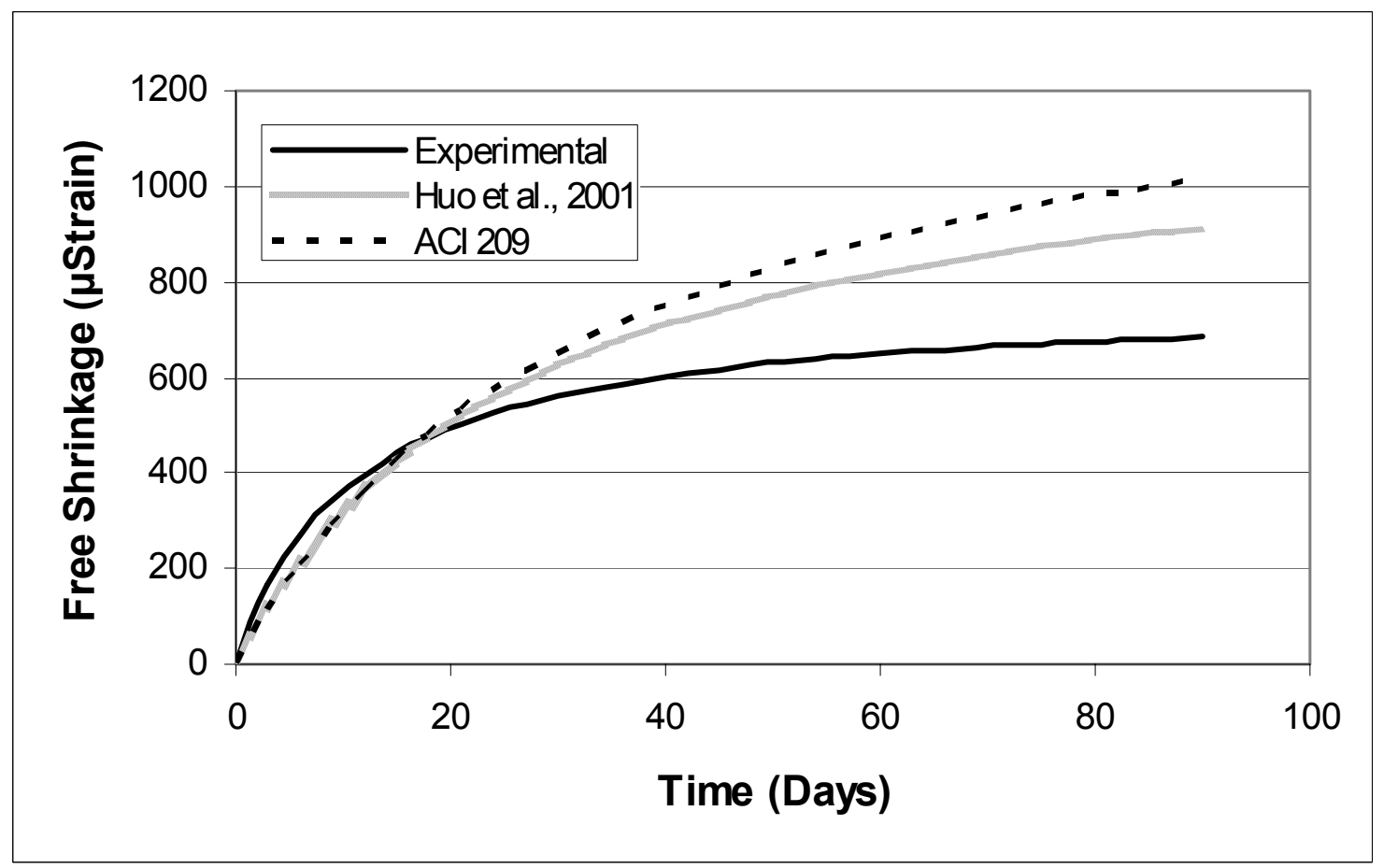

Figure 4.17 Predictions for Free Shrinkage Strain for MMC-FA 


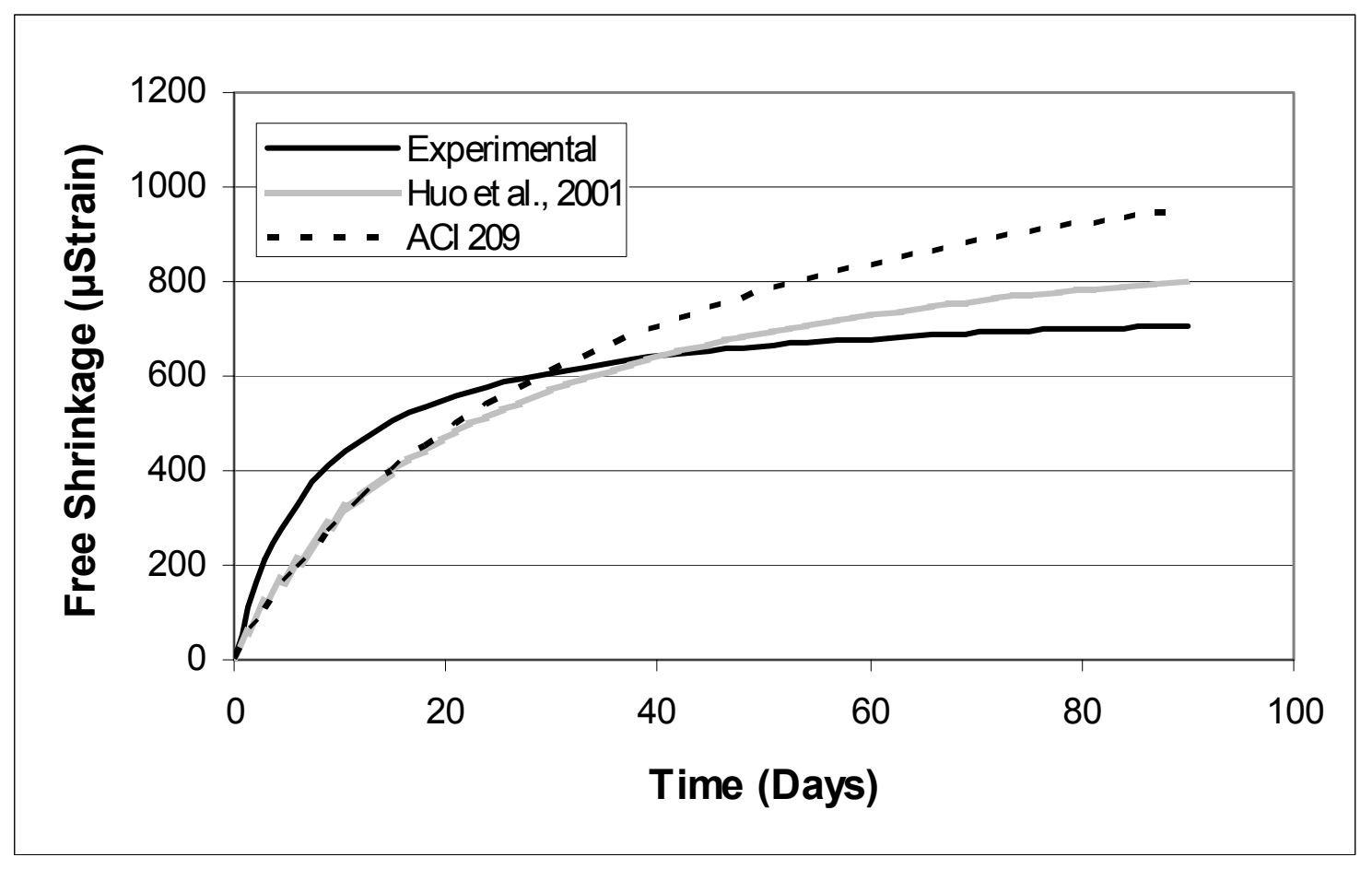

Figure 4.18 Predictions for Free Shrinkage Strain for FRC

Figure 4.15 shows that equations from ACI 209 grossly overestimated the free shrinkage in LMC, whereas the equation of Huo et al. (2001) slightly overestimated the response and can be considered acceptable. It appears that ACI 209 equation cannot predict the free shrinkage development of LMC accurately. Figures 4.16 through 4.18 show that both the prediction equations from ACI 209 and Huo et al. (2001) underestimated the early age shrinkage values of MMC, MMC-FA and FRC, and overestimated the late age shrinkage values. However, the differences were much less than for LMC. Both the ACI 209 and Huo et al. (2001) did not consider the influence of microsilica, fly ash, latex and fibers in their prediction equations. It is necessary to include the effect of admixtures and develop a new equation for prediction of a particular 
mixture. The following equations are suggested for various overlay mixtures used in this study:

$$
\begin{aligned}
\text { For LMC: } & \left(\varepsilon_{s h}\right)_{t}=\frac{t}{22.15+t}\left(769 \times 10^{-6}\right) \\
\text { MMC: } & \left(\varepsilon_{s h}\right)_{t}=\frac{t}{9.46+t}\left(769 \times 10^{-6}\right) \\
\text { MMC-FA: } & \left(\varepsilon_{s h}\right)_{t}=\frac{t}{11.15+t}\left(769 \times 10^{-6}\right) \\
\text { FRC: } & \left(\varepsilon_{s h}\right)_{t}=\frac{t}{7.92+t}\left(769 \times 10^{-6}\right)
\end{aligned}
$$

where,

$$
\begin{aligned}
& \left(\varepsilon_{s h}\right)_{t}=\text { shrinkage strain in./in. } \\
& \mathrm{t}=\text { time after the end of initial curing } \\
& \text { Initial curing }=24 \text { hour under wet burlap at } 73 \pm 5^{\circ} \mathrm{F} .
\end{aligned}
$$

\subsubsection{Rapid Chloride Permeability}

Figure 4.19 shows the charge passed vs. time diagram of four overlay mixtures. Figure 4.20 shows the comparison of chloride permeability values, which were obtained over 6 hours. Among LMC, MMC, MMC-FA and FRC, LMC had the highest chloride permeability. The charge passed through LMC was 822 Coulombs. FRC had the second highest chloride permeability. MMC-FA had the lowest chloride permeability. All of the four overlay mixtures satisfied the WVDOH specification which is 1000 Coulombs at 90 days. When compared with Table 1 of ASTM 1202, all of the overlay mixtures exhibited very low chloride permeability, which is a highly beneficial characteristic of protective overlays for reinforced concrete bridge deck slabs. 


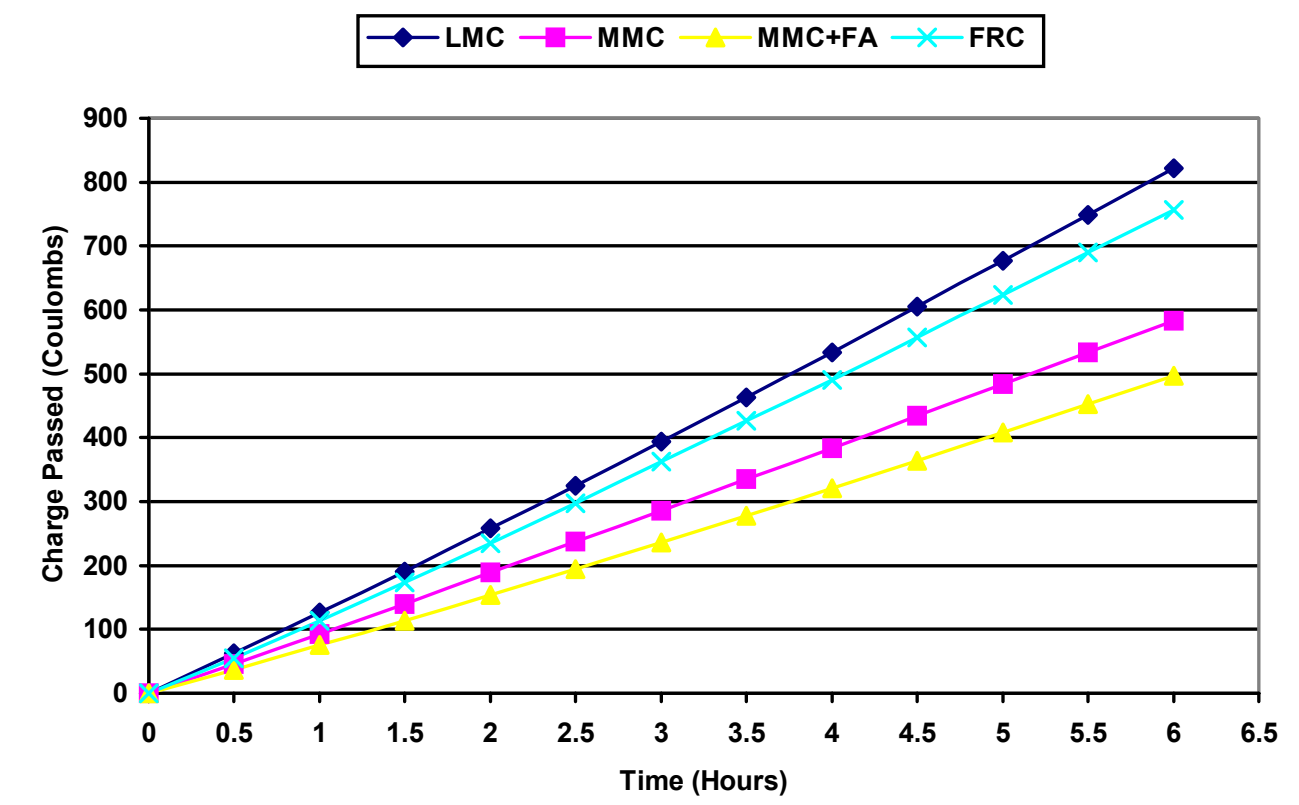

Figure 4.19 Chloride Permeability with Time

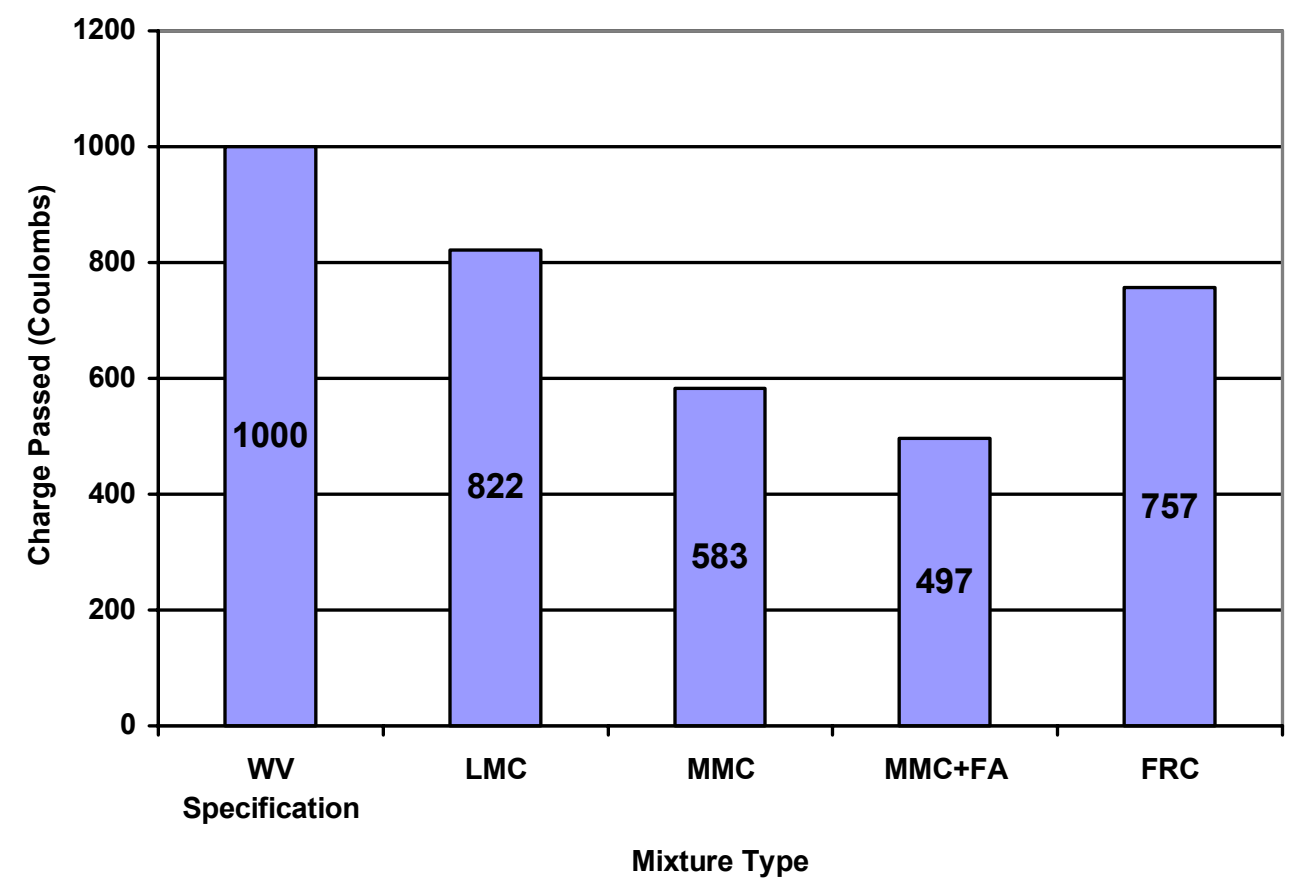

Figure 4.20 Comparison of Chloride Permeability Values (Value of NC is not shown) 


\section{Chapter 5}

\section{Evaluations of Interface of Bi-layer Specimens \\ by Direct Shear Test}

This chapter describes the design and fabrication of a shear testing apparatus, manufacturing of bi-layer specimens, and evaluations of overlay-substrate concrete interfaces through direct shear tests.

\subsection{Design and Fabrication of Shear Testing Apparatus}

The apparatus was designed as a block-shear tool by modifying the shear device typically used for wood specimens to determine shear properties per ASTM D 905. The tool was fabricated using high quality steel and was designed to accommodate the bilayer specimens and be capable of fitting into the compression grips of an MTS machine.

The apparatus was composed of the following components: 1) two end blocks with groove; 2) two sliding type side blocks, each with a dovetail tongue; 3) two stepped plates, with one each for top and bottom. The components were joined together by steel bolts. Figures 5.1 and 5.2 clearly show the assembled view of the shearing apparatus. The tongue and groove connection was made to enable the side plates (inside) to slide with respect to the end plates. The top and bottom plates were made stepped to enable the movement of the bi-layer specimen after failure. The top and bottom stepped plates have threads so that they can be fitted to the top and bottom grips of an MTS machine by 
suitable steel bolts (Figures 5.3 and 5.4). The robust design of the apparatus and the heavy end plates prevent the bending of the entire device. The sliding side blocks hold the concrete bi-layer specimen laterally and protect it from premature cracking during testing. The compressive load induced by the actuator of the MTS machine is transferred to the interface through the bi-layer specimen (Figure 5.5), which induces direct shear stress at the interface. The device, therefore, transfers the direct shear load efficiently through the interface without much eccentricity, and at the same time not deliberately applying the stress directly at the interface which greatly influences the nature of failure.

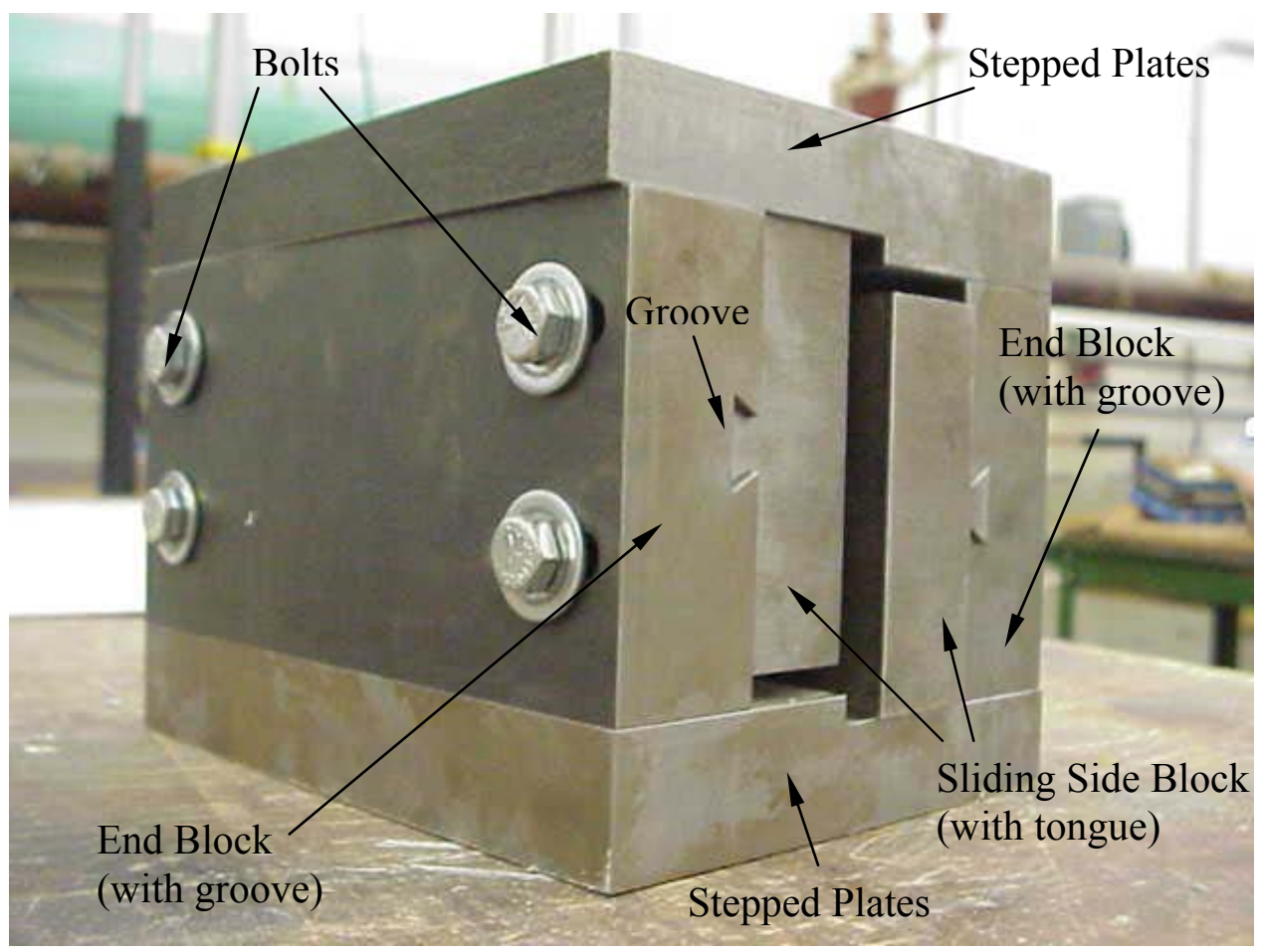

Figure 5.1 Shear Testing Apparatus 


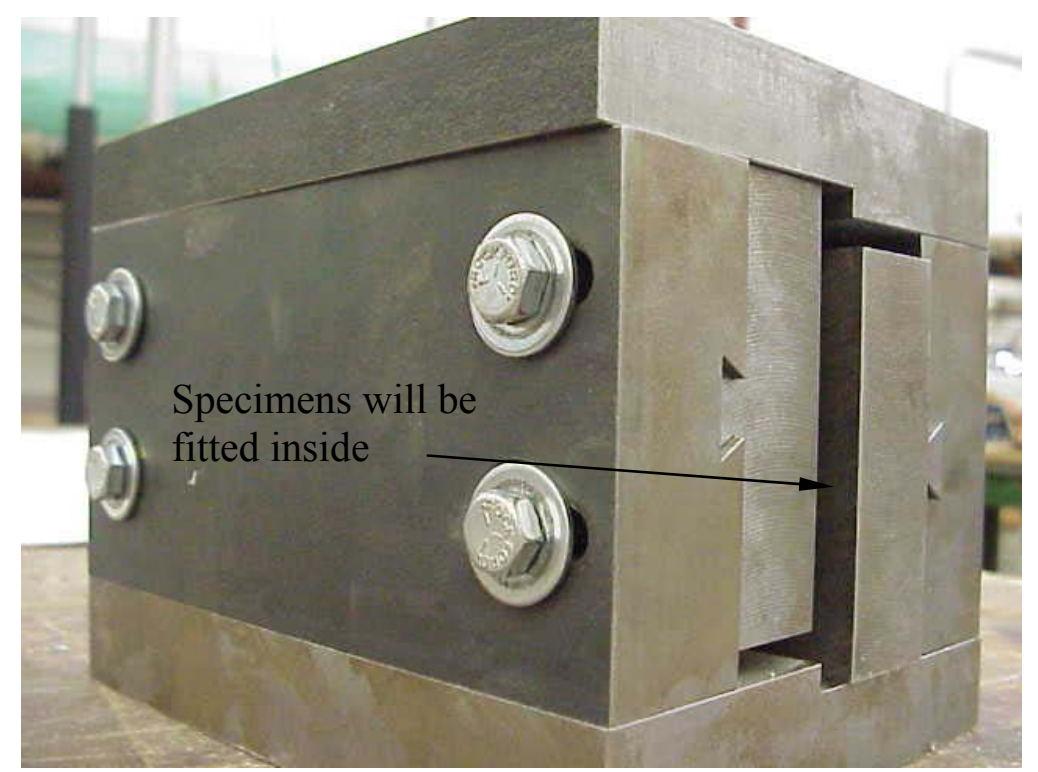

Figure 5.2 Shear Testing Apparatus-A Closer View

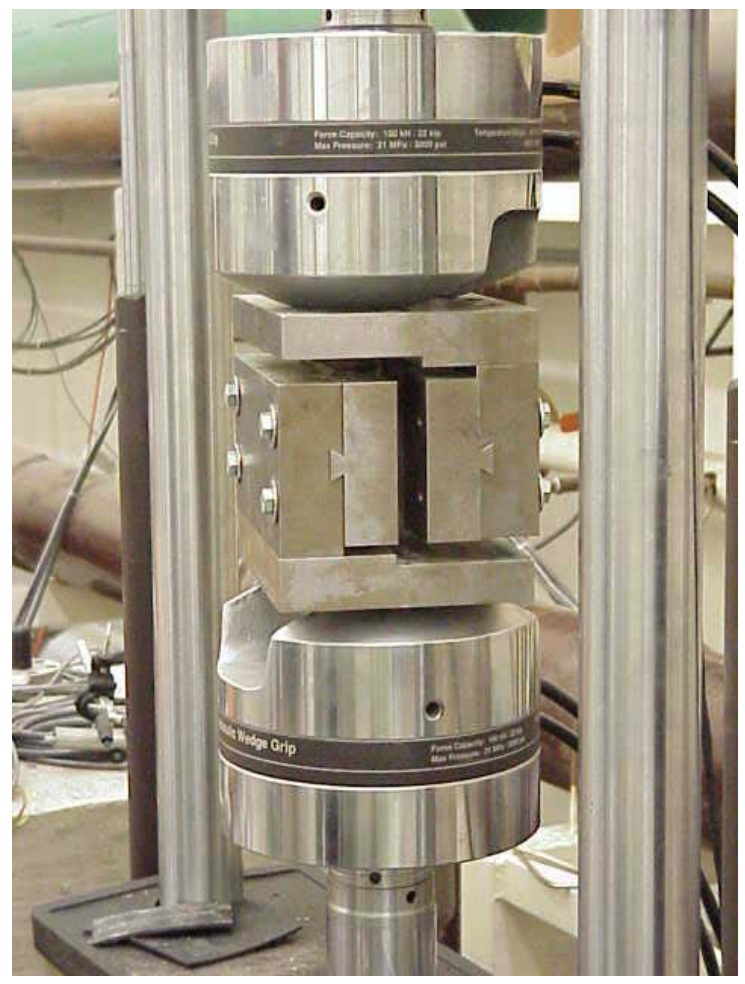

Figure 5.3 The Steel Apparatus Fixed on the MTS

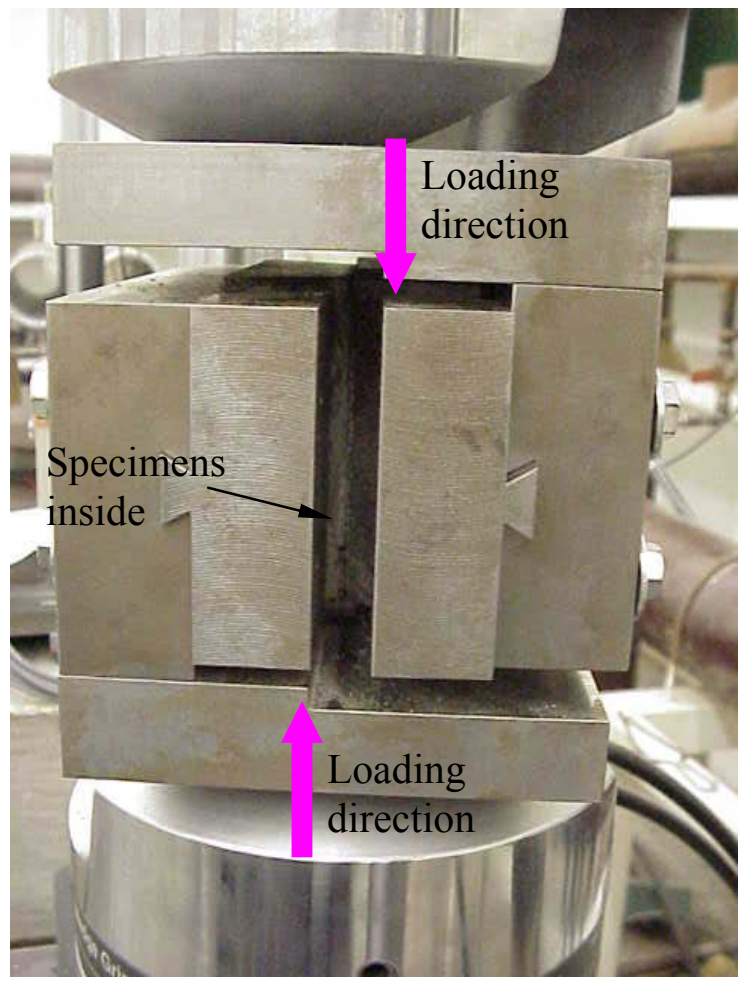

Figure 5.4 Detail View of The Steel Apparatus 


\subsection{Manufacturing of Bi-layer Specimens}

A "butterfly" double wedge type symmetrical specimen was used with notches around the interface periphery to induce the crack deliberately through the interface. The specimen geometry and dimensions are shown in Fig. 5.5.

A total of sixty four bi-layer composite specimens were manufactured. The test specimens were cast in partitioned wooden molds in two layers. The bottom layer was used to cast the substrate. The top layer was used to cast the overlay. The substrate was made of NC and the overlays were made of LMC, MMC, MMC-FA and FRC mixtures.

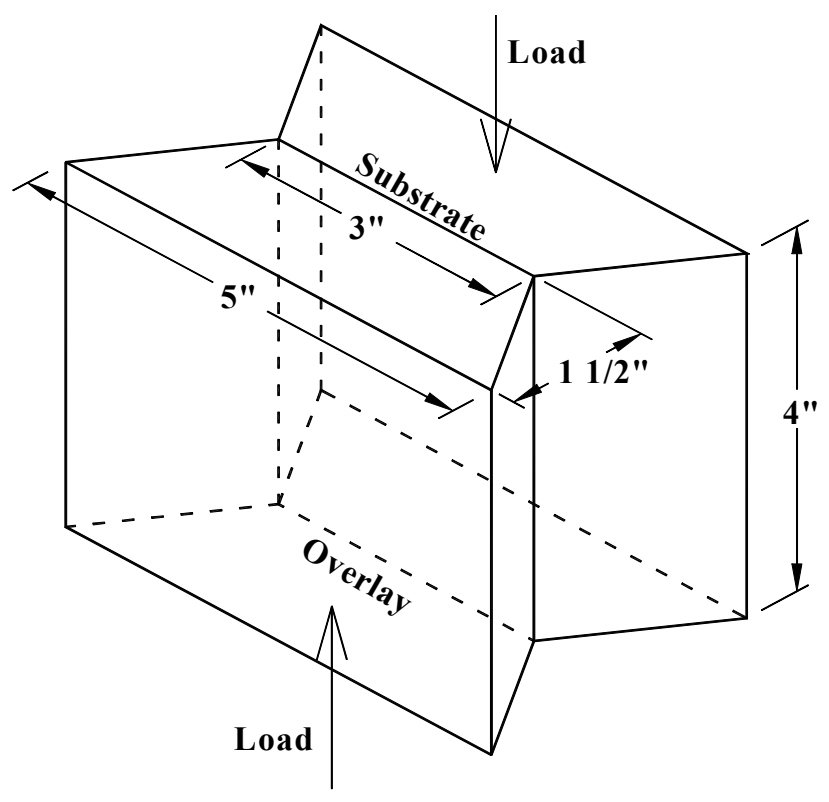

Figure 5.5 Specimen Geometry with Dimensions (Not to Scale)

In total sixty four bi-layer composite specimens were fabricated for the current study with two different substrate surface preparations. Initially all the substrates of thickness $1 \frac{1}{2}$ in. were cast using NC (Table 3.7) in a partitioned wooden mold and 
vibrated in a table vibrator. Figures 5.6 and 5.7 show the specimens within a number of partitioned molds, and a typical unit cell, respectively. After about 6 hours (just before final setting of concrete) half of the substrates (32 substrates) were scarified mechanically with a steel brush and vacuumed to simulate similar field conditions. Figures 5.8 and 5.9 show the typical mechanically treated surface. All the substrates were covered under wet burlap at a temperature of $73 \pm 5{ }^{\circ} \mathrm{F}$ for 28 days until the corresponding overlays were poured over them. The other half of the substrates was etched with acid per ASTM D 4260 after 26 days of wet burlap curing. Figures 5.10 and 5.11 show the typical acid etched substrate surface. After treating with acid, the surface was thoroughly washed with water, which was tested per ASTM D 4262 to ensure that $\mathrm{pH}$ of concrete surface is above 7.0. After acid etching, the substrates were covered with wet burlap at a temperature of $73 \pm 5{ }^{\circ} \mathrm{F}$ until the overlays were poured over them. Before pouring of overlays, the substrate surfaces were taped with waterproof tape to form $1 / 4$ in. notch around the specimens (Figure 5.12). The second layer of wooden molds was set on the top of the present substrate layer (Figure 5.13). Bonding slurries made of the same overlay mixtures without coarse aggregate and extra water were applied thoroughly and scrubbed into the surface according to the guideline given by the WVDOH. In case of FRC, the fiber was not included in the slurry used. Finally four overlays of LMC, MMC, MMC-FA and FRC (Table 3.7) of thickness $1 \frac{1}{2}$ in. were placed within the top molds. Then the entire set of bi-layer specimens were covered under wet burlap at a temperature of $73 \pm 5{ }^{\circ} \mathrm{F}$ within the molds until 28 days, when all of them were demolded and covered in a plastic sheet until the day of testing. For each overlay type, a total of 16 specimens were produced with eight specimens for each type of surface preparation. For the two types of surface 
treatments, in this study the mechanically scarified surface will be referred as "Mechanical" type and the acid-etched surface will be referred as "Chemical" type.

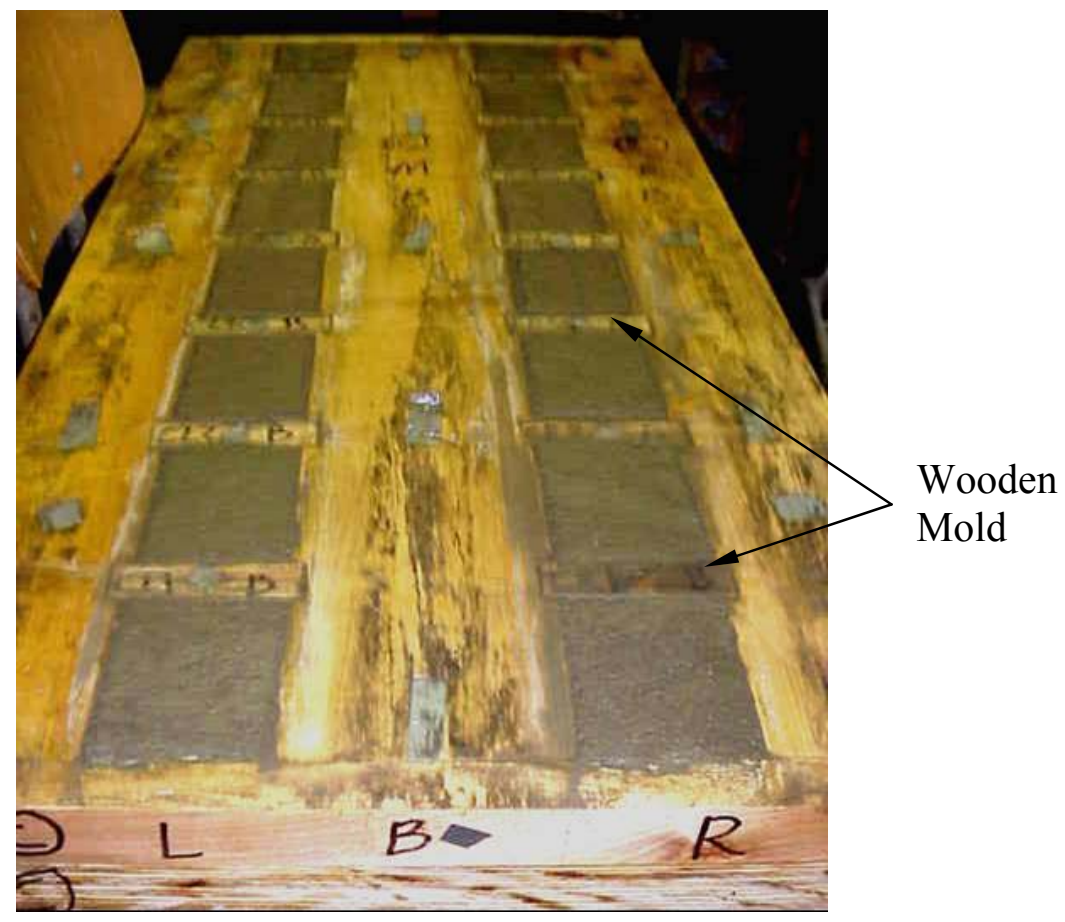

Figure 5.6 Substrate Specimens Cast in Partitioned Wooden Molds

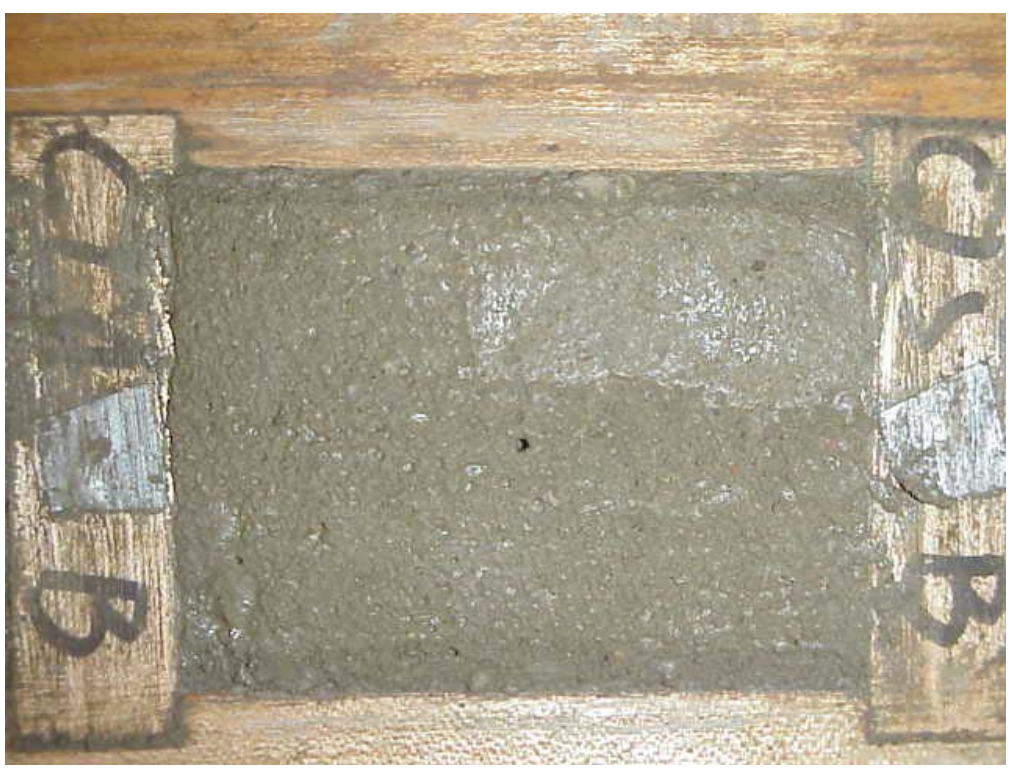

Figure 5.7 Substrate Surface after Casting (closer view) 


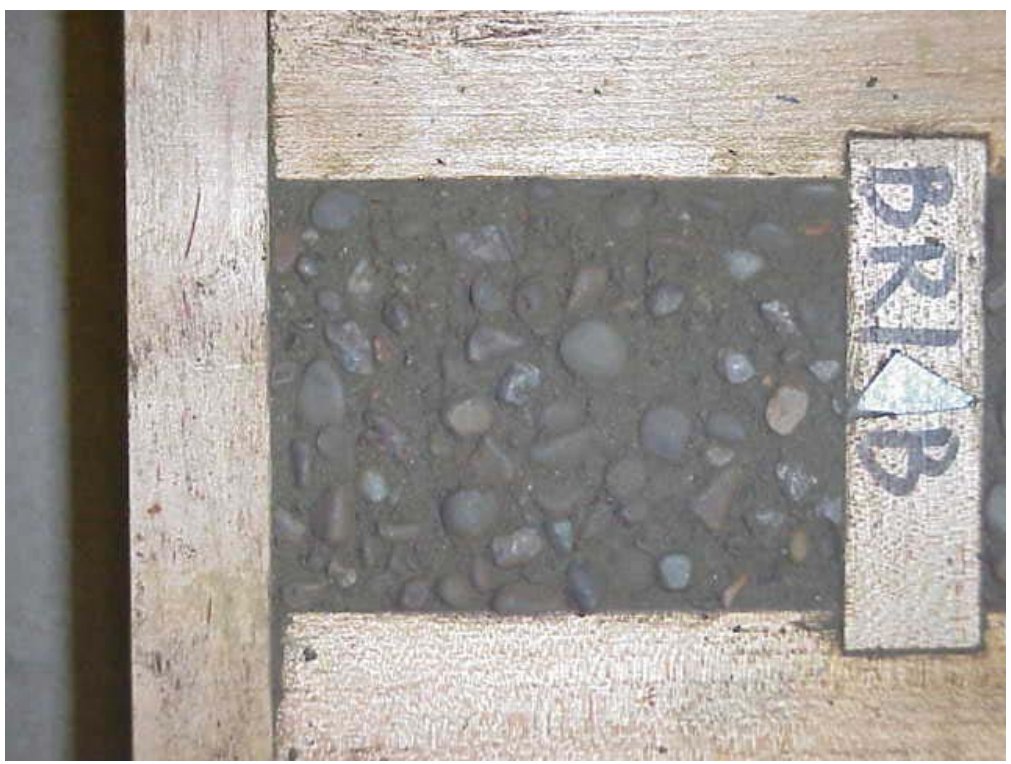

Figure 5.8 Mechanically Scarified Substrate Surface Within Mold

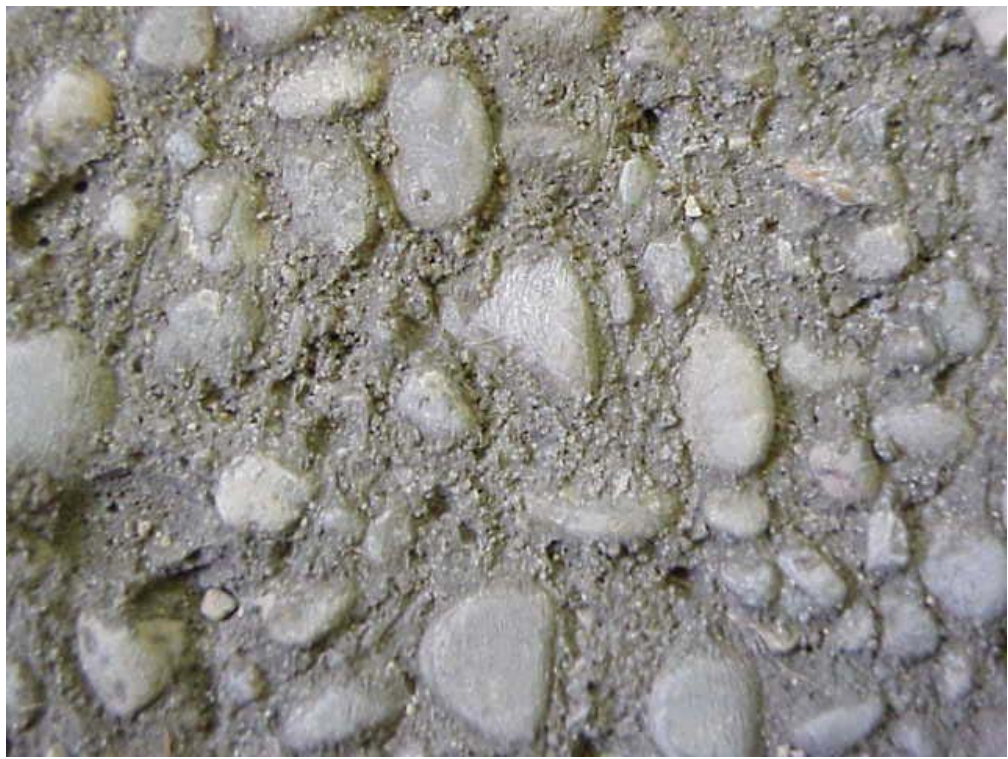

Figure 5.9 Closer View of Mechanically Scarified Surface (Gravels are exposed but embedded within the mortar matrix) 


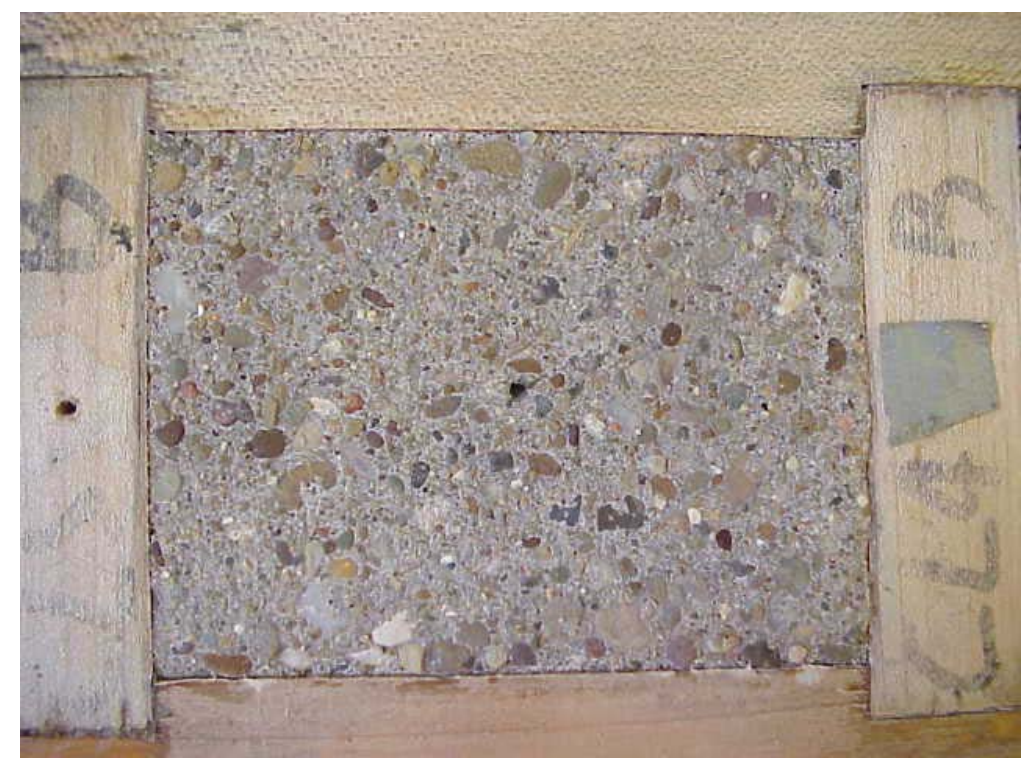

Figure 5.10 Acid Etched Substrate Surface within Mold

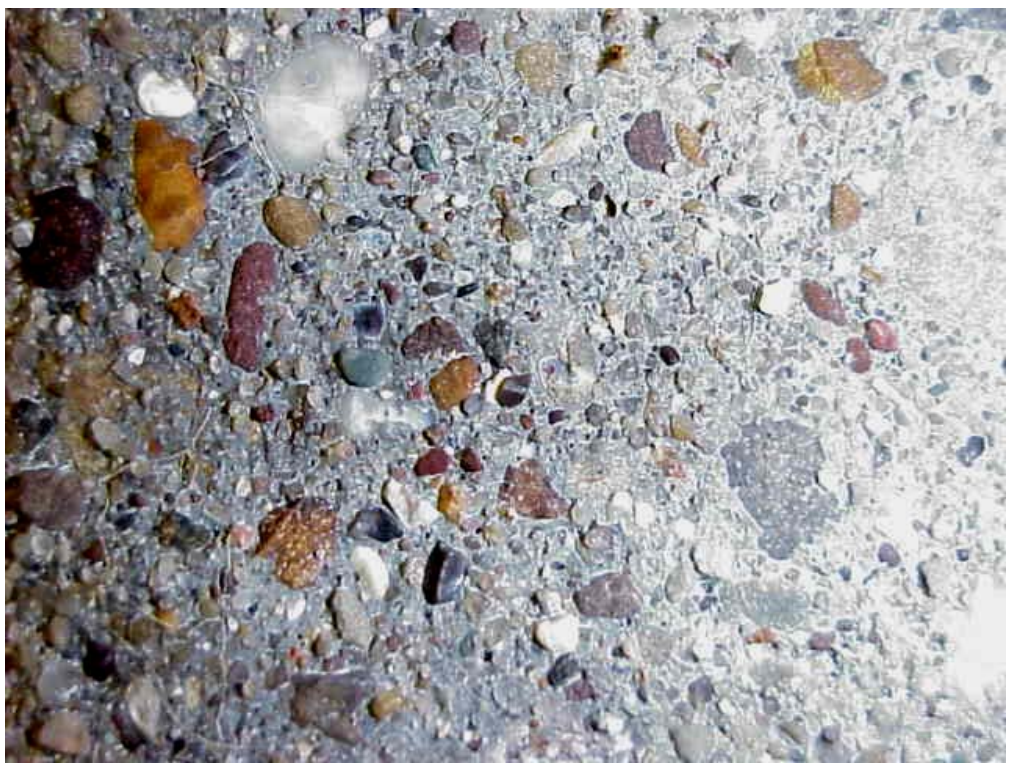

Figure 5.11 Closer View of Acid Etched Concrete Surface 


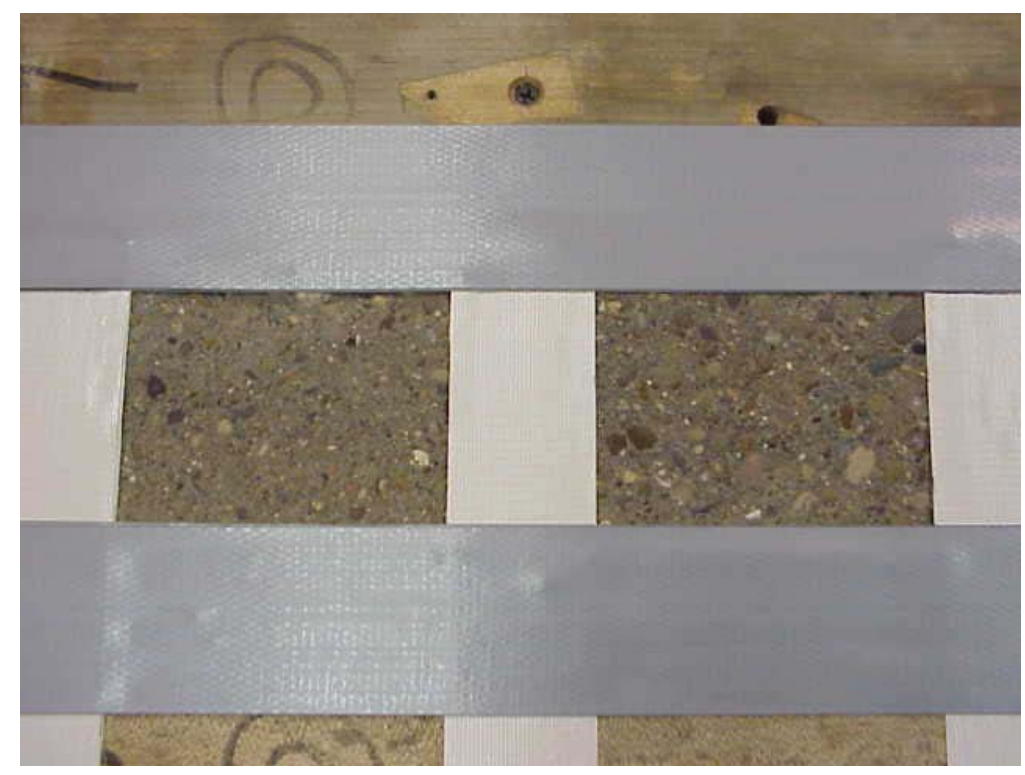

Figure 5.12 Waterproof Tape to Form 1/4 in. Notch

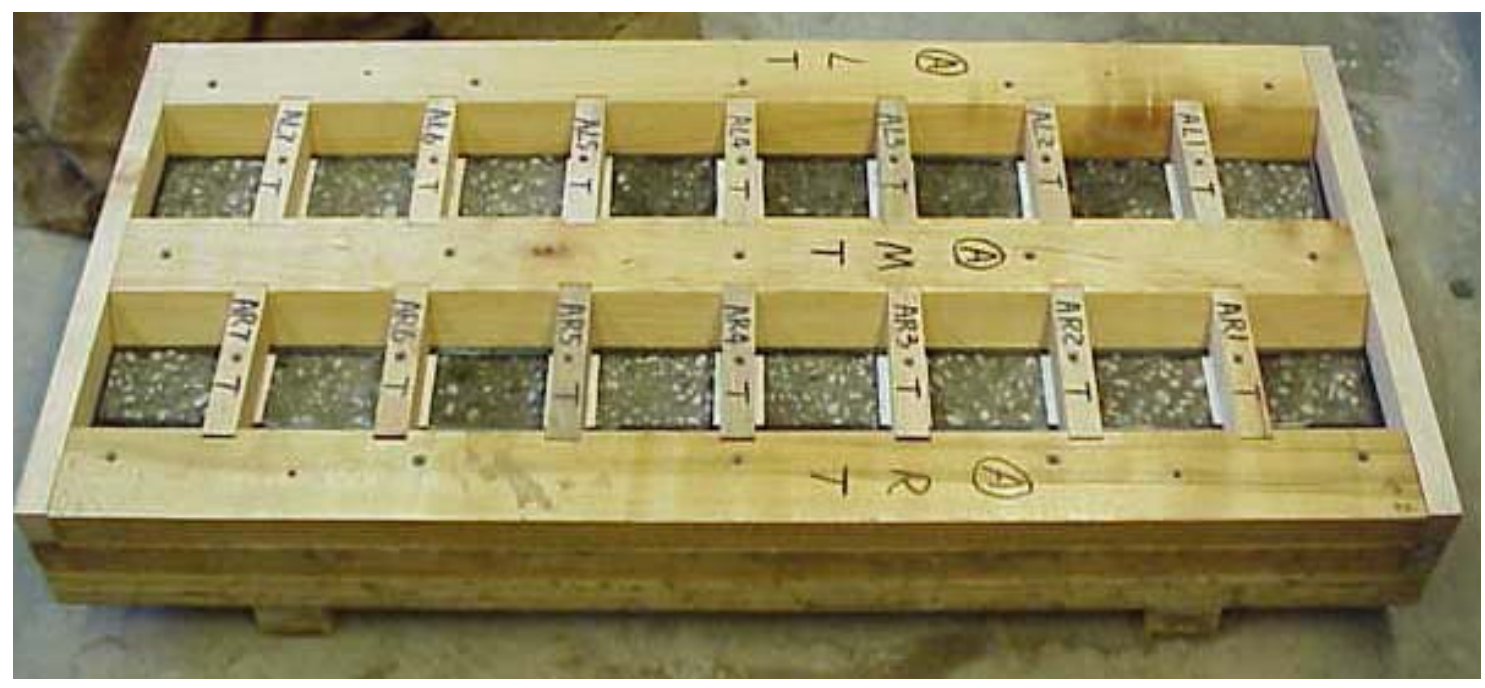

Figure 5.13 Second Layer of Wooden Molds for Overlay Casting

Figures $5.14 \mathrm{a}$ and $5.14 \mathrm{~b}$ show the typical specimen designated as butterfly notched specimen. The interface size of this bi-layer specimen is 2.5 in. x 3.5 in. giving an area of 8.75 in. $^{2}$ Figure 5.15 displays the setting of a specimen within the shear apparatus. 


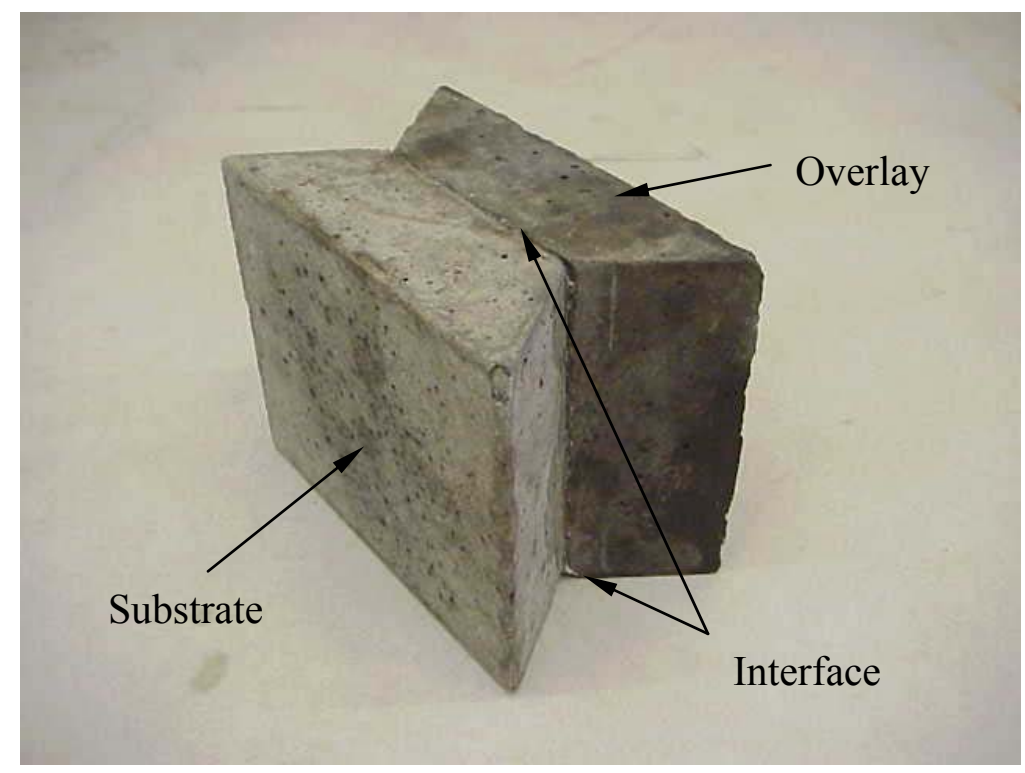

Figure 5.14 (a) A Typical Butterfly Notched Specimen for Direct Shear Test

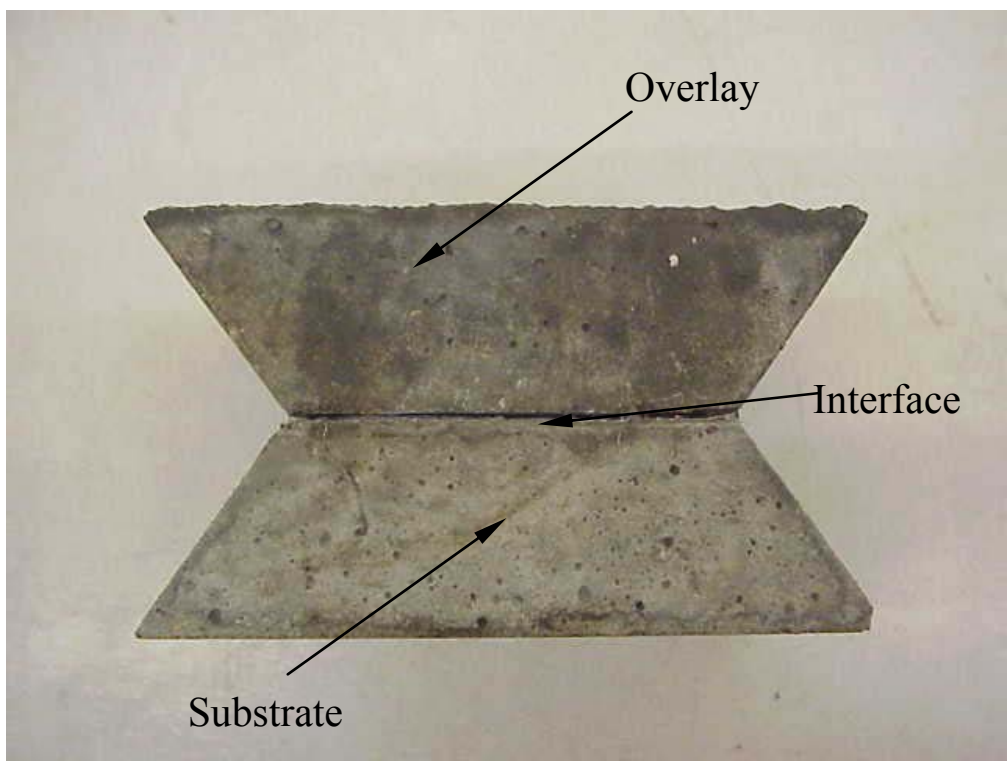

Figure 5.14 (b) Another View of The Specimen 


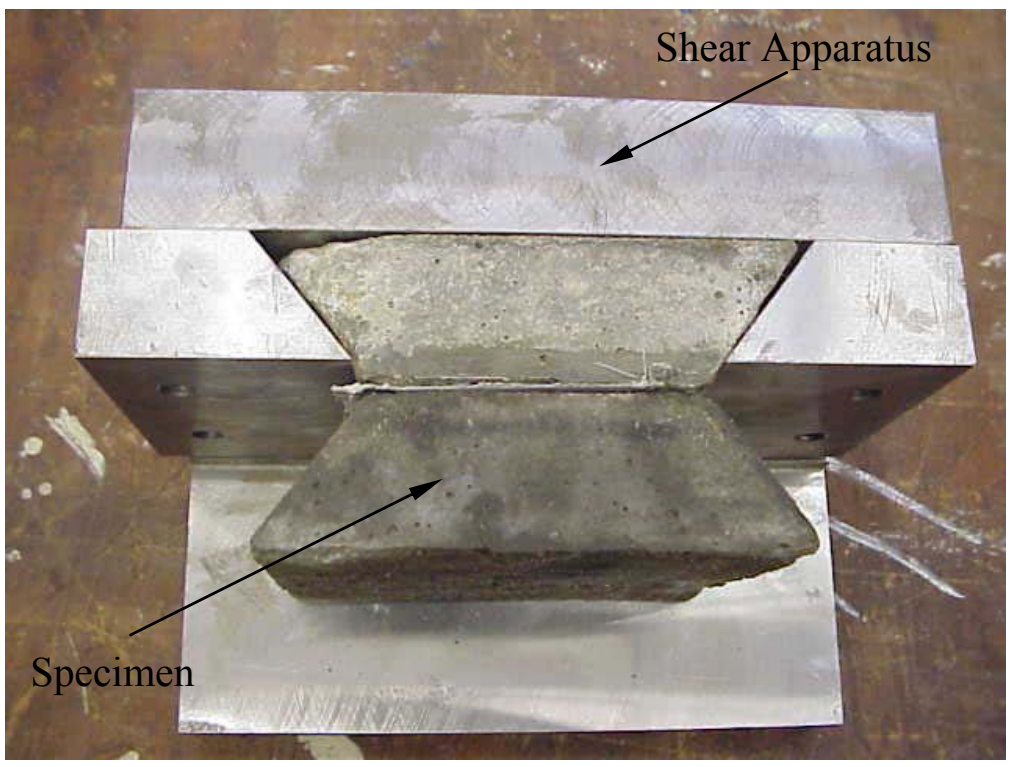

Figure 5.15 Specimen Fitted Within The Shear Apparatus

\subsection{Testing of Bi-layer Specimens in Direct Shear}

A total of 56 bi-layer specimens out of 64 cast specimens were tested by direct shear on an MTS machine with a 22,000 lb load-cell capacity. Eight specimens were discarded due to manufacturing defects. Table 5.1 shows the number of specimens tested for each overlay type. A uniaxial vertical compressive load was applied through a neoprene rubber strip on one half of the specimen at a constant displacement rate of 0.02 in./min. to induce direct shear through the interface area of $8.75 \mathrm{in}^{2}$ as stated above. The rate of displacement was finalized after a number of trials. The maximum load at failure and nature of failure of the specimen were noted in each case. Tests were completed within two days by a single operator. After failure, each specimen was examined to identify the nature of failure. Table 5.2 shows the values and mode of failure of the specimens. Figures 5.16a through 5.16d show the nature and character of failure of each type of bi-layer specimens. 
Table 5.1 Number of Specimens Tested

\begin{tabular}{|c|c|c|c|c|}
\hline Mixture Types & LMC & MMC & MMC-FA & FRC \\
\hline $\begin{array}{c}\text { Number of Specimens } \\
\text { (Mechanical) }\end{array}$ & 8 & 8 & 7 & 8 \\
\hline $\begin{array}{c}\text { Number of Specimens } \\
\text { (Chemical) }\end{array}$ & 8 & 2 & 8 & 7 \\
\hline
\end{tabular}

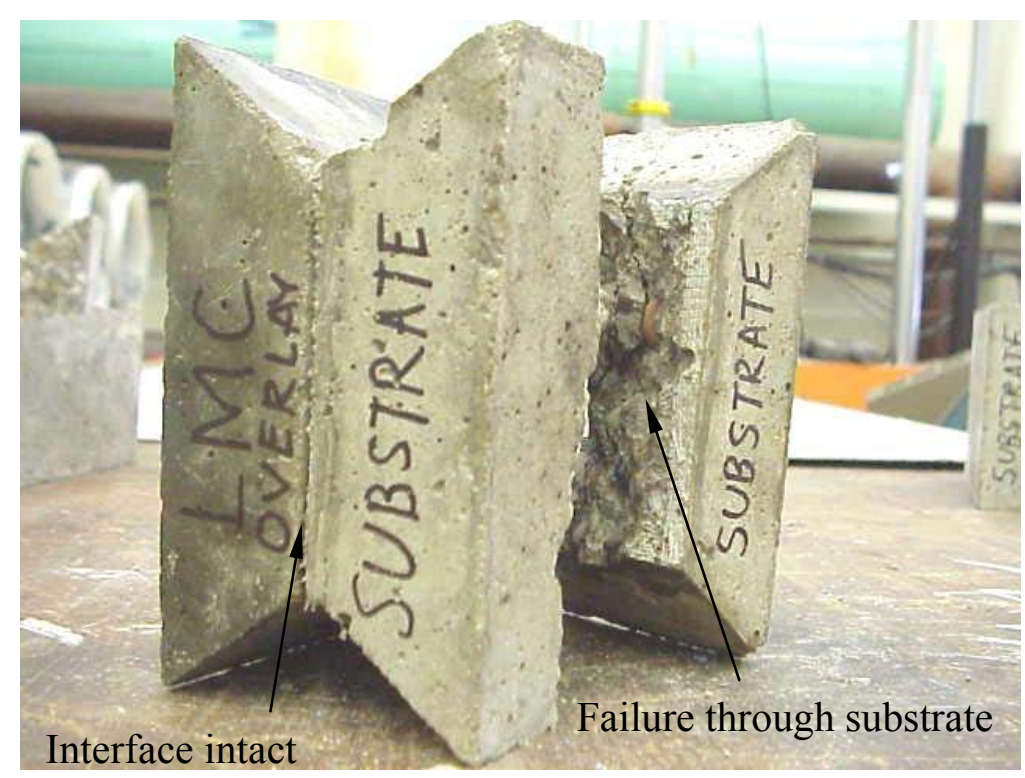

Figure 5.16 (a) LMC-Substrate: Substrate Failure-Interface Intact

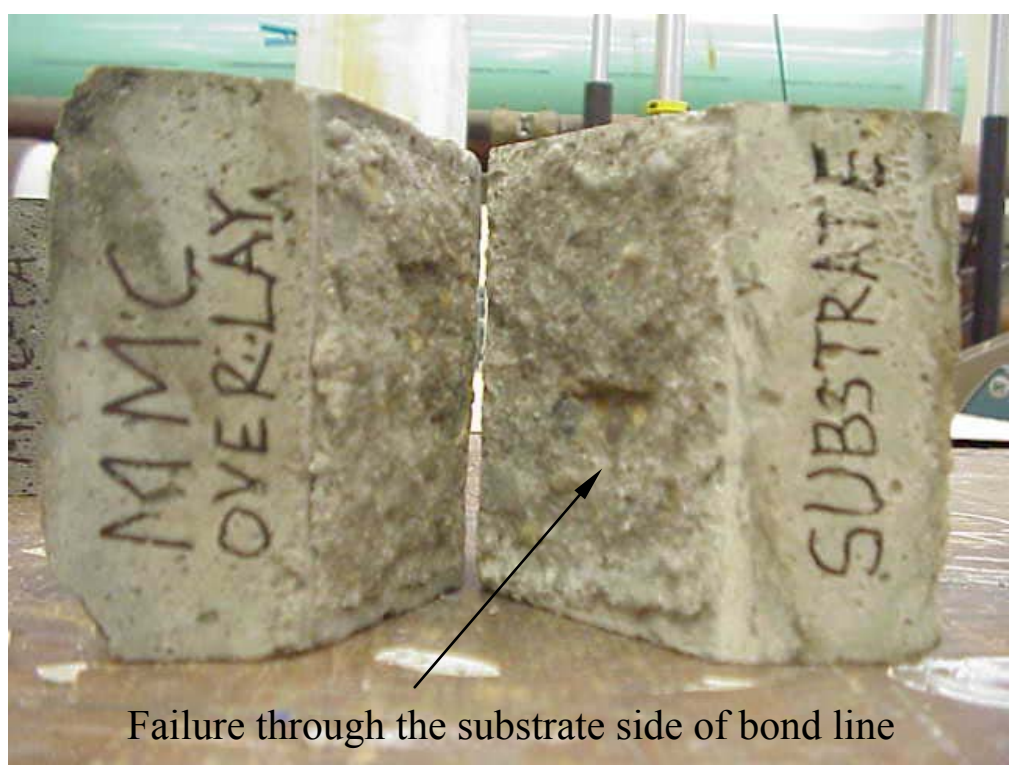

Figure 5.16 (b) MMC-Substrate: Interface Failure 


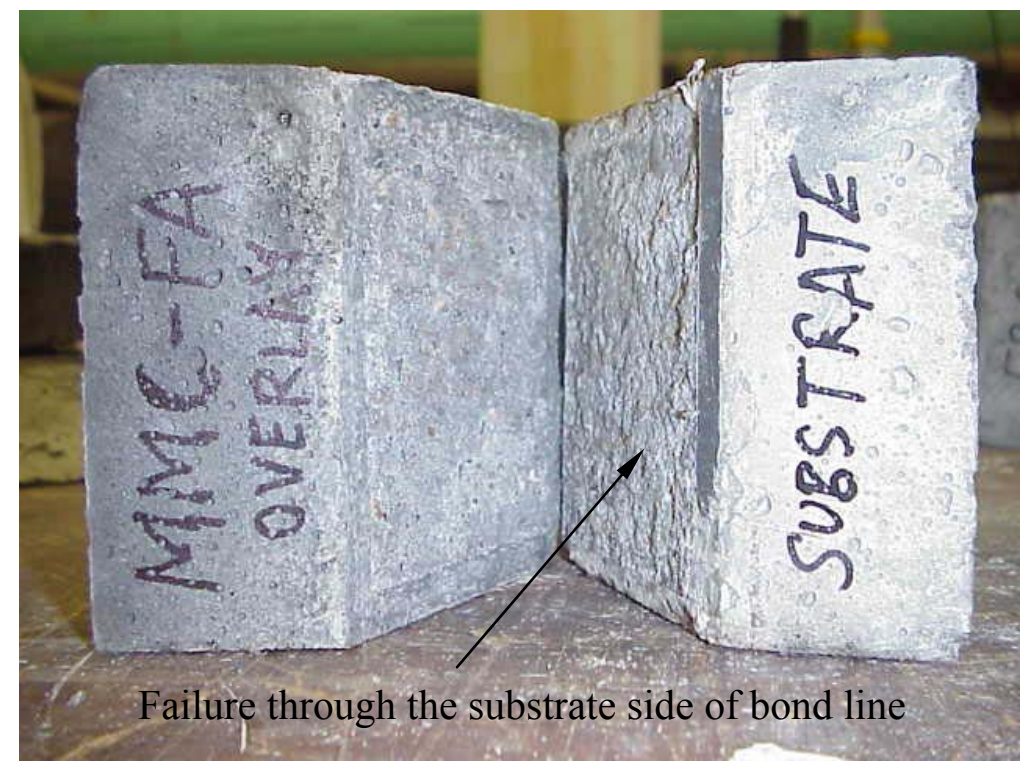

Figure 5.16 (c) MMC-FA-Substrate: Interface Failure

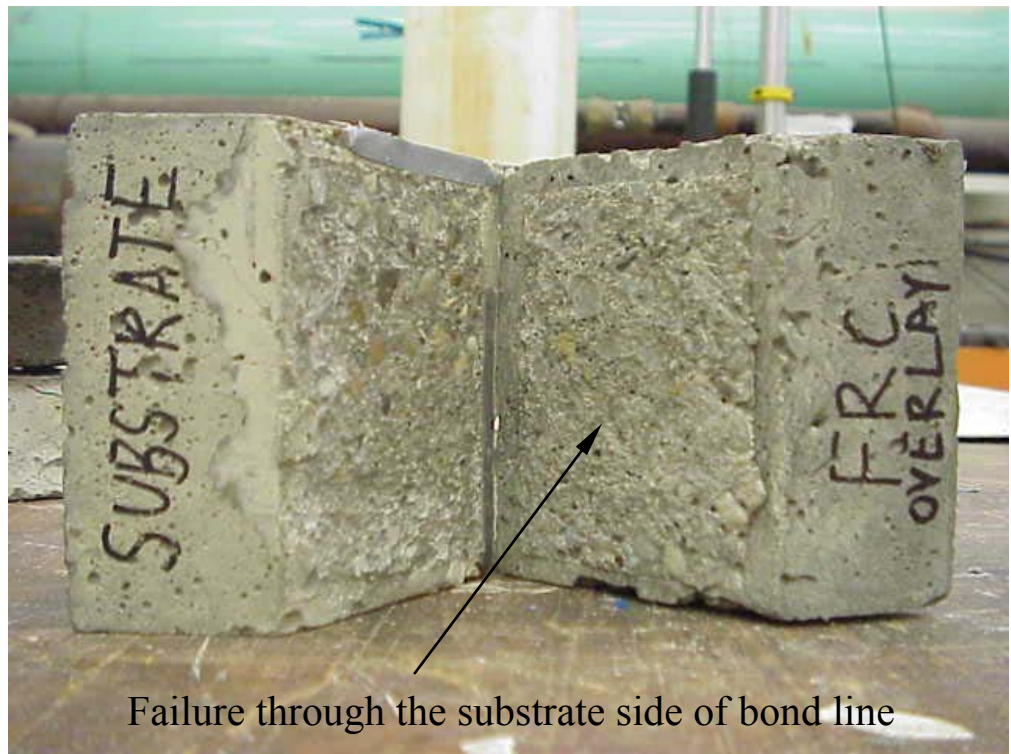

Figure 5.16 (d) FRC-Substrate: Interface Failure 
Table $5.2 \quad$ Direct Shear Test Results

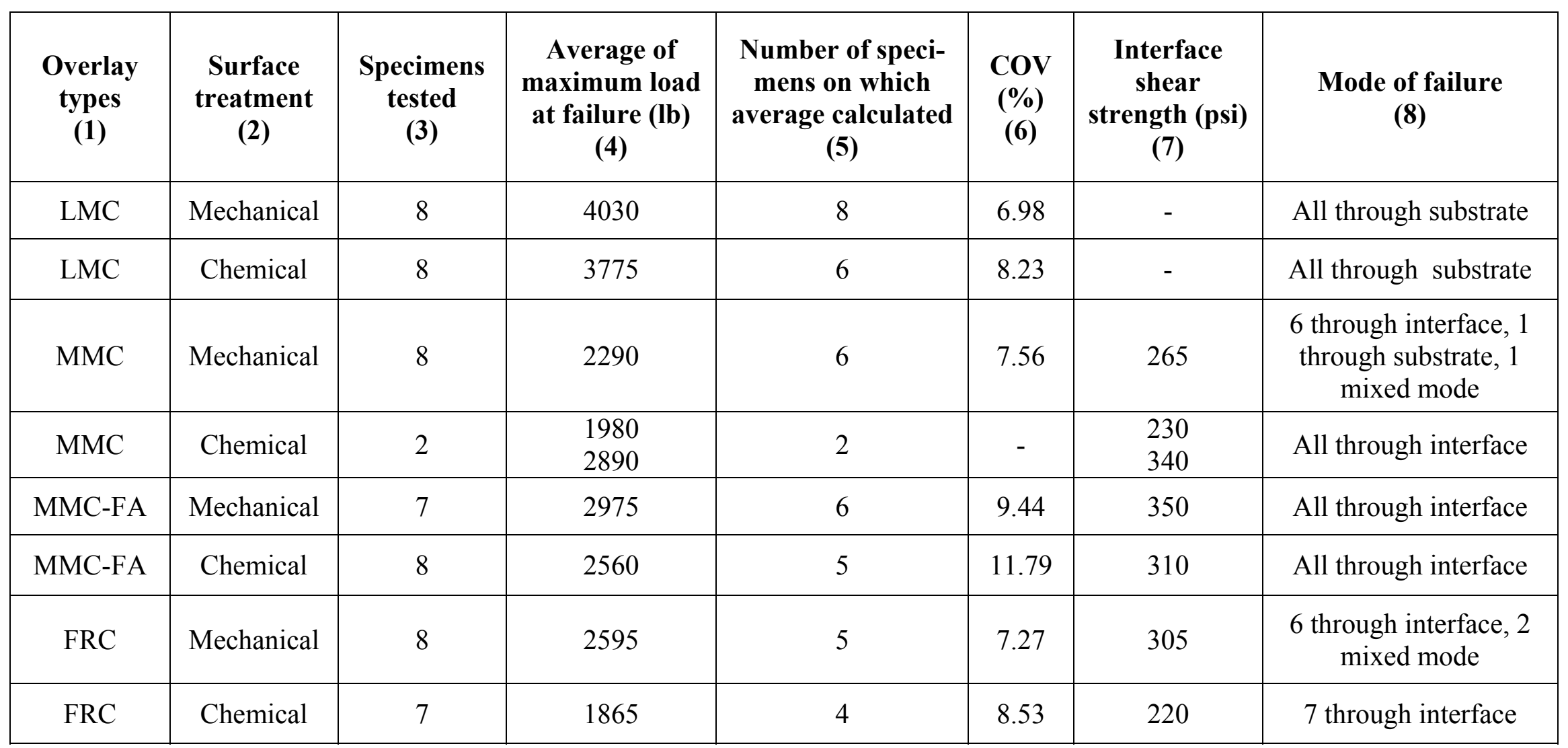

- Column (2) - "Mechanical" means scarified surface, "Chemical” means acid-etched surface.

- Column (4) - Maximum average load at failure is the average of maximum loads of the specimens included (see column (5)). Other values were discarded due to large scatter.

- Column (6) - COV is the coefficient of variation of the data which were used to calculate the maximum average load.

- Column (7) - Interface shear strength is the average shear strength of those specimens which failed through the interface only.

- Column (7) - "Mixed mode" means the failure through both interface and substrate. 


\subsection{Discussions of Shear Test Results}

\subsubsection{Evaluation of LMC}

It is evident from the results (Table 5.2) that in all cases of LMC-substrate bilayer specimens, the failure plane occurred preferentially through the substrate (Figure 5.16 (a)), for both types of surface treatment - mechanical and chemical. This is due to the effectiveness of the LMC- based bonding slurry with its extremely high adhesion strength that did not allow the interface to fail. Further it may be stated that the shear strength of the interface is more than that of the substrate material (not measured). Deming et al. (1994) and Warner et al. (1998) suggested that failure through the substrate concrete is always desirable, because it is an indicator that the overlay material is stronger than the substrate. In this study, the mechanical surface treatment performed slightly better than the chemical treatment. The coefficient of variation (COV) values for eight specimens each were $6.98 \%$ and $8.23 \%$ for mechanical and chemical treatment, respectively. Considering the manufacturing complexity and variations in material properties, the COV is not statistically significant. Knab and Spring (1989) observed COV values of $4.7 \%$ to $10.1 \%$ on a similar material when tested by friction grip, pipe nipple and slant shear tests. Kuhlman (1990) observed a COV of $8.3 \%$ in his tensile bond test. The values of COV in the current study of LMC-substrate bi-layer are used as an indication of the precision of the results of direct shear test.

\subsubsection{Evaluation of MMC}

For MMC, the failure was found to occur through the interface in eight specimens out of 10 tested (Table 5.2). The interface failure plane occurred precisely through the 
substrate side of the bond line (Figure 5.16 (b)), which is expected due to the relatively lower strength of NC. The effect of chemical treatment versus mechanical treatment could not be evaluated because of only two specimens with chemical treatment available for testing in case of MMC. The interface strengths of $265 \mathrm{psi}$ (mechanical), and $230 \mathrm{psi}$ and 340 psi (chemical) are comparable with other published results (Dhir, 1984; Knab and Spring, 1989; Kuhlmann, 1990; Hindo, 1990; and Deming et al., 1994), with some variations due to differences in geometry of specimens, test methods including load transfer, bonding agents and surface preparations. The COV for the eight MMC (mechanical) specimens is $7.56 \%$ which demonstrates the consistency of the present test method.

\subsubsection{Evaluation of MMC-FA}

Table 5.2 further shows that MMC-FA had shear strengths of 350 psi and 310 psi for mechanical and chemical treatment, respectively. It indicates that mechanical treatment performed marginally better than chemical treatment. All of 15 specimens failed through the interface, with the failure plane precisely passing through the bond line of the substrate side (Figure 5.16 (c)). Comparisons of shear bond strength of MMC-FA with MMC alone reveal that replacement of cement with fly ash did not negatively affect the bond strength. The COV values are $9.44 \%$ (mechanical) and $11.79 \%$ (chemical) for test data of seven and eight specimens each, respectively. This further demonstrates the relative consistency of the test method adopted. 


\subsubsection{Evaluation of FRC}

The interface shear strengths of FRC are 305 psi and 220 psi respectively, for mechanical and chemical treatments. Mechanical treatment performed better than chemical treatment in this case also. The observation agrees well with Wells et al., 1999, who evaluated the bond strength of concrete overlays utilizing four different surface preparations. In their study the bond strengths of hand wire-brushing case (mechanical) and shot blasting case (mechanical) were higher than a brooming-and-vacuuming (a thorough cleaning) process, when cement-silica fume grout was used. For all cases in the current study except LMC, a similar bonding grout was used, and the chemical etching treatment may be thought to be similar to the brooming-and-vacuuming (a thorough cleaning) process (Wells et al., 1999) in a way that both do not alter the surface roughness much. In 13 specimens out of total of 15 specimens, the failure plane passed through the interface. Some fiber bridging was observed at the interface after failure. The failure plane passed precisely through the bond line of the substrate side (Figure 5.16 (d)). The COV values are $7.27 \%$ and $8.53 \%$ for mechanical and chemical treatment, respectively. It is observed that the addition of fibers by itself in overlay concrete did not improve the interface strength. From the present study it is further evident that the bonding slurry/grout played a significant role in improving the interface behavior. Therefore the use of the same bonding slurry as used in MMC resulted in similar bond strength values. 
Table 5.3 Comparison of Interface Shear Strength of Current Research with Other Published Data

\begin{tabular}{|c|c|c|c|c|c|}
\hline & Specimen Types & LMC & MMC & MMC-FA & FRC \\
\hline Current Study & $\begin{array}{l}\text { Butterfly Notched } \\
\text { Specimen }\end{array}$ & $*$ & 275 psi & 328 psi & 260 psi \\
\hline Dhir, 1984 & Cubical Specimen & \multicolumn{4}{|c|}{ Direct shear test: $60-410 \mathrm{psi}$} \\
\hline $\begin{array}{c}\text { Knab \& Spring, } \\
1989\end{array}$ & Cylinder Specimen & \multicolumn{4}{|c|}{$\begin{array}{l}\text { 14-day PCC: } 282 \text { psi (Tension, Friction Grips); } 426 \text { psi (Tension, Pipe Nipple Grips) } \\
\text { 7-day LMC: } 131 \text { psi (Tension, Friction Grips); } 217 \text { psi (Tension, Pipe Nipple Grips) } \\
\text { 14-day LMC: } 293 \text { psi (Tension, Friction Grips); } 393 \text { psi (Tension, Pipe Nipple Grips) }\end{array}$} \\
\hline Hindo, 1990 & Cylinder Specimen & \multicolumn{4}{|c|}{ LMC: $103-278$ psi (Tension Test) } \\
\hline Kuhlmann, 1990 & Cylinder Specimen & \multicolumn{4}{|c|}{ 28-day LMC: $324-378$ psi (Tension, Pipe Nipple Grips) } \\
\hline $\begin{array}{l}\text { Deming et al., } \\
1994\end{array}$ & Cylinder Specimen & \multicolumn{4}{|c|}{ PC: 358 psi (Tension Test) } \\
\hline $\begin{array}{l}\text { Wells et al., } \\
1998\end{array}$ & Cylinder Specimen & \multicolumn{4}{|c|}{ 350-450 psi (Tension Test) } \\
\hline \multicolumn{2}{|c|}{$\begin{array}{c}\text { Canadian Standard Association (CSA) } \\
\text { minimum requirement }\end{array}$} & \multicolumn{4}{|c|}{$130 \mathrm{psi}$} \\
\hline \multicolumn{2}{|c|}{$\begin{array}{l}\text { U.S. generally accepted value } \\
\text { (Bergren, 1981) and IOWA } 406 \text { test }\end{array}$} & \multicolumn{4}{|c|}{200 psi } \\
\hline
\end{tabular}

* Failure occurred through substrate. Failure loads were the maximum among all the mixtures. 


\subsubsection{General Comparisons}

Table 5.3 furnished the comparison of current results with published information. Among all the published information, only Dhir, 1984, reported direct shear test results for both laboratory and field overlay-substrate systems. He obtained a wide range of values from 61 psi to 423 psi depending on the location of sampling. The data show that laboratory bond strengths were much higher than the field values, and they were in the range of 365 psi to 423 psi. The present test method is also a direct shear test and shows a comparable range of values with Dhir, 1984. Except for LMC showing bond strength higher than the material strength of substrate concrete, the other overlay-substrate combinations exhibited direct shear strengths in the range of 213 psi to 340 psi. These values are above the generally accepted bond strength of concrete resurfacing material, which is approximately 200 psi (Dhir, 1984). The direct shear strength values obtained from the present study are also above the bond strength requirement by the Canadian Standards Association (CSA), A 23.1-M 94, which is 130 psi. General comparisons of average maximum load capacity of all specimens indicate that LMC-substrate could transfer a maximum average load of 3902 lb, followed by MMC-FA-substrate of $2769 \mathrm{lb}$, MMC-substrate of $2388 \mathrm{lb}$ and FRC-substrate of $2231 \mathrm{lb}$. 'Mechanical' type of surface preparation was superior to 'Chemical' type irrespective of overlay mixtures.

The range of COV values for the entire study is $6.98 \%$ to $11.79 \%$, which seems to be reasonable considering the variability of production of cementitious composite materials. The reported COV values for tensile bond tests and slant shear tests of Portland cement concrete and latex-modified concrete repairing materials by other authors (Knab and Spring, 1989; Kuhlmann, 1990) lie in the range of $4.8 \%$ to $8.3 \%$. The slightly higher 
$\mathrm{COV}$ values indicate relatively larger scatter in our test data compared to reported tensile bond test (pipe nipple) and slant shear test data. This larger variability may be due to the effect of using the bonding slurry with extra water added to the mixture, which was done to ensure a better spreading ability of the bonding slurry on the substrate. This process might have caused some variability in the production of the bi-layer specimens. However, from the consistency obtained in the interface failures through the relatively weaker bond line on the substrate side of the majority of the bi-layer specimens (except LMCsubstrate), and from the comparable shear strength data obtained with respect to published information, we can infer that the present new direct shear test is a promising method for evaluating overlay-substrate bond characteristics. 


\section{Chapter 6}

\section{Conclusions}

This chapter draws conclusions on the entire study. General conclusion for each material characterizations and interface evaluations are made separately, and a recommendation for future work is also included.

\subsection{Material Characterizations}

From test results, it is observed that air content of LMC was the lowest among all the mixtures, at $3.8 \%$. Due to the presence of latex, silicone type defoamer was used in LMC to control the excessive air-entrainment, which is detrimental to LMC's performance as overlay material.

Knab and Spring, 1989, reported that in tension and slant shear tests of high-air content LMC and base concrete bi-layer system, the failure surface always propagated through high-air content LMC instead of base concrete, but in the case of normal air content LMC and base concrete bi-layer system, the failure occurred preferentially through the base concrete, which is a desirable failure mode. In the current study, therefore, it is expected that low air content of LMC would enhance its performance as overlay material. The air-content values are, however, sufficient to resist the damaging effect of freezing-thawing in the field. For the other overlays the air contents are in the range of $7-8 \%$, which ensure their durability against freezing-thawing. The high slump 
used for all the mixtures, as $5.5-7.5$ in., would be good for pouring and vibration and finishing of the overlays in the field. The specifications of various departments of transportation are within this range of values for slump and air content.

Since NC is used as the substrate for all bi-layer systems, it is important that both compressive and splitting tensile strength values (Tables 4.2 and 4.3) are high enough to ensure that the material will not fail prematurely during interface evaluations. Also the concrete should be strong enough to withstand the mechanical and chemical surface preparation processes. Among the overlay mixtures, FRC has the highest compressive and splitting tensile strengths, respectively 8860 psi and 825 psi, due to fiber addition. MMC-FA exhibited slightly lower compressive and splitting tensile strengths due to partial replacement of cement with fly ash; however, the values are acceptable for overlay material. Between the two most commonly used and effective overlay systems (Halvorsen, 1993), namely LMC and MMC , the MMC has about $20 \%$ higher compressive strength than LMC, but LMC has slightly higher (about $4.5 \%$ ) tensile strength and significantly higher flexural strength than MMC. Overall, all the mixtures developed in this study are of good and consistent quality in terms of their fresh and hardened concrete properties, which is a prerequisite for the acceptance of the material in field applications and also for proper interface evaluations.

Comparing the differences of strength, ductility and shrinkage of overlays and substrate, it is found that FRC had the largest difference and MMC-FA had the least difference with the substrate concrete. However, a further study of bi-layer interface shear did not reveal any correlation between these material property differences and interface shear strength. Each overlay has its own characteristics and is suitable for a 
particular application. For example in places where economy and chloride permeability are of importance, use of MMC-FA or MMC is recommended. When toughness or ductility of the riding surface is important, LMC or FRC may be recommended. In case of problem of shrinkage due to drying, LMC is preferred over FRC. Also construction of LMC is relatively easier than FRC. Lower modulus of elasticity of LMC compared to FRC will also help to reduce the shrinkage strain due to restraint from substrate. Where the problem of plastic shrinkage is of concern, FRC with polypropylene fiber (as used in the current study) is the appropriate overlay.

\subsection{Interface Evaluations}

Successful interface bond characterization was possible through a newly devised direct shear apparatus. This test method seems to be highly suitable for screening and selections of various overlays for their compatibility with substrate concrete. Precision of the test method is evident from the reasonably low COV values obtained, though there are opportunities to improve the quality control of specimen preparations. The proposed test method is also effective for the evaluation of bond strength of a number of commonly used overlay materials, which is evident from the consistency of test results and modes of failure.

The interface failures of almost all the specimens towards the substrate side of the bond line clearly indicate that compatibility between the bonding slurry and overlay was more than compatibility between the bonding slurry and substrate. This is possible because of the similar types and maturity (bonding slurries were applied during the pouring of overlays) of bonding slurries and overlay concrete. Where interface failure 
took place, the weakest plane seems to be the substrate side of the bonding slurry line. Extra water was added to the bonding slurry for ease of application and better wetting of substrate; this formed some porous zones which might have created a weak bond line. The characteristic failure of LMC through the substrate does not necessarily indicates the weakness of the substrate; rather it indicates the strong bond strength of the interface. This high bond strength is primarily evident for latex based slurry.

In general it may be concluded that latex-modified slurry can be used as a bonding slurry for other overlay mixtures (MMC, MMC-FA and FRC) to improve also their interface bond strength. However, compatibility of LMC slurry and non-LMC overlays needs to be investigated. The slurry may also be modified by reducing the water-cement ratio so that less porosity is formed at the interface. It is important to find the optimum combinations of overlay, slurry and surface preparation.

\subsection{Recommendations for Future Work}

Based on the results of the current study, the following recommendations are made:

1. More overlay types such as high-early strength concrete, very-highearly-strength concrete, epoxy-modified concrete, low-slump dense concrete and metakaoline modified concrete may be studied for gaining knowledge on other types of overlay materials.

2. The rate of loading for flexural strength and toughness test needs to be modified in order to capture data within the descending branch of the stress-strain curve. 
3. The influence of different kinds of surface preparations of substrate should be studied on the interface bond strength. Different surface conditions may be formed by simulating actual field conditions.

4. The effects of substrate maturity (age of substrate) on bond strength should be studied.

5. The effects of slurry on interface bond strength should be studied.

6. The shear apparatus may be modified to accommodate a cylindrical shaped specimen so that field cored bi-layer specimens can be tested in direct shear and be compared with laboratory data.

7. Environmental effects on the performance of interfaces, such as effects of alternating wetting and drying in sulfate solutions and freezingthawing in salt solutions should be studied.

8. The shear strength values of bi-layer specimens obtained by using this newly devised shear test apparatus should be compared with other typical direct shear test and SHRP 2025 test methods. 


\section{Bibliography}

1. AASHTO T 22-92, "Compressive Strength of Cylindrical Concrete Specimens," Standard Specifications for Transportation Materials and Methods of Sampling and Testing, 17th Edition, 1995, pp. 11-17.

2. AASHTO T 119-93, "Slump of Hydraulic Cement Concrete," Standard Specifications for Transportation Materials and Methods of Sampling and Testing, 17th Edition, 1995, pp. 194-195.

3. AASHTO T 121-86, "Weight per Cubic Foot, Yield, and Air Content of Concrete," Standard Specification for Transportation Materials and Methods of Sampling and Testing, 17th Edition, 1995, pp. 196-198.

4. AASHTO T 152-93, "Air Content of Freshly Mixed Concrete by the Pressure Method," Standard Specifications for Transportation Materials and Methods of Sampling and Testing, 17th Edition, 1995, pp.255-262.

5. AASHTO T 160-93, "Length Change of Hardened Hydraulic Cement Mortar and Concrete," Standard Specifications for Transportation Materials and Methods of Sampling and Testing, 17th Edition, 1995, pp. 196-198.

6. AASHTO T 277-93, "Electrical Indication of Concrete's Ability to resist Chloride Ion Penetration," Standard Specifications for Transportation Materials and Methods of Sampling and Testing, 17th Edition, 1995, pp.196-198.

7. American Society for Testing and Materials, 1995 Annual Book of ASTM Standards, vol.04.02, Concrete and Aggregates.

8. ASTM C 39-86, "Standard Test Method for Compressive Strength of Cylindrical Concrete Specimens," in 1995 Annual Book of ASTM Standards, V04.02, Concrete and Aggregates, American Society for Testing and Materials, pp. 20-24.

9. ASTM C 78-94, "Standard Test Method for Flexural Strength of Concrete (Using Simple Beam with Third-Point Loading)," in 1995 Annual Book of ASTM Standards, V04.02, Concrete and Aggregates, American Society for Testing and Materials, pp. 32-34. 
10. ASTM C 138-92, "Standard Test Method for Unit Weight, Yield, and Air Content (Gravimetric) of Concrete," in 1995 Annual Book of ASTM Standards, V04.02, Concrete and Aggregates, American Society for Testing and Materials, pp. 83-85.

11. ASTM C 143-90a, "Standard Test Method for Slump of Hydraulic cement concrete," in 1995 Annual Book of ASTM Standards, V04.02, Concrete and Aggregates, American Society for Testing and Materials, pp. 88-90.

12. ASTM C 157-93, "Standard Test Method for Length Change of Hardened Hydraulic-Cement Mortar and Concrete," in 1995 Annual Book of ASTM Standards, V04.02, Concrete and Aggregates, American Society for Testing and Materials, pp. 101-106.

13. ASTM C 192-90a, "Standard Practice for Making and Curing Test Specimens in the Laboratory," in 1995 Annual Book of ASTM Standards, V04.02, Concrete and Aggregates, American Society for Testing and Materials.

14. ASTM C 231-91b, "Standard Test Method for Air Content of Freshly Mixed Concrete by the Pressure Method," in 1995 Annual Book of ASTM Standards, V04.02, Concrete and Aggregates, American Society for Testing and Materials, pp. 140-147.

15. ASTM C 496-96, "Standard Test Method for Splitting Tensile Strength of Cylindrical Concrete Specimens," in 1995 Annual Book of ASTM Standards, V04.02, Concrete and Aggregates, American Society for Testing and Materials, pp. 268-271.

16. ASTM C 618-99a, "Standard Test Method for Coal Fly Ash and Raw or Calcined Natural Pozzolan for Use as a Mineral Admixture in Concrete," in 1995 Annual Book of ASTM Standards, V04.02, Concrete and Aggregates, American Society for Testing and Materials, pp. 305-308.

17. ASTM C 1018-97, "Standard Test Method for Flexural Toughness and FirstCrack Strength of Fiber-Reinforced Concrete (Using Beam With Third-Point Loading)," in 1995 Annual Book of ASTM Standards, V04.02, Concrete and Aggregates, American Society for Testing and Materials, pp. 528-535.

18. ASTM C 1064-86, "Standard Test Method for Temperature of Freshly Mixed Portland Cement Concrete," in 1995 Annual Book of ASTM Standards, V04.02, 
Concrete and Aggregates, American Society for Testing and Materials, pp. 528529.

19. ASTM C 1202-91, "Standard Test Method for Electrical Indication of Concrete's Ability to Resist Chloride Ion Penetration," in 1995 Annual Book of ASTM Standards, V04.02, Concrete and Aggregates, American Society for Testing and Materials, pp. 627-632.

20. ASTM C 1240-00, "Standard Test Method for Use of Silica Fume as a Mineral Admixture in Hydraulic-Cement Concrete, Mortar, and Grout," in 1995 Annual Book of ASTM Standards, V04.02, Concrete and Aggregates, American Society for Testing and Materials, pp. 652-657.

21. ASTM D 4260-88, "Standard Practice for Acid Etching Concrete," in 1995 Annual Book of ASTM Standards, V06.02, Concrete and Aggregates, American Society for Testing and Materials, pp. 272-273.

22. ASTM D 4262-83, "Standard Test Method for $\mathrm{pH}$ of Chemically Cleaned or Etched Concrete Surface," in 1995 Annual Book of ASTM Standards, V06.02, Concrete and Aggregates, American Society for Testing and Materials, pp. 276.

23. SHRP Product 2025, "Determination of The Interfacial Bond Strength of Concrete to Concrete," in SHRP Product Reports of Concrete Assessment and Rehabilitation Transition Report, AASHTO Innovative Highway Technologies, pp. 93-98.

24. Babaei, Khossrow and Hawkins, Neil M., "Performance of Bridge Deck Concrete Overlays," ASTM Special Technical Publication, n 1100, Dec 5, 1989, pp. 95108.

25. Babaei, Khossrow and Hawkins, Neil M., "Performance of Rehabilitated/ Protected Concrete Bride Decks," Corrosion Forms and Control for Infrastructure, ASTM STP 1137, American Society for Testing and Materials, 1992, pp. 140154.

26. Banthia, N.; Yan, C.; and Mindess, S., "Restrained Shrinkage Cracking in Fiber Reinforced Concrete: A Novel Test Technique," Cement and Concrete Research, v 26, n 1, Jan, 1996, pp. 9-14. 
27. Berke, N. S., "Microsilica and Concrete Durability," Transportation Research Record, n 1204, 1988, pp. 21-26.

28. Bunke, Dennis, "ODOT Experience with Silica-Fume Concrete," Transportation Research Record, n 1204, 1988, pp. 27-35.

29. Cady, Philip D.; Weyers, Richard E.; and Wilson, David T., "Durability and Compatibility of Overlays and Bridge Deck Substrate Treatments," Concrete International, v 6, n 6, June, 1984, pp. 36-44.

30. Calvo, Luis and Meyers, Martin, "Overlay Materials for Bridge Decks," Concrete International: Design and Construction, v 13, n 7, Jul, 1991, pp. 46-47.

31. Christensen, Donald W.; Sorenson, Eigil V.; and Radjy, Farrokh F., "Rockbond: A New Microsilica Concrete Bridge Deck Overlay Material," Official Proceedings - International Bridge Conference, 1984, pp. 151-160.

32. Deming, Brian M.; Aktan, Haluk; and Usmen, Mumtaz, "Test for Polymer Overlay Interface on Concrete," Proceedings of the Materials Engineering Conference 804, Oct, 1994, pp. 709-715.

33. Detwiler, Rachel J.; Kojundic, Tony; and Fidjestol, Per, "Evaluation of Bridge Deck Overlays," Concrete International, v 19, n 8, Aug, 1997, pp. 43-45.

34. Dhir, M. P., "A Study on the Effect of Temperature Variations on the Bonding of Concrete Overlays," Journal of The American Concrete Institute, v 81, n 2, MarApr, 1984, pp. 172-179.

35. Fitch, Michael G. and Abdulshafi, Osama A., "Field and Laboratory Evaluation of Silica Fume Modified Concrete Bridge Deck Overlays in Ohio," Transportation Research Record, n 1610, 1996, pp. 20-27.

36. Fowler, D. W., "Polymers in Concrete: A Vision for The $21^{\text {st }}$ Century," Cement and Concrete Composites, v 21, n 5-6, Oct-Nov, 1999, pp. 449-452.

37. Glauz, Doran L., "Latex-Modified Concrete Overlay on Plain-Jointed Concrete Pavement," Cement, Concrete and Aggregates, v 17, n 2, Dec, 1995, pp. 201-204.

38. Halvorsen, Grant T., "Bridge Deck Overlays," Aberdeen's Concrete Construction, v 38, n 6, Jun, 1993, pp. 415-419.

39. Hindo, Kal R., "In-Place Bond Testing and Surface Preparation of Concrete," Concrete International: Design and Construction, v 12, n4, Apr, 1990, pp. 46-48. 
40. Holland, Terence C., "Practical Considerations for Using Silica Fume in Field Concrete," Transportation Research Record, n 1204, 1988, pp. 2-7.

41. Kaufman, Wayne and Keeling, Ed, "West Virginia DOH Overlays 1-70 and 164,” Asphalt, v 1, n 1, Spring, 1987, pp. 11-12.

42. Knab, Lawrence I. and Spring, Curtis B., "Evaluation of Test Methods for Measuring the Bond Strength of Portland Cement Based Repair Materials to Concrete," Cement, Concrete and Aggregates, v 11, n 1, Summer, 1989, pp. 3-14.

43. Kuhlmann, Louis A., "Test Method for Measuring the bond Strength of LatexModified Concrete and Mortar,” ACI Materials Journal, v 87, n 4, Jul-Aug, 1990, pp. 387-394.

44. Kuhlmann, L., "Cracks in Latex-Modified Concrete Overlays----How They Get There, How Serious They Are, and What To Do About Them," Transportation Research Record, n 1301, 1991, pp. 17-21.

45. Luther, Mark D., "Silica-Fume (Microsilica) Concrete in Bridges in The United States," Transportation Research Record, n 1204, 1988, pp. 11-20.

46. Northcott, G.D.S., "Concrete Overlays- A Review of Current Practice," Highways and Transportation, v 40, n 3, Mar, 1993, pp. 15-20.

47. Ozyildirim, Celik, "Laboratory Investigation of Concrete Containing Silica Fume For Use in Overlays," ACI Materials Journal (American Concrete Institute), v 84, n 1, Jan-Feb, 1987, pp. 3-7.

48. Ozyildirim, Celik, "Experimental Installation of A Concrete Bridge-Deck Overlay Containing Silica Fume,” Transportation Research Record, n 1204, 1988, pp. 3641.

49. Ozyildirim, Celik, "Laboratory Investigation of Low-Permeability Concretes Containing Slag and Silica Fume," ACI Materials Journal, v 91, n 2, Mar-Apr, 1994, pp. 197-202.

50. Ozyildirim, C.; Moen, C.; and Hladky, Sh., "Investigation of Fiber-Reinforced Concrete for Use in Transportation Structures," Transportation Research Record, n 1574, Nov, 1996, pp. 63-70. 
51. Ramakrishnan, V.; Wu, George Y.; and Hosalli, Girish, "Flexural Behavior and Toughness of Fiber Reinforced Concretes," Transportation Research Record, n 1226, 1989, pp. 69-77.

52. Shahrooz, B. M.; Gillum, Arnol J.; Cole, Jeremiah; and Turer, Ahmet, "Bond characteristics of overlays placed over bridge decks sealed with HMWM," Transportation Research Record, n 1697, 2000, pp. 24-30.

53. Sprinkel, Michael M., "High Early Strength Latex-Modified Concrete Overlay," Record, n 1204, 1988, pp. 42-51.

54. Sprinkel, Michael M., "High Early Strength Latex Modified Concrete," Concrete Construction, v 33, n 9, Sep, 1988, 831-836.

55. Sprinkel, Michael M., "Twenty-Year Performance of Latex-Modified Concrete Overlays," Transportation Research Record, n 1335, 1992, pp. 27-35.

56. Sprinkel, Michael M., "Very-Early-Strength Latex-Modified Concrete Overlay," Virginia Transportation Research Council, Dec, 1998.

57. Sprinkel, Michael M. and Ozyildirim, Celik, "Shrinkage of High-Performance Concrete Overlays on Route 60 in Virginia," Transportation Research Record, n 1610, Aug, 1998, pp. 15-19.

58. Steele, G. W. and Judy, J. M., "Polymer-Modified Concretes in Bridge Deck Overlay Systems," Chloride Corrosion of Steel in Concrete, ASTM STP 629, American Society for Testing and Materials, 1977, pp. 110-115.

59. Wallace, Mark, "Overlaying Decks with LMC," Concrete Construction, v 32, n 12, Dec, 1987, pp. 1027-1033.

60. Walters, D. Gerry, "Latex Hydraulic Cement Additives," Transportation Research Record, n 1204, 1988, pp. 71-76.

61. Walters, D. Gerry, "Silica Fume, Latex-Modified Portland Cement Mortars and Concretes," Transportation Research Record, n 1301, 1991, pp. 12-16.

62. Warner, James; Bhuyan, Sam; Smoak, W. Glenn; Hindo, Kal R.; and Sprinkel, Michael, "Surface Preparation for Overlays," Concrete International, v 20, n 5, May, 1998, pp. 43-46.

63. Weil, Thomas G., "Addressing Parking Garage Corrosion with Silica Fume," Transportation Research Record, n 1204, 1988, pp. 8-10. 
64. Wells, John A.; Robert, D. Stark; and Dimos, Polyzois, "Getting Better Bond in Concrete Overlays," Concrete International, v 21, n 3, March, 1999, pp. 49-52.

65. Whiting, Dziedzic, "Chloride Permeabilities of Rigid Concrete Bridge Deck Overlays,” Transportation Research Record, n 1234, 1989, pp. 24-29. 


\section{APPENDIX A}

\section{Detailed Literature Review}

Steele and Judy, 1977 summarized the research and field usage of latex-modified concrete overlay in West Virginia. They indicated that the application of a relatively thin (1 to 2 in.) overlay of Portland cement concrete or mortar containing a latex (styrene butadiene) modifier may result in a significant increase in the useful life of bridge decks.

They mentioned that the first latex overlay was placed in West Virginia in 1961, using conventional equipment under the supervision of Dow Chemical Company personnel. Performance of this overlay was considered very well over the years.

They studied concrete proportions and overlay application of 18 structures, including both new construction and renovation of existing decks, which have received the latex-modified concrete overlay. They summarized a comprehensive evaluation of the overlay characteristics. Some of the measured characteristics include consistency, air content, setting time, compressive strength, freeze-thaw resistance, bond to concrete, length change, bond to steel, chloride penetration, and corrosion of reinforcing steel and visual observation of the decks under traffic.

They concluded that compared to other types of treatment under evaluation, the latex-modified concrete has been the most satisfactory of those in place long enough to have developed a history of performance. Postconstruction evaluations would indicate some cracking and some evidence of chloride penetration, although at a slower rate than in conventional concrete. Bond of overlay to substrate remains satisfactory, again with 
some evidence of incipient delamination. Overall appearance of the overlays remains good, with no serious distress to date.

Cady et al., 1984 used the freeze-thaw test to evaluate the durability and compatibility of bridge deck substrate and overlays. It describes the detailed experiment method and results.

Both durability and compatibility were evaluated in rapid freezing and thawing tests (ASTM C666, Method A). The following table summarized the substrate treatment/overlay systems evaluated in their research.

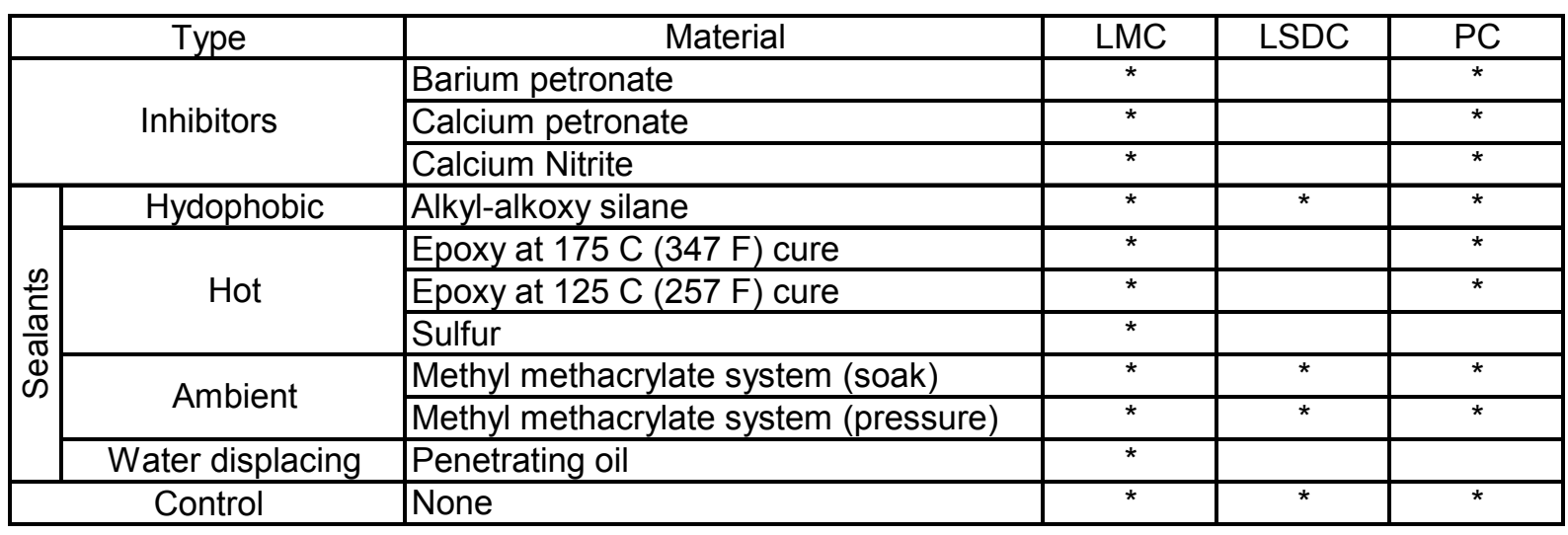

When they cast the substrate, the retarded surface laitance was removed by washing with water, because sandblasting would not have produced the same degree of relief as a scarified deck.

- Impregnation procedures: The MMA system pressure impregnation required a complex apparatus.

- Overlays casting: The bonding agents of LSDC, LMC and PC are a neat cement paste, a latex-cement paste slurry, and a monomer (MMA-PMMA mixture) with an initiator ( $4 \%$ by weight of CADOX BFF-50), respectively. 
- Substrate and overlays materials: The fine aggregate was the glacial-fluvial bank sand. The coarse aggregate was the dense fine to medium-fine grained dolomitic limestone. Mixing procedures for PC were in the FHWA's Polymer Concrete Overlay User's Manual.

- Test procedure: Freeze-thaw cycling was consisted of freezing from 40 to $0{ }^{\circ} \mathrm{F}$ (4.4 to $\left.-17.8{ }^{\circ} \mathrm{C}\right)$ and thawing from 0 to $40{ }^{\circ} \mathrm{F}\left(-17.8\right.$ to $\left.4.4{ }^{\circ} \mathrm{C}\right)$ over a total cycle length of 2.5 hours. The planned total test duration was 500 cycles. Due to the equipment malfunction, some series were not carried out the full 500 cycles. However, the 300 cycles required in ASTM C666 were achieved in all test series.

The substrate specimens containing the penetrating oil, a water-displacing penetrate, displayed severe cracking and deterioration. Likewise, the sulfur-impregnated substrate specimens showed sever deterioration and loss of material in durability testing. Except for the fourth test series, the latex modified concrete and polymer concrete overlays performed exceedingly well relative to durability.

They suggested that only MMA impregnated substrate (soak or pressure) shows promise among the combinations of surface treatments tested in their study.

Christensen et al., 1984 summarized test programs on three bridge deck overlay materials: latex-modified concrete (LMC), low-slump dense concrete (LSDC) and a new material, ROCKBOND, which is a high-strength microsilica concrete (MMC). 
The following Table shows concrete mix designs in their study.

\begin{tabular}{|c|c|c|c|c|c|c|c|}
\hline $\begin{array}{c}\text { Concrete } \\
\text { Type }\end{array}$ & $\begin{array}{c}\text { Cement } \\
\mathrm{lb} / \mathrm{yd}^{3}\end{array}$ & $\begin{array}{c}\text { Water } \\
\mathrm{lb} / \mathrm{yd}^{3}\end{array}$ & $\begin{array}{c}\text { Latex } \\
\text { Solids } \\
\mathrm{lb} / \mathrm{yd}^{3}\end{array}$ & $\begin{array}{c}\text { Microsilica } \\
\text { Solid } \\
\mathrm{lb} / \mathrm{yd}^{3}\end{array}$ & $\begin{array}{c}\text { Fine } \\
\text { Agg. } \\
\text { Total } \\
\text { Agg. } \\
\text { Ratio }\end{array}$ & $\begin{array}{c}\text { Air } \\
\text { content } \\
(\%)\end{array}$ & $\begin{array}{c}\text { Slump } \\
\text { In. }\end{array}$ \\
\hline LMC & 659 & 231 & $98.8^{*}$ & & 0.60 & $5.2-6.0$ & $8-10^{* * *}$ \\
\hline LSDC & 822 & 271 & & & 0.50 & $4.6-5.2$ & 0.5 \\
\hline MMC & 681 & 258 & & $101^{* *}$ & 0.50 & $3.2-4.8$ & $6.5-8$ \\
\hline Substrate & 799 & 224 & & & 0.44 & 3.5 & 2 \\
\hline
\end{tabular}

* Styrene/Butadiene polymer type, $46.3 \%$ solids in solution, $8.4 \mathrm{lbs} / \mathrm{gal}$.

** Added as EMSAC-B 51/5\% water, $44.8 \%$ microsilica solids.

*** At five minutes after completion of mixing.

In their study, the following tests were performed: compressive strength (ASTM C39), flexural strength (ASTM C293), shear-bond strength, freeze-thaw resistance (ASTM C666), rapid chloride ion permeability (ASTM C1202), and abrasion resistance (ASTM C944).

The shear-bond strength test was performed in a direct shear testing device which consists of two heavy steel yokes in which each end of the composite core are tightly mounted. The yokes are separated by brass spacers 0.25 in. thick, and loosely held together by two steel channels, one on each side. The assembled device with a core in position was tested in compression, resulting in a shear failure at the region of the bond.

Based on the test results, they concluded that:

1. The addition of microsilica to Portland cement concrete drastically reduces chloride ion permeability.

2. High strength MMC has excellent freeze-thaw resistance without purposely entrained air.

3. Very high strengths are attainable with MMC. Compressive strengths over $12000 \mathrm{psi}$ and flexural strengths over $1200 \mathrm{psi}$ are achieved. 
4. The bond strength of MMC to existing substrate concrete is very high, perhaps as much as 1300 psi for high strength mix designs.

5. The high strength, freeze-thaw resistance, and low chloride-ion permeability of MMC indicate that it is a valuable material for highway construction, not only for bridge deck overlays, but also for full-depth pavement and bridge deck slabs, as well as for structural concrete.

6. High strength and durable MMC can now be made on a routine basis using commercially available microsilica additives.

Kaufman \& Keeling, 1987 reported that the West Virginia DOH has successfully completed cracking and seating on two bridges with asphalt overlay operations in I-70 near Wheeling and I-64 near Charleston.

On I-70 near Wheeling, before cracking, the slabs were sawed into 15 foot sections. Cracking was done with a guillotine-type drop-hammer, making breaks every 18 to 24 in. Seating of the cracked Portland cement concrete (PCC) was done with a 50ton rubber-tired roller. Then the entire 7-mile section was tack-coated. WVDOH did not permit traffic on the project until the overlay was complete. On I-64 near Charleston, WVDOH used a drop-hammer to crack the PCC and a 50-ton rubber-tired roller to seat it.

As in the case of the I-70 project near Wheeling, West Virginia DOH officials expect 8 to 10 years of service out of the I-64 overlay. 
Ozyildirim, 1987 batched and tested hydraulic cement concretes containing silica fume in the laboratory to assess their suitability for use in overlays having a minimum thickness of $1 \frac{1}{4}$ in. $(32 \mathrm{~mm})$.

The evaluation was conducted in the laboratory in two phases. In Phase I, tests were made on 4 in. by 8 in. cylinders fabricated from trial batches prepared to obtain the mixture proportions for workable concretes with satisfactory strength and low permeability. In Phase II, the main testing program was conducted. The properties studied were compressive, flexural, and bond strengths, freeze-thaw resistance, and dimensional stability (thermal expansion and drying shrinkage).

In Phase I, silica fume from a single source, SF1, was used. In Phase II, silica fume from two sources, SF1 and SF2, were used. SF1 had a silica content of $87.2 \%$ and SF2 a content of 93.2 percent.

From the test results obtained in the study, the conclusions are as follows:

1. Concrete containing SF at a low replacement rate of $5 \%$ and at a w/c of 0.40 or less can provide satisfactory strength and a low permeability for bridge deck overlays with a minimum thickness of $1 \frac{1}{4} \mathrm{in}$.

2. The permeability measured in coulombs, of concretes containing SF was lower than that of the controls. At the lower w/c, lower coulomb values were obtained.

3. The average freeze-thaw performance of concretes with SF was satisfactory.

Wallace, 1987 described the application of LMC overlay on a bridge deck. He prepared the surface thoroughly by following methods: scarifying, handchiping, 
sandblasting, blow-cleaning, and dampening. The LMC was batched in a mobile batcher mixer. The overlay thickness was $1 \frac{1}{4}$ in. minimum. The concrete placement temperature was $45-85^{\circ} \mathrm{F}$.

The following table shows a typical LMC mixed by Wallace.

\begin{tabular}{|c|c|c|c|c|c|c|c|c|}
\hline $\begin{array}{c}\text { Cement } \\
(\mathrm{lb})\end{array}$ & $\begin{array}{c}\text { Sand } \\
(\mathrm{lb})\end{array}$ & $\begin{array}{c}\text { Stone } \\
(\mathrm{lb})\end{array}$ & $\begin{array}{c}\text { Latex } \\
(\mathrm{gal})\end{array}$ & $\begin{array}{c}\text { Water } \\
(\mathrm{gal})\end{array}$ & $\begin{array}{c}\text { Air- } \\
\text { entraining } \\
\text { agent }\end{array}$ & $\begin{array}{c}\text { w/c } \\
\text { ratio }\end{array}$ & $\begin{array}{c}\text { Slump } \\
\text { (in) }\end{array}$ & $\begin{array}{c}\text { Air } \\
\text { content } \\
(\%)\end{array}$ \\
\hline 658 & 1,710 & 1,140 & 24.5 & $19 \mathrm{max}$ & None & $0.4 \mathrm{max}$ & $4-6$ & $61 / 2 \mathrm{max}$ \\
\hline
\end{tabular}

He recommended that:

- Preparing new decks is similar to preparing old decks, except in case of new decks scarifying and handchipping are not necessary.

- Placement of concrete should be quick, because working time can be as short as 10 minutes.

- The concrete should be finished with a self-propelled finishing machine in the present case, though roller finishers are the most popular in general.

- The concrete should be damp-cured for the first 24 hours, followed by dry curing for 72 hours.

- An LMC overlay should not be placed less than $1 \frac{1}{4}$ in. thick, next to a parallel strip of overlay which is less than 72 hours old, or when rain is expected. An LMC overlay should not be placed at temperatures lower than $40^{\circ} \mathrm{F}$ or when the surface evaporation rate is more than $0.15 \mathrm{lb} / \mathrm{ft}^{2}$ per hour.

- Placing a latex overlay is a continuous operation. The worker should not brush on latex grout far ahead of concrete placement. The worker should not place 
concrete far ahead of the finishing machine. They should cover the concrete with wet burlap and polyethylene before the surface begins to dry.

Berke, 1988 described the results from experiments to determine the effects of microsilica on concrete freeze-thaw resistance and on the permeability to chlorides and subsequent early corrosion rates of steel in the concrete.

A normal Type I Portland cement (ASTM C 150) and silica fume were used. The mix proportions are based on two overlapping factorial designs consisting of 12 different mix designs and one repetition for a total of 13 mixes. Cement factor was kept at approximately $600 \mathrm{lb} / \mathrm{c} . y$. , and w/c were $0.38,0.43$ and 0.48 . Silica fume was proportioned as an additive (rather than as cement replacement) at $3.75,7.5$, and $15 \%$ by weight of cement.

He used the following test methods: compressive strengths test (ASTM C 39), freeze-thaw test (ASTM C 666, Method A), rapid chloride permeability test (AASHTO T-277), and acid soluble chloride test (Florida DOT Research Report 203 PB 289620).

He concluded that:

- The addition of silica fume to concrete improves the compressive strength and resistivity while reducing chloride permeability.

- Silica fume improves the resistance to the onset of chloride-induced corrosion of steel in concrete.

- Lowering the $\mathrm{w} / \mathrm{c}$ of concrete improves the performance gain of adding silica fume. 
- Properly air-entrained concretes with silica fume have excellent resistance to freeze-thaw damage.

Bunke, 1988 studied three bridge overlay cases and the data on mixing, placing, curing, compressive and flexural strengths, resistance to freezing and thawing and permeability were presented.

The three cases are:

Structure 1---120ft long and 32ft wide overlay. Use latex-modified concrete overlays and used silica fume on only one lane.

Structure $2---27 \mathrm{ft}$ long and $32 \mathrm{ft}$ wide silica-fume modified concrete overlay. A finishing aid was used.

Structure 3---123 ft long and 34 wide silica-fume modified concrete overlay. A finishing aid was used on the first few feet of the surface.

Abrasive blasting was used as the deck preparation, followed by an air blast immediately before the overlay placement, to clean the surface. A grout was applied to the clean and scarified surface just ahead of the overlay placement. The finished overlay surfaces were covered with a single layer of wet burlap. The silica-fume projects were placed at various temperatures and humidity.

He used following test methods: ASTM C 39, ASTM C 78, ASTM C 143, ASTM C 231, ASTM C 457 and ASTM C 666.

He concluded that:

- $\quad$ The addition of silica-fume to concrete makes it less permeable and therefore more resistant to chloride penetration. Permeability decreases, 
as silica-fume content increases, and very low permeability are achievable.

Compressive and flexural strengths increase with the addition of silicafume to concrete.

- If proper curing is achieved, a crack free overlay or deck can be obtained. A 72-hr. continuous water cure is advisable.

- High silica-fume content can cause finishing problems. Silica fume of $15 \%$ by mass appears to be the maximum amount that should be used.

- The addition of silica fume had no detrimental effects on the air-void system.

- A reliable bond can be achieved when overlaying a bridge deck if the old wearing surface is removed to sound concrete and a bonding grout is scrubbed into the surface. No delamination has been discovered to date.

- $\quad$ Silica-fume-modified concrete can be mixed successfully in a mobile mixer or in a central mixer. Latex-modified concrete should be mixed in a mobile mixer.

- The cost of silica-fume-modified concrete placed as an overlay is similar to that of a latex-modified overlay.

And he recommended that:

- $\quad$ Decrease Ohio DOT's specified silica-fume content to $10 \%$ by mass of cement. This maintains favorable permeability characteristics, produces a more economical mix, and reduces the possibility of finishing problems. 
- Use an air-entraining admixture. A proper air-void system can be achieved when the proper quantity of air-entraining admixture is used.

Luther, 1988 reviewed silica-fume-concrete (SFC) used in bridges in the United States.

He indicated that silica-fume concrete has been used with increasing frequency in bridge decks and associated structures in the United States since 1983. Most SFs contain at least $85 \%$ amorphous silicon dioxide $\left(\mathrm{SiO}_{2}\right)$ and have a specific surface above $20 \mathrm{~m}^{2} / \mathrm{g}$. Silica fume is a highly reactive pozzolan that refines the Portland cement paste pore structure.

Luther reported the experiences of several places, such as Ohio DOT, Univ. of Cincinnati, Kentucky DOH, New York DOT, Tennessee DOT, Michigan DOT, Maine DOT, Virginia DOT, Illinois DOT, City of Milwaukee, Wisconsin, Pennsylvania DOT, Indiana DOH, Vermont AOT and Washington DOT.

He still mentioned some applications of silica fume other than overlays. These are Full-Depth Bridge-Related Applications, Bridge-Related Marine Applications and Miscellaneous Bridge-Related Applications.

His conclusions are:

- $\quad$ SFC at dosages between 5 and $15.5 \%$ can be manufactured, placed, finished, and cured using conventional equipment. Measures must be taken to prevent plastic shrinkage cracking.

- $\quad$ There are several motives for using SFC: to provide a chloride barrier, to develop high-early strength, to achieve high-ultimate strength, to 
provide abrasion resistance, and to improve bond strength. Expectations in regard to the original motives for using SFC appear to have been met. Interest in SFC is increasing, and SFC is now being specified in bridges.

Holland, 1988 reviewed the practical aspects of working with silica fume in ready-mixed concrete, with emphasis on the use of silica fume in the performanceenhancement role.

He summarized several forms of silica fume, which is available commercially in the United States. They are dry products: 1) As-produced silica fume, 2) As-produced silica fume with dry chemical admixtures, 3) Densified silica fume with dry chemical admixtures, and 4) Densified silica fume without dry chemical admixtures, and wet products: 1) Silica fume slurry, 2) Silica fume slurry with low dosages of chemical admixtures, and 3) Silica fume slurry with high dosages of chemical admixtures.

He indicated that specifications for silica-fume concrete must be considered on three levels: first, specifications for the silica fume itself; second, specifications for admixtures containing silica fume; and third, project specifications for concrete incorporating silica fume as an admixture. Each of these areas is currently a source of problems in the United States.

He also indicated that five critical areas much be considered when producing concrete containing silica fume; measuring, adding, mixing, using a high-range waterreducing admixture and controlling concrete temperature.

He mentioned that in the application process, transporting, placing and consolidating of silica-fume concrete behave very much like conventional concrete. 
However, the greatest differences between conventional concrete and silica-fume concrete have shown up during finishing. Reducing bleeding is the key to adjust these differences. He also mentioned that proper curing is particularly important for silica-fume concrete.

He concluded that silica fume is a material that offers significant potential for improvements in some properties of concrete. The only one difference that cannot be overcome is that silica-fume concrete will be less forgiving than conventional concrete of any attempts to cut corners.

Ozyildirim, 1988 summarized the experimental installation of a concrete bridge deck overlay containing silica fume (SF).

In his study, the bridge overlaid with SF concrete was built in 1941. The minimum thickness of the overlay containing silica fume was specified as $1.25 \mathrm{in}$. Silica fume was added at $7 \%$ or $10 \%$ by weight of Portland cement.

A Type II cement and a commercially available silica-fume slurry were used. The following table shows mixture proportions.

\begin{tabular}{|c|c|c|}
\hline & Silica Fume, 7\% & Silica Fume, $10 \%$ \\
\hline Portland cement & $658 \mathrm{lb} / \mathrm{yd}^{3}$ & $658 \mathrm{lb} / \mathrm{yd}^{3}$ \\
\hline Silica fume & $46 \mathrm{lb} / \mathrm{yd}^{3}$ & $66 \mathrm{lb} / \mathrm{yd}^{3}$ \\
\hline Maximum w/c & 0.40 & 0.40 \\
\hline Fine aggregate & 1,269 & 1,225 \\
\hline Coarse aggregate & 1,516 & 1,516 \\
\hline Air content & $7+\_2 \%$ & $7+2 \%$ \\
\hline
\end{tabular}

In his study, concrete samples for testing were obtained from the middle third of the truck load. Four batches were tested individually for slump (ASTM C 143), air 
content (ASTM C 231), and temperature at the freshly mixed stage; and from the same batches, specimens were prepared for tests on the hardened concrete.

Compressive strength test (AASHTO $\mathrm{T}$ 22) showed that 1-day compressive strengths exceeded 3000 psi in concretes.

Flexural strength test (ASTM C 78) showed the results ranged from 763 psi to 957 psi.

To determine bond strengths, specimens were prepared by overlaying slabs cut from 4 in. diameter cylinders and subjecting the interface to shear after 28-day moistcuring of the overlay.

Chloride permeability test (AASHTO T 277) showed all the concretes exhibit values below 1,000 coulombs.

The results of Freezing and Thawing test (ASTM C 666) indicated that the resistance to cycles of freezing and thawing is low or marginal when the air content was below the specified limit. Concrete with air content within the specification exhibited satisfactory resistance to cycles of freezing and thawing.

He concluded that:

- Concretes containing SF can be a cost-effective alternative to LMC for use as thin overlays on bridge decks.

- Concretes containing 7 or $10 \%$ SF exhibited satisfactory strengths and very low chloride permeabilities.

- The resistance of concretes to cycles of freezing and thawing was satisfactory when air content was within the specification. 
- Addition of more HRWRA at the job site does not appear to affect the strength and chloride permeability of the concrete.

Sprinkel, 1988 studied the first high early strength latex-modified concrete (LMC-HE) overlay to be constructed for the Virginia DOT. His research was to refine currently used LMC mixtures to allow the installation of a LMC-HE overlay that can be subjected to traffic in less than $24 \mathrm{hr}$.

The LMC-HE mixture used in the overlay was selected after three trial batches. These were prepared in the laboratory using the ingredients that would be used in the overlay for field application. The installation procedure for the LMC-HE overlay was the same as for an LMC overlay. A comparison of the mixture proportions for typical A4 concrete without latex, typical LMC and the LMC-HE lab mix is shown in the following Table.

\begin{tabular}{|c|c|c|c|}
\hline Material & A4 & LMC & LMC-HE \\
\hline Cement, $\mathrm{lb} / \mathrm{yd}^{3}$ & 635 & 658 & 815 \\
\hline $\mathrm{w} / \mathrm{c}$ & 0.45 & 0.37 & 0.34 \\
\hline Latex, gal/bag & 0 & 3.5 & 3.0 \\
\hline Air, percent & $5-8$ & $3-7$ & $3-7$ \\
\hline Fine aggregate, $\mathrm{lb} / \mathrm{yd}^{3}$ & 1178 & 1571 & 1402 \\
\hline Coarse aggregate, $\mathrm{lb} / \mathrm{yd}^{3}$ & 1809 & 1234 & 1142 \\
\hline
\end{tabular}

Cylinders of concrete, 4 in. diameter by 8 in high, were fabricated and tested in compression using steel end caps and neoprene pads (AASHTO T 22). The following table shows the test results. 


\begin{tabular}{|c|c|c|c|c|}
\hline \multicolumn{5}{|c|}{ Compressive Strength (psi) } \\
\hline Age & LMC & LMC-HE & SBL LMC-HE & NBL LMC-HE \\
\hline $6 \mathrm{hr}$. & --- & --- & --- & 130 \\
$7 \mathrm{hr}$. & 120 & --- & --- & 320 \\
$8 \mathrm{hr}$. & --- & --- & --- & 930 \\
$9 \mathrm{hr}$. & --- & --- & --- & 1,520 \\
$10 \mathrm{hr}$. & --- & --- & --- & 1,990 \\
$11 \mathrm{hr}$. & --- & --- & --- & 2,190 \\
$12 \mathrm{hr}$. & 580 & 2,330 & 3,000 & 2,360 \\
$14 \mathrm{hr}$. & --- & --- & --- & 2,570 \\
$18 \mathrm{hr}$. & 1,150 & 3,290 & --- & --- \\
$24 \mathrm{hr}$. & 1,570 & 3,740 & 4,010 & 3,190 \\
$2 \mathrm{day}$ & 2,360 & 4,330 & --- & --- \\
$7 \mathrm{day}$ & 3,360 & 5,100 & 5,230 & 4,650 \\
$28 \mathrm{day}$ & 4,630 & 6,210 & 6,140 & 5,260 \\
\hline
\end{tabular}

Sprinkel used the guillotine shear apparatus to do the shear bond strength test. The results show that on the average, the LMC-HE overlay is bonded as well as the standard LMC overlays. Shear bond strengths 200 psi are adequate for good performance. Both of LMC and LMC-HE have more than adequate bond strength, and LMC-HE can develop adequate bond strength within 12 hours. The following figure shows the guillotine shear apparatus. The following Table shows his test results. 

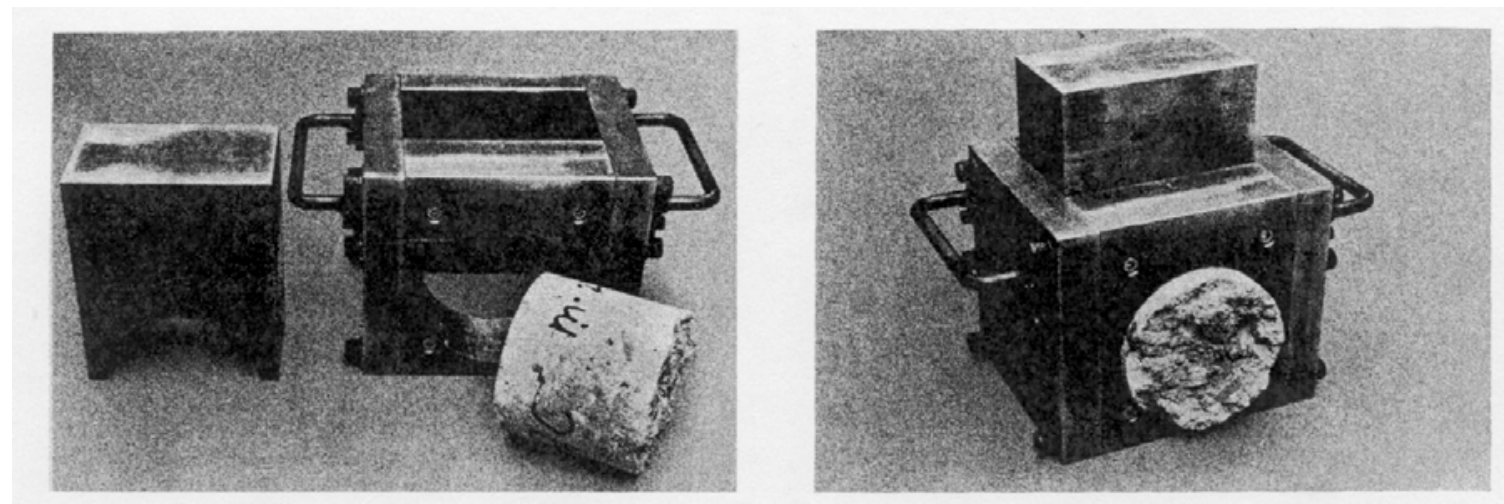

FIGURE 4 Apparatus used to subject cores to shear.

\begin{tabular}{|c|c|c|c|c|}
\hline \multirow{2}{*}{ Age } & \multicolumn{2}{|c|}{ Specimens } & \multicolumn{2}{c|}{ Cores } \\
\cline { 2 - 5 } & SBL LMC-HE & NBL LMC-HE & LMC-HE & LMC \\
\hline $6 \mathrm{hr}$. & --- & 40 & --- & --- \\
$7 \mathrm{hr}$. & --- & 130 & --- & --- \\
$8 \mathrm{hr}$. & --- & 150 & --- & --- \\
$9 \mathrm{hr}$. & --- & 160 & -- & --- \\
$10 \mathrm{hr}$. & --- & 160 & --- & --- \\
$11 \mathrm{hr}$. & --- & 290 & --- & -- \\
$12 \mathrm{hr}$. & 360 & 340 & --- & --- \\
$14 \mathrm{hr}$. & --- & 240 & 460 & --- \\
$24 \mathrm{hr}$. & 600 & 400 & --- & --- \\
$7 \mathrm{day}$ & --- & 650 & 580 & --- \\
$28 \mathrm{day}$ & 620 & 550 & 620 & 740 \\
$1 \mathrm{yr}$. & --- & --- & --- & 810 \\
$3 \mathrm{yr}$. & --- & --- & --- & 560 \\
$4 \mathrm{yr}$. & --- & --- & --- & 780 \\
8 yr. & --- & --- & --- & 530 \\
9 yr. & --- & --- & 690 \\
13 yr. & --- & & & \\
\hline
\end{tabular}


A rapid permeability test (AASHTO T 277) was used to measure the permeability to chloride ions of 2 in.-thick slices cut from 4 in. diameter cores taken from the bridge decks and 4 in. diameter cylinders prepared with the concrete mixtures. The following table shows the test results.

\begin{tabular}{|c|c|c|c|c|c|}
\hline \multirow{2}{*}{$\begin{array}{c}\text { Concrete } \\
\text { Age }\end{array}$} & \multirow{2}{*}{$\begin{array}{c}\text { Type } \\
\text { Specimen }\end{array}$} & \multicolumn{4}{|c|}{ Permeability, Coulombs } \\
\hline & & LMC & Lab Mix 2 & SBL LMC-HE & NBL LMC-HE \\
\hline 3 wk. & Clinder & 1,462 & 2,744 & --- & --- \\
\hline 4 wk. & Cores & --- & --- & 2,457 & --- \\
\hline 6 wk. & Clinder & --- & 1,932 & 1,819 & 2,783 \\
\hline 6 wk. & Cores & --- & --- & --- & 3,269 \\
\hline $12 \mathrm{wk}$. & Clinder & --- & --- & 1,745 & 3,437 \\
\hline $6 \mathrm{mo}$. & Clinder & --- & 917 & --- & --- \\
\hline $6 \mathrm{mo}$. & Cores & 928 & & --- & --- \\
\hline $1 \mathrm{yr}$. & Clinder & --- & 324 & 371 & 347 \\
\hline $1 \mathrm{yr}$. & Cores & 712 & --- & 1,464 & 2,018 \\
\hline $3 \mathrm{yr}$. & Cores & 708 & --- & --- & --- \\
\hline $4 \mathrm{yr}$. & Clinder & 80 & --- & --- & --- \\
\hline $4 \mathrm{yr}$. & Cores & 545 & --- & --- & --- \\
\hline $8 \mathrm{yr}$. & Cores & 367 & --- & --- & --- \\
\hline $9 \mathrm{yr}$. & Cores & 464 & --- & --- & --- \\
\hline $13 \mathrm{yr}$. & Cores & 1,298 & --- & --- & --- \\
\hline \multicolumn{6}{|c|}{ Relationship between Coulombs and Permeability } \\
\hline \multirow{2}{*}{\multicolumn{3}{|c|}{$\begin{array}{c}\text { Coulombs } \\
>4000\end{array}$}} & \multicolumn{3}{|c|}{ Permeability } \\
\hline & & & \multicolumn{3}{|c|}{ High } \\
\hline \multicolumn{3}{|c|}{$2000-4000$} & \multirow{2}{*}{\multicolumn{3}{|c|}{$\begin{array}{c}\text { Moderate } \\
\text { Low }\end{array}$}} \\
\hline \multicolumn{3}{|c|}{$1000-2000$} & & & \\
\hline \multicolumn{3}{|c|}{$100-1000$} & \multicolumn{3}{|c|}{ Very Low } \\
\hline \multicolumn{3}{|c|}{$<100$} & \multicolumn{3}{|c|}{ Negligible } \\
\hline
\end{tabular}

Six to eight 3 in. $x 4$ in. $x 16$ in. beams were prepared during the construction of A4 (typical concrete), LMC, and LMC-HE overlays and subjected to the freezing and thawing test (ASTM C 666 Procedure A). All the concrete mixtures passed the test.

The shrinkage of the LMC-HE at 28 days was $0.042 \%$, somewhat greater than the $0.024 \%$ typical of A4 concrete but slightly less than the $0.049 \%$ typical for standard LMC concrete. (ASTM C 511)

A bald-tire skid number (ASTM E 524) of 41 and a treaded-tire number (ASTM E 501) of 44 were measured at $40 \mathrm{mph}$ several months after the LMC-HE overlay was 
opened to traffic. Numbers of 46 and 51 respectively, were measured approximately 1 year later. All four numbers indicate that the tined texture is providing very good skid resistance.

Sprinkel concluded that:

- An evaluation of 12 bridges with LMC overlays ranging in age form 1 to 13 yr indicated that the overlays were soundly bonded to the base concrete and provide good protection against the infiltration of chloride ion.

- The shear strength of the bond between the LMC overlays and the base concretes was about the same or greater than that of the base concrete, indicating that good bonds were achieved and maintained.

- The permeability to chloride ions based on the rapid permeability test was an average of 773 coulombs for a 1.25 in. thick LMC overlay and 4,590 coulombs for the base concretes.

- The bond strengths were about the same for LMC overlays of all ages, but the permeability to chloride ion typically decreased with age.

- Based on the data collected after 1 yr in service, the LMC-HE overlay provided a bond strength and permeability that was equal to that provided by an LMC overlay.

- Based on the early age bond and compressive strength data and 1-year performance data, an LMC-HE overlay can be opened to traffic within $24 \mathrm{hr}$. 
Sprinkel, 1988 studied the high early strength latex modified concrete (LMC-HE) used for an LMC overlay on a Route 340 bridge in Virginia. The following Table shows mixture proportions of conventional concrete, LMC and LMC-HE.

\begin{tabular}{|c|c|c|c|}
\hline Material & $\begin{array}{c}\text { Conventional } \\
\text { concrete }\end{array}$ & LMC & LMC-HE \\
\hline Cement, lb./cu. yd. & 635 & 658 & 815 \\
\hline Water-cement ratio & 0.45 & 0.37 & 0.34 \\
\hline Latex, gal./bag & 0 & 3.5 & 3.0 \\
\hline Air, \% & 5 to 8 & 3 to 7 & 3 to 7 \\
\hline Fine aggregate, lb./cu. yd. & 1,178 & 1,571 & 1,402 \\
\hline Coarse aggregate, lb./cu. yd. & 1,809 & 1,234 & 1,142 \\
\hline
\end{tabular}

The concrete for the southbound lane was placed on May 21, 1986, beginning at 7:00 a.m. with an air temperature of $60^{\circ} \mathrm{F}$. The concrete for the northbound lane was placed on June 19,1986 , beginning at 6:10 a.m. with an air temperature of $85^{\circ} \mathrm{F}$.

The following table shows compressive strength results for LMC-HE samples from paving both lanes of the bridge and laboratory-made specimens, and shows the comparison of standard LMC.

\begin{tabular}{|c|c|c|c|c|}
\hline \multirow{2}{*}{$\begin{array}{c}\text { Concrete } \\
\text { age }\end{array}$} & \multicolumn{4}{|c|}{ Compressive strength, psi } \\
\cline { 2 - 5 } & $\begin{array}{c}\text { Standard } \\
\text { LMC }\end{array}$ & $\begin{array}{c}\text { Lab-mixed } \\
\text { LMC-HE }\end{array}$ & $\begin{array}{c}\text { Southbound } \\
\text { Lane LMC-HE }\end{array}$ & $\begin{array}{c}\text { Northbound } \\
\text { Lane LMC-HE }\end{array}$ \\
\hline $12 \mathrm{hr}$. & 580 & 2330 & 3000 & 2360 \\
$24 \mathrm{hr}$. & 1570 & 3740 & 4010 & 3190 \\
7 days & 3360 & 5100 & 5230 & 4650 \\
28 days & 4630 & 6210 & 6140 & 5260 \\
\hline
\end{tabular}


Sprinkel used a guillotine shear apparatus to measure shear strength at the bond line of cores, which were cut from the bridge deck and laboratory specimens. He tested at 12 hours, 24 hours, 28 days and 1 year, and compared with shear bond test results from conventional LMC cores taken from bridge overlays up to 13 years old. The following table shows his test results. LMC-HE overlays bond as well as standard LMC overlays.

\begin{tabular}{|c|c|c|c|c|}
\hline \multirow{2}{*}{$\begin{array}{c}\text { Concrete } \\
\text { Age }\end{array}$} & \multicolumn{4}{|c|}{ Shear bond strength, psi } \\
\cline { 2 - 5 } & \multicolumn{2}{|c|}{ Molded specimens } & \multicolumn{2}{c|}{ Cores } \\
\hline $12 \mathrm{hr}$. & 360 & Louthbound lane & Northbound lane & LMC \\
$24 \mathrm{hr}$. & 600 & 440 & --- & --- \\
28 days & 620 & 400 & 460 & --- \\
1 year & --- & 550 & 580 & --- \\
3 years & --- & --- & 620 & 740 \\
4 years & --- & --- & --- & 810 \\
8 years & --- & --- & --- & 560 \\
9 years & --- & --- & --- & 780 \\
13 years & --- & --- & --- & 530 \\
\hline
\end{tabular}

He tested the permeability of laboratory prepared LMC-HE mix, and compared with standard LMC. The following figure shows his test results. The laboratory prepared LMC-HE mix had a higher permeability at early ages than the standard LMC. However, at an age of about 26 weeks LMC-HE and LMC have about the same permeability. 


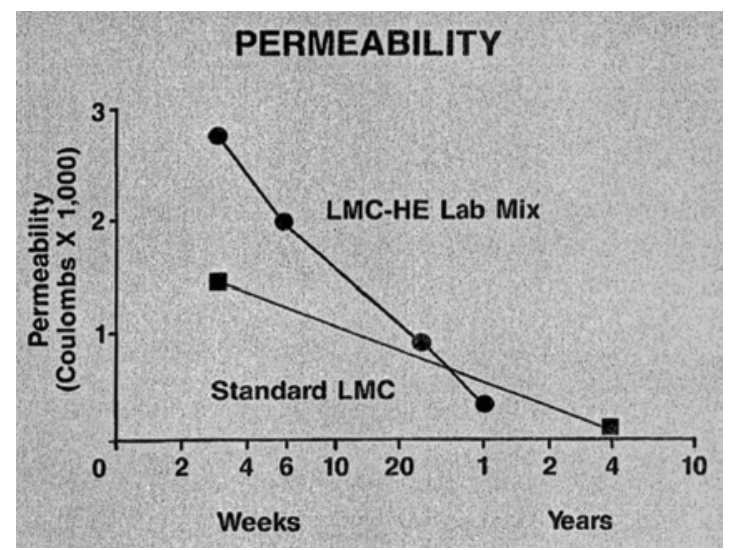

Sprinkel's study results show that it is practical to accelerate LMC overlay construction by using Type III cement and a higher cement content. Under normal conditions, workers should be able to install the overlay on a weekend and open the bridge to traffic within a day. During cold weather, the LMC-HE may not take traffic in a day but will cure more rapidly than a standard LMC, thus reducing inconvenience to motorists.

Walters, 1988 described the history, chemistry, types, and production of latexes, and discussed the problems and advantages of latex used to modify hydraulic cement mixes.

Latex is a dispersion of organic polymer particles in water. Many types of latex are on the market, but about 95 percent of them are not suitable for use with hydraulic cements. The majority of latex types used with hydraulic cements are Styrene-butadiene copolymers (S-B), Polyacrylic esters (PAE), Styrene-acrylic copolymers (S-A), Vinyl acetate homopolymers (PVA), Vinyl acetate-ethylene copolymers (VAE), Vinyl acetateacrylic copolymers (VAC), and Vinyl acetate-vinyl ester of versatic acid copolymers (VAVEOVA). 
Two processes govern latex modification: cement hydration and latex film formation. Each type of polymer latex can and usually does impart different properties to hydraulic cement mixtures. Using latex in hydraulic cement mixes generally increases the cost of raw materials.

When latex-modified hydraulic cement concrete or mortar is being prepared, it is essential that the mixing time be kept to a minimum, usually less than 3 minutes. If a latex-modified mix is being placed when the surface of the mix is exposed to good drying conditions, such as windy and low humidity, the polymer particles of the latex may coalesce to form a latex skin on the surface of the mix prior to noticeable cement hydration. The skin or crust may exhibit mud-cracking due to shrinkage of the latex skin before the cement hydration has proceeded enough so that the mix has sufficient strength to withstand the shrinkage forces. In summary, the benefits of using latex are resistance to penetration of fluids, improvement in adhesion and improvement in strength.

He concluded that the use of latex with hydraulic cements results in a co-matrix that gives improvements in adhesion, resistance to transmission of fluids and some strength properties. Generally this use is justified economically only to improve adhesion and/or water resistance of the system. The type of latex must be carefully selected to ensure its suitability for use with hydraulic cements and for the intended application. Although latex-modified mixes require short mixing times and often require steps to avoid mud-cracking, the system uses normal hydraulic cement techniques except that normal curing is not required. 
Weil, 1988 provided an overview of experience with silica-fume concrete used as a corrosion-protection system for parking garages.

He indicated silica fume is a by-product of silicon, ferrosilicon, or other silicon alloy production in a submerged are electric furnace. It contains a silica $\left(\mathrm{SiO}_{2}\right)$ content of $85 \%$ or greater and has as an extremely fine particle size, which has caused some researchers to call it a "super pozzolan." The ultra-fine particle size of roughly 0.1 micrometers allow the silica fume to fill the voids in the cement paste and between the cement paste and aggregate while the pozzolanic feature causes reaction with the excess calcium hydroxide $\left(\mathrm{Ca}(\mathrm{OH})_{2}\right)$. This process results in a far less permeable microstructure matrix that appears homogeneous and that has no gaps and not large crystals of $\mathrm{Ca}(\mathrm{OH})_{2}$.

Besides reducing concrete chloride permeability, silica-fume concrete has many other benefits: increased abrasion and erosion resistance; increased resistance to aggressive chemical acid attack; and most importantly, compressive and flexural strength enhancement. Silica fume develops higher strength in concrete due to the same factors that reduce chloride permeability — by combining with the excess calcium hydroxide to produce more calcium silicate hydrate paste and filling the pores between the aggregate and cement grains. More paste with fewer voids creates a better bond between the aggregate, producing higher strengths.

He concluded that even with all its advantages, silica-fume concrete does require extra attention during finishing and curing. Due to the cohesiveness of silica-fume concrete, it is recommended that slumps at least an inch higher than normally placed be used. Another area of caution is the reduced amount of bleed water after a slab is placed. ACI 302, Guide for Concrete Floor and Slab Construction, or ACI 30B, Standard Practice 
for Curing Concrete, should be followed to reduce the possibility of plastic shrinkage cracks. Weil, 1988 recommended procedures include fogging during finishing and wet burlap or the use of curing compounds during curing.

Ramakrishnan et al., 1989 evaluated the behavior and performance characteristics of the most commonly used fiber reinforced concretes (FRC) for potential airfield pavements as overlay applications.

They studied concretes with and without four different types of fibers. These are 1) 2 in. long hooked-end steel fibers used were glued together side by side into bundles with a water-soluble adhesive. During the mixing process, the glue dissolved in water and the fibers separated into individual fibers, creating an aspect ratio of 100;2) The straight steel fibers used were made from low carbon steel with a rectangular cross section of 0.009 on. X $0.030 \mathrm{in}$. and a length of $0.75 \mathrm{in}$. Their aspect ratio was approximately $40 ; 3$ ) 2 in. long corrugated steel fibers used were produced from a mild carbon steel with an aspect ration of 40 to 65 ; and 4) the polypropylene fibers used were collated, fibrillated, and $3 / 4$ in. long. These fibers were tested in four different quantities $(0.5,1.0,1.5$, and 2.0 percent by volume), and the same basic mix proportions were used for all concretes.

In their study, the following tests were executed: 1) freshly mixed concrete was tested for slump (ASTM C143), air content (ASTM C231), fresh concrete unit weight (ASTM C138), temperature, time of flow through an inverted cone (ASTM C995) and vibe time; 2) cylinders were tested for compressive strength (ASTM C39) and static modulus (ASTM C469) at 28 days of age; 3) beams were tested at 28 days for static flexural strength (ASTM C1018) and pulse velocity (ASTM C597). 
Based on the experimental investigation, they concluded that:

- The workability of fresh FRC can be improved and maintained with the addition of an appropriate amount of superplasticizer. Generally, there was no difficulty in placing and finishing.

- There was no change in the elastic wave transmission properties of he concrete due to the addition of fibers, as indicated by the measured pulse velocities.

- Compared with plain concrete, FRC has higher first-crack strength, static flexural strength, toughness index, ductility, and post-crack energy absorption capacity. The improvement increases with increasing fiber content.

- $\quad$ For each fiber, there is a unique relationship between the flexural strength and the fiber content.

- $\quad$ The failure mode of FRC is ductile. The degree of ductility depends on the fiber type and is directly proportional to the fiber content.

- The higher the fiber content of FRC, the lower the corresponding postcrack load drop.

Whiting and Dziedzic, 1989 studied the chloride permeability of rigid concrete bridge deck overlays. A total of 13 latex-modified concrete (LMC) overlays, 10 superplasticized dense concrete (SDC) overlays, and two condensed silica fume concrete (CSFC) overlays were investigated. 
In their study, cores were obtained from existing LMC, SDC, and CSFC overlays and tested for chloride ion content and rapid chloride permeability. Overlays ranged in age from 1 month to 14 years. Other test specimens were cast during construction of LMC and SDC overlays and a CSFC bridge deck during the 1987 construction season. Specimens were subjected to 90-day chloride ponding and rapid chloride permeability test (RCPT, AASHTO T277-83).

Chloride contents values of LMC cores in the near-surface ( 0 to $0.5 \mathrm{in}$.) layer range from $0.05 \%$ to $0.40 \%$. There is a sharp decrease in chloride content with depth. For the most part, high chloride contents are associated with LMC overlays servicing for the longest period of time. Results of RCPT on in-place core slices indicated that LMC permeability tends to decrease with age. Most of the results after 1 year of age lie below 600 coulombs.

They concluded that:

- Rigid concrete overlay systems, such as LMC, SDC, and CSFC can be used to reduce infiltration of chloride ions into reinforced concrete bridge decks with varying degrees of effectiveness. The most impermeable overlays appeared to be the incorporating condensed silica fume concrete.

- Latex-modified concrete represented the next level of relative permeability. Initial permeabilities typically were in the low to very low category and decrease substantially over a period of years. However, substantial amounts of chloride can migrate into LMC given sufficient time and exposure to severe conditions. 
- SDC overlays appeared to be somewhat more permeable than their LMC or CSFC counterparts. Initial permeabilities were generally in the moderate range, and high permeability values had been encountered. Over a period of years, it appeared that permeability of SDC would decrease to low values.

- The rapid chloride permeability test showed good potential for use as a means of establishing relative effectiveness of rigid overlay materials. The test may be carried out on test cylinders prepared at the jobsite and agreed well with more time-consuming procedures, such as 90 -day salt ponding.

Babaeie and Hawkins, 1990 studies were based on the result of a Washington, DOT — sponsored research that examined the performance of its bridge deck LMC and LSDC concrete overlays.

They indicated that many highway agencies have adopted latex-modified concrete (LMC) and/or low-slump dense concrete (LSDC) overlay protective strategies since the late 1970s. The performance of bridge deck overlays is judged by their durability, impermeability, and effectiveness in retarding continued corrosion of reinforcing steel in decks already contaminated with salt. Detailed field and laboratory studies were conducted on twelve selected concrete overlaid bridge decks (six LMC and six LSDC) in Washington to determine performance and where unforeseen problems had occurred in the overlays performance to recommend modifications to design and construction procedures. 
Their conclusions were:

1. Bridge deck concrete overlays will typically require major maintenance, in the form of resurfacing, after about 25 years of service. Even when there is no deterioration caused by corrosion, maintenance will be needed due to extensive wear and rutting in wheeltracks as well as loss of skid resistance.

2. LMC and LSDC concrete overlays are resistant but not impermeable to salt intrusion. The rate of chloride intrusion depends on the frequency and severity of salt applications and the degree of cracking of the concrete overlay.

3. The degree of cracking of the overlay depends on the plastic and drying shrinkage characteristics of the mix used in the overlay, placement, and curing procedures, bridge flexibility, and traffic intensity.

4. LMC and LSDC concrete overlays are able to retard continued corrosion of the reinforcing steel in salt-contaminated underlying decks by partially blocking the penetration to the reinforcing bar of moisture and oxygen, two key elements for corrosion to occur. However, overlay surface cracking can cause loss of that ability.

Calvo \& Meyers, 1991 investigated the overlay systems for bridge decks. They indicated that traditional polymer overlay systems have been deficient in several performance characteristics: 1) insufficient flexibility to minimize deck cracks transmitting through the overlay; 2) moisture insensitivity in some of the formulated 
products; 3) abrasion resistance for overlay longevity; 4) skid resistance; 5) chloride ion and water resistance; 6) freeze-thaw resistance; 7) long curing time increasing traffic down time. And there are some limitations of latex-modified concrete overlays and microsilica overlays, such as curing time and cracking protection.

They introduced one new overlay system, an epoxy overlay system, which can meet or exceed many of the performance criteria required by ASTM C 881-87. They also introduced the application methods of this new overlay system.

Based on their study, they concluded that polymer overlays are becoming increasingly popular with state DOTs as protective barriers for bridge decks, especially when it is necessary to reopen the bridge to traffic as quickly as possible. Epoxy overlays such as the new system have been successfully used for other above-grade wearing surfaces including highways, parking decks, and ramps.

Kuhlmann, 1991 investigated the cause, effect, and prevention of cracks in LMC overlays. The shallow cracks had the appearance of tears that are typically caused by late tining, when the crust has begun to form on the surface, whereas the deep crack appeared to be from plastic shrinkage. He used the rapid permeability test (AASHTO T 277-83). Chloride permeability was measured on the cores with cracks, and compared to a core without cracks. He found that the shallow crack has little effect on the permeability of the overlay but the deep crack has a significant effect.

After the LMC cured, Kuhlmann sealed the cracks with a variety of materials, including epoxy and methacrylate (both of low viscosity), sodium silicate, and latexcement slurry. The treatment was to seal the deep cracks with a low-viscosity polymer, 
and treat the shallow tears as cosmetic blemishes by covering them with a latex-cement slurry. The first step to prevent cracks in LMC overlays is to try and prevent it from occurring in the first place. The second step is related to the curing schedule. It indicates that during the initial wet-cure period, slight expansion of the concrete occurs, and that by extending the wet cure beyond 1 day there is potential to offset shrinkage stresses that occur during the dry-cure period.

He concluded that:

1. Cracks in LMC were not always detrimental to the long-term performance of the material. Shallow tears from late-finishing operations need not be sealed. Deep cracks should be sealed, using low-viscosity epoxy or methacrylate sealers.

2. Cracking in LMC can be controlled by proper attention to the quality of the materials used in the mix as well as the construction procedures used to place it.

Walters, 1991 used silica-fume and latex together in Portland cement mixtures to improve permeability resistance of the mortar or concrete to deicing salts.

He indicated that styrene-butadiene (S-B) latex-modified mortars and concretes (LMCs) have been used since 1959 as protective overlays for bridge and parking-garage decks.

Although LMC has low permeability to water-soluble salts, it is significantly higher than that of SFC; also the compressive strength of LMC is significantly lower. 
Conversely, it is accepted that SFC has lower adhesion and flexural strength values than those of LMC, and the latter does not require extensive moist curing.

Walters prepared four mortars. One contained no admixtures, the second had a ratio of SF to Portland cement of 0.10 , the third a ratio of S-B polymer to cement of 0.15 , and the fourth used both admixtures with ratios of SF and S-B polymer to cement of 0.10 and 0.15 , respectively.

In Walters's work, the following test procedures were used:

- Flow of mortars (ASTM C230), 25 drops;

- Wet densities were determined by measuring the mass in grams required to fill a 400-ml Vicat cup and dividing the value by 400 ;

- Compressive strength of mortars (ASTM C109);

- Flexural strength (ASTM C78);

- Permeability (AASHTO T277);

- Adhesion-tensile bond method developed by Kuhlmann;

- Dry densities were determined by measuring the mass of the various test specimens and dividing by their relative and approximate volume.

Values for coefficients of variations (COV) were determined for adhesion (tensile bond), permeability, flexural strength, and compressive strength. SFC gave a significantly lower permeability than that of the LMC, which in turn was significantly lower than that of the unmodified mortar. However, the permeability of the SFLMC was significantly lower than that of the SFC. The bond strength of the SFLMC was significantly higher than those of either of the unmodified and SF mortars, and the former approached that of the LMC. 
Walters's study indicated that the combined use of SF and S-B latex could yield a material with outstanding permeability resistance without significant loss of other advantageous properties. Such a concrete has excellent permeability resistance and acceptable compressive strength, while maintaining the good adhesion and flexural strength properties of latex-modified concrete.

Babaei and Hawkins, 1992 determined the relative effectiveness of three bridge deck protective systems (LMC overlay, LSDC overlay, and cathodic protection (CP)) in preventing or halting reinforcing steel corrosion and corrosion-induced deterioration in salt contaminated concrete. They selected five LMC, five LSDC, and two CP bridges on which to conduct detailed field investigations and determine the relative performance of the systems.

They indicated that the protection of reinforced concrete bridge decks against corrosion of reinforcing steel has been a major effort for highway agencies in the United States. The majority of bridge decks were originally constructed according to design practices that did not provide sufficient protection against reinforcing steel corrosion. As a result, the application of deicing salt on some bridge decks during winter, or salt from marine environments, have caused embedded reinforcing steel to corrode and expand and therefore have caused the concrete to crack and deteriorate internally.

In their study, all of the test bridges were located in the state of Washington. The test bridges had experienced severe corrosion induced deterioration and/or severe salt contamination before rehabilitation and protection. The nominal thicknesses of LMC and LSDC overlays were $38 \mathrm{~mm}\left(1 \frac{1}{2}\right.$ in.) and $51 \mathrm{~mm}(2 \mathrm{in}$.$) , respectively. Both CP systems$ 
were slotted systems built into the bare decks. In both decks the slots were primarily longitudinal. They were about $19 \mathrm{~mm}(3 / 4 \mathrm{in}$.) deep, $25 \mathrm{~mm}$ ( 1 in.) wide, $0.3 \mathrm{~m}(1 \mathrm{ft}$.$) apart,$ and filled with a conductive polymer. Field testing of the test bridge decks was conducted during the summer/fall of 1988 and spring/summer of 1989. At the time of the testing, the average age of both the LMC and LSDC overlays was about seven years, and the average age of the $\mathrm{CP}$ installations was about five years. The test areas on each deck comprised the driving lane and the adjacent shoulder.

The conclusions are:

1. After an average of seven years of service, both LMC and LSDC overlaid decks showed various levels of post-overlay corrosion-induced deterioration rates. Those rates ranged from none to about $1 \%$ of the deck area per year. The average deterioration rate of LMC decks was $0.4 \%$ of the deck area per year, and that of LSDC decks was $0.5 \%$ of the deck area per year.

2. The post-overlay deterioration rates of the LMC and LSDC overlaid decks correlated with the magnitude of overlay surface cracking. The deteriorated areas almost always coincided with surface cracking. However, surface cracking was also found in sound areas. Overlay surface cracking has the potential to accelerate corrosion-induced deterioration by wetting the deck and by periodically facilitation, through drying, the intrusion of new water and oxygen into the concrete. 
3. The effect of overlay surface cracking on the deterioration of decks overlaid with LMC seemed to be more severe than the effect of cracking on the deterioration of decks overlaid with LSDC. This difference in behavior is probably related to the thickness of the overlay.

4. The mode of corrosion-induced deterioration in the concrete overlaid decks was internal cracking of the concrete surrounding the corroding bar, propagation of the internal crack diagonally toward the overlay interface, and extension of the internal crack along the overlay interface. This condition had caused the overlay to debond near the corroding bar.

5. After about five years of service, both of the cathodically protected decks showed satisfactory performance with regard to the corrosion of the reinforcing steel.

6. Three problems with the durability of the slotted CP systems were noted. Those were

- small and shallow spalls in the concrete adjacent to the slots,

- internal crack in the concrete that originated from the bottom of the slot, and

- acid deterioration at the interface of the slot and deck concrete. The first two problems were related to the slots and traffic impact. The third problem was related to the humidity of the environment. 
7. On the basis of a bridge deck life-time costs and the unit costs used in this study for installing a protective system and rehabilitating/resurfacing the deck, a concrete overlay strategy seems to be more cost effective than $\mathrm{CP}$ systems. However, if any continuation of corrosion or corrosion-induced deterioration cannot be tolerated, because of structural integrity concerns, then cathodic protection may be a better alternative.

Sprinkel, 1992 studied fourteen bridge decks with latex-modified concrete (LMC) overlays ranging in age from 2 to 20 years and two overlays without latex.

The LMC overlays on bridges 1B, 1D, and 2 and the overlays without latex on bridges $1 \mathrm{~A}$ and $1 \mathrm{C}$ were placed as part of the construction of a new deck. The overlays on the other 11 bridges were used to rehabilitate older decks. Bridges 1-A, 1-B, 1-C, and 1$\mathrm{D}$ are separate spans of 2 bridges. Spans 1-B and 1-D have 2 in.-thick LMC overlays, and spans 1-A and 1-C have 2 in. thick PCC overlays without latex ( 2 in. maximum slump). The LMC overlays on bridges 2 and 4 do not contain coarse aggregate. Bridge 4 has five spans. Spans A, B, and C were overlaid with LMC, and spans 4-D and 4-E were completely replaced with A4 concrete. Unless indicated otherwise, the data refer to spans A, B, and C. Two liquid membrane curing materials were used to cure four experimental areas of the overlays of bridge 17. Bridge 18 was Virginia's first high-early-strength LMC (LMC-HE) overlay. The following Table shows the general information of decks.

Sprinkel did the rapid permeability test (AASHTO T 277), bond strength tests, compressive strength test, chloride ion content test (AASHTO T260), and half-cell 
potential test (ASTM C876-77). He evaluated the rate of corrosion, shrinkage cracks, and spalls and patches.

Three cores were removed from each of the 14 LMC overlays and the 2 overlays without latex and subjected to shear tests. The average shear bond rupture strength of the LMC overlays was 640 psi, with $71 \%$ of the failures in the base concretes. The average shear strength for the LMC overlays was 931 psi as compared with 581 psi for the overlays without latex. The average shear strength of the base concretes was 603 psi.

Seven ACI 503R tensile adhesion tests were conducted on each of the 14 LMC overlays and the 2 overlays without latex. The average tensile rupture strength of the LMC overlays was 233 psi with $68 \%$ of the failures in the base concretes. The tensile bond strength data agree with the shear bond strength data.

The results of shear and tensile strength tests showed the shear and tensile bond strengths of the LMC overlays and the overlays without the latex are high, and the strength of the bond interface is usually as high or higher that that of the base concrete.

Four cores that had diameters of 2.25 in. and were approximately 6.5 in. long were removed from each of the 14 LMC overlays and the 2 overlays without latex. The cores were sawed perpendicular to the length before testing for compressive strength. The length of the base concrete specimens ranged from 2.5 to 4.0 in. and that of the overlay specimens from 2.0 to $3.9 \mathrm{in}$. The compressive strength of the base concretes ranged from 2860 to $6400 \mathrm{psi}$, with an average of $4500 \mathrm{psi}$. The compressive strength of the LMC overlays ranged from 5450 to 7330 psi, with an average of 5950 psi for the overlays on rehabilitated decks and 5740 psi for the overlays on new decks. The compressive strength of the overlays without latex ranged form 4280 to 4900 psi; the average was 4590 psi. 
The data of chloride ion content test indicated that LMC overlays placed on decks with less than $2 \mathrm{lb} / \mathrm{yd}^{3}$ of chloride ion at the rebar can be expected to have a service life of more than 20 years. The high quality Portland cement concrete overlays without latex showed greater negative increases in half-cell potentials (ASTM C 876-77), greater increases in chloride content, and higher rates of corrosion than the LMC overlays.

He concluded that:

1. The average permeability to chloride ions of a 1.25 in.-thick LMC overlay was 630 coulombs, which is $12 \%$ of the 5274 coulombs found to be the average permeability of the class A4 base concrete on which the overlays were placed. Two in.-thick overlays with and without latex had permeability of 101 and 1305 coulombs, respectively.

2. The shear and tensile rupture strengths at the bond interface between the LMC overlay and the base concretes were typically as good as or better than the shear and tensile strengths of he base concretes, and good bond has been achieved and maintained for 20 years. Although higher bond rupture strengths can be obtained with LMC than with concrete without latex, the higher strengths are not usually obtained because of the low strength of the scarified surface of the base concrete.

3. LMC overlays have been placed over salt-contaminated concrete and steel exhibiting half-cell potentials more negative than $-0.35 \mathrm{~V}$ CSE, and the performance of these overlays continues to be good for as long as 20 years.

4. The half-cell potential measurements and chloride content determinations showed that the LMC overlays are performing satisfactorily. 
5. High-quality PCC overlays without latex showed greater negative increases in half-cell potentials, greater increases in chloride content, and a higher percentage of higher rates of corrosion than similar LMC overlays.

6. LMC overlays placed on decks with less than $2.0 \mathrm{lb} / \mathrm{yd}^{3}$ of chloride ion at the rebar can be expected to have a life of more than 20 years.

Halvorsen, 1993 introduced the purposes for using concrete bridge deck overlays. These are: restoring riding quality, providing added cover as protection for reinforcement, and modifying existing roadway alignment or deck drainage. He said most overlays in US are bonded to the original bridge deck. In some cases unbonded overlays are placed to protect waterproofing membranes.

He indicated that for construction of bonded overlays, the condition of the surface, or substrate, is very important. Hydromilling and shotblasting are common methods for removing unsound concrete and contaminants form the upper surface of an existing deck. Before placing Portland cement-based overlays, wet the existing substrate, then remove standing water. Many specifiers also require applying a bonding material to the existing substrate before placing overlay concrete.

Also curing is important to successful overlay performance. Early curing is especially critical for overlay materials since the mix water content is inherently low and little water loss can be tolerated. Plastic shrinkage, drying shrinkage, and thermal effects can cause cracking unless concrete temperature and moisture content are carefully controlled. 
Halvorsen mentioned three overlay types. They are Low-slump, high-density concrete (LSDC); Silica-fume concrete (SFC); and Latex-modified concrete (LMC).

LSDC is commonly called the "Iowa mix" because of extensive use in that state of a low-slump, high-density overlay mix since 1965 . The high cement content and low water content lead to reduced permeability. However, their low slump can make placement and consolidation difficult.

Silica-fume concrete tends to have a high strength, which leads to good abrasion resistance. Though it mixes are less permeable to moisture, air entrainment is required to produce frost-resistant concrete. Slightly increased dosages of air-entraining admixtures may be needed. Currently, mixes for bridge deck overlays typically contain 40 to 100 pounds per cubic yard of silica fume, with a water-cement ratio of about 0.35 to 0.40 . And slumps should be around 8 in.

Latex-modified mortar was first used as a bridge deck overlay material in 1956. A material called "styrene-butadiene latex" normally is used to modify the properties of Portland cement concrete. Usually supplied as a milky-looking liquid, this material changes the concrete pore structure and reduces its permeability. Compressive strengths may be about the same or slightly less than concretes with similar materials and w/c. Besides being highly impermeable, LMC is noted for bonding tenaciously to the concrete substrate. Typical mixes include latex solids in the amount of $0.15 \%$ by weight of Portland cement and a maximum w/c of about 0.40 .

He concluded that excellent performance can be expected from bridge deck overlays if materials and construction are carefully selected and executed. 
Northcott, 1993 studied in the current practice of concrete overlays, which focused on the economic benefit.

He indicated that concrete overlays can be bonded or unbonded to the existing concrete pavement. Bonded overlays are usually much thinner than unbonded ones. Depending on their purpose they can be: Very Thin-Bonded overlays-under $30 \mathrm{~mm}$ or Thin-bonded overlays -50 to $160 \mathrm{~mm}$. Thin bonded overlays can provide an economical solution in strengthening the pavement and for specific purposes: 1) Restoration of surface profile evenness; 2) Improvement of skid resistance; and 3) Strengthening flexible or concrete pavements in areas where there are restrictions on levels.

Various treatments of the concrete surface have been attempted in different experiments, such as cleaning, scarifying, milling, grooving, shot-blasting, and sandblasting.

Thick concrete overlays can be laid without the need for bonding as they provide a separate structural layer for strengthening the pavements. Minimum thickness is 150 $\mathrm{mm}$.

He concluded that overlays are a more economical method of strengthening and maintaining existing concrete and bituminous roads and restore high-speed skid resistance.

Ozyildirim, 1994 evaluated the general range of combinations of slag and silica fume that could be expected to provide suitable strength and permeability at maximum economy. 
In his study, Type II or III Portland cement, silica fume, and slag were used as cementitious materials. The fine aggregate was siliceous sand, and the coarse aggregate was granite gneiss with a nominal maximum size of $25 \mathrm{~mm}(1 \mathrm{in}$.$) . The air-entraining$ admixture was neutralized vinsol resin at the range of 0.5 to $1.0 \mathrm{ml} / \mathrm{kg}$ ( 0.75 to $1.5 \mathrm{oz}$ per $100 \mathrm{lb})$.

First test series: The freshly mixed concrete was tested for air content (ASTM C231, Pressure Method), slump (ASTM C143), and unit weight (ASTM C138). From each batch, nine cylinders measuring $100 \mathrm{~mm}$ diameter by $200 \mathrm{~mm}$ long (4 in. diameter by 8 in. long) were fabricated for tests on hardened concrete for compressive strength (AASHTO T 22 with neoprene caps) at 1, 7, and 28 days, and four cylinders measuring $100 \mathrm{~mm}$ diameter by $100 \mathrm{~mm}$ long (4 in, diameter by $4 \mathrm{in}$. long) were fabricated for tests of rapid chloride permeability (AASHTO T 277, ASTM C 1202) at 28 days and 1 year.

Second test series: The six batches of concrete were tested for air content, slump, and unit weight. Eighteen $100 \mathrm{~mm}$ diameter by $200 \mathrm{~mm}$ long (4 in. diameter by $8 \mathrm{in}$. long) cylinders were moist-cured at different temperatures and tested in compression at 7 and 28 days. Within 45 min after mixing, specimens in plastic molds with caps were stored in different environments at 6,23 , and $38{ }^{\circ} \mathrm{C}\left(43,73\right.$, and $\left.100{ }^{\circ} \mathrm{F}\right)$.

The results of the first test series showed that concrete with adequate strength and very low permeability can be obtained at 28 days when a small amount of silica fume is used in combination with slag and Type III Portland cement.

The results of the second test series showed that the higher initial curing temperature resulted in lower permeability. 
He concluded that the use of slag or silica fume as a portion of the cementitious material in concrete results the lower chloride permeability, and the strength development will be slower than that of plain concrete.

Glauz, $\mathbf{1 9 9 5}$ did the pull-off tests to determine the overlay tensile adhesion.

In his study, the LMC overlay was $25 \mathrm{~mm}$ (1 in.) thick placed on cracked and seated Portland cement concrete pavement (PCCP). The LMC was specified to have $0.445 \mathrm{~L}$ of latex per $\mathrm{kg}$ of cement ( $5 \mathrm{gal} / \mathrm{sack}$ ) and $389 \mathrm{~kg}$ cement per cubic meter of concrete $(7 \mathrm{sack} / \mathrm{cy})$. The cement was specified as Type II with an alkali content of $0.6 \%$ or less. Lanes one and two were overlaid in two consecutive nights, both lanes at the same time. Lane three was done about a month later.

A modified California Test 420 (similar to ACI 503R, Appendix A) was used. The test results indicated the surface preparation and placement techniques were adequate. After one year, the overlay was found to be debonded at more of the transverse joints and some of them were breaking up under traffic. He did the pull-off tests again. The average pull-off strength of $2.54 \mathrm{MPa}$ is significantly greater than the strengths. However, some reflective cracking got worse, and repaired with polyester concrete. After two years, the overlays continues to look bad with extensive plastic shrinkage cracks that get more obvious as the top corners get rounded by snow-chain wear. The additional delaminations will be repaired with polyester concrete so that the overlay can continue to be monitored. 
He concluded that:

1. A high latex content overlay could be placed and finished using ordinary equipment and finishing techniques.

2. A latex-modified concrete overlay would bond well to a dry clean substrate without wetting or buttering the substrate.

3. Curing compound, when placed at a nominal rate of $3.7 \mathrm{~m}^{2} / \mathrm{L}$, would act as an adequate cure to prevent plastic shrinkage cracking of latex-modified concrete.

4. Detailing of joint construction to ensure joint alignment was very important to prevent delaminations at the joints.

Banthia et al., 1996 developed a novel test technique to assess the cracking potential of cement-based materials when used as a bonded overlay.

They indicated that among the different solutions proposed for controlling shrinkage cracking in applications, the most promising is the use of randomly distributed fibers of steel or polypropylene which provide bridging forces across cracks and thus prevent them from growing.

To develop a test procedure in which realistic conditions of restraint were imposed on an overlay undergoing early-age shrinkage, they cast specimens directly on to a substrate and assembled them in a drying environment to induce cracking. Meanwhile, they used steel fiber in the concrete to assess the validity of the data generated using the proposed technique. The mix proportion of substrate concrete and 
overlay concrete, steel fiber reinforced concrete (SFRC), are shown in the following Table.

\begin{tabular}{|c|c|c|}
\hline Ingredients & Substrate Concrete & Concrete for Testing \\
\hline Cement & 0.9 & 1.0 \\
\hline Silica Fume & 0.1 & -- \\
\hline Water & 0.28 & 0.55 \\
\hline Sand & 1.36 & 1.00 \\
\hline Aggregate (4.74-10.0 mm) & 1.36 & 1.00 \\
\hline Superplasticizer (ml per kg cement) & 2.5 & -- \\
\hline Dramix ZC 30/50 Steel Fibers (\%) & -- & $0.0,0.1,0.5,1.0$ \\
\hline$f_{c}^{\prime}(\mathrm{MPa})$ & 80 & 25 \\
\hline
\end{tabular}

The following Table shows their test results (48 hours after casting).

\begin{tabular}{|c|c|c|c|c|c|c|c|c|c|}
\hline & $\begin{array}{c}\text { Vf } \\
(\%)\end{array}$ & $\begin{array}{c}\mathrm{t}_{\text {first }}{ }^{\mathrm{a}} \\
(\mathrm{min})\end{array}$ & $\begin{array}{c}\mathrm{t}_{80 \%}{ }^{\mathrm{b}} \\
(\mathrm{min})\end{array}$ & $\begin{array}{c}\mathrm{W}_{\mathrm{mzx}}^{\mathrm{c}} \\
(\mathrm{mm})\end{array}$ & $\begin{array}{c}\mathrm{W}_{\mathrm{c}}^{\mathrm{d}} \\
(\mathrm{mm})\end{array}$ & $\begin{array}{c}\mathrm{L}_{\mathrm{c}}^{\mathrm{e}} \\
(\mathrm{mm})\end{array}$ & $\mathrm{L}_{\mathrm{c}} / \mathrm{w}_{\mathrm{c}}$ & $\begin{array}{c}\mathrm{A}_{\text {crack }}{ }^{\mathrm{f}} \\
\left(\mathrm{mm}^{2}\right)\end{array}$ & $\mathrm{n}^{\mathrm{g}}$ \\
\hline \multirow{3}{*}{ Plain } & -- & 2 & 40 & 2.83 & 4.51 & 231 & 51.2 & 526 & 2 \\
\hline \multirow{3}{*}{ SFRC } & 0.1 & 2 & 65 & 1.84 & 4.17 & 342 & 82.0 & 473 & 3 \\
\cline { 2 - 10 } & 0.5 & 17 & 200 & 0.69 & 4.82 & 821 & 170.3 & 368 & 14 \\
\cline { 2 - 10 } & 1.0 & 50 & 240 & 0.38 & 0.38 & 72 & 189.5 & 27 & 1 \\
\hline
\end{tabular}

\footnotetext{
${ }^{a}$ time after demolding at which the first crack appears

${ }^{\mathrm{b}}$ time after demolding at which $80 \%$ of $\mathrm{A}_{\text {crack }}$ is achieved

${ }^{c}$ max observed crack width

d cumulative crack width

${ }^{\mathrm{e}}$ cumulative crack length

${ }^{\mathrm{f}}$ total crack area

${ }^{g}$ number of cracks
}

Based on limited tests, they concluded that steel fibers not only reduced the maximum crack widths but also caused multiple cracking in the composite up to a fiber volume fraction of $0.5 \%$. At $1 \%$ fibers by volume, only minimal cracking was seen to occur even under a particularly severe environment. 
Fitch and Abdulshafi, 1996 evaluated the properties of silica fume modified concrete (SFMC) mixes that have been used by the Ohio DOT for bridge deck overlays since 1984 under field and laboratory conditions. The research methods included construction monitoring of 9 overlay placement projects, visual inspections of 145 decks, in-depth condition surveys of 28 decks, and testing of laboratory SFMC mixes with materials obtained form the construction monitoring projects.

The SFMC overlays were required:

- Overlay not less than $3.2 \mathrm{~cm}$ (1.25 in.) thick;

- SFMC mixture proportions as shown in the following Table and maximum w/c (not including silica fume) of 0.36 ;

\begin{tabular}{|c|c|c|c|c|c|}
\hline \multicolumn{7}{|c|}{ Quantities of Material per Cubic Meter (Dry Weights*) } \\
\hline $\begin{array}{c}\text { Type of } \\
\text { Coarse }\end{array}$ & $\begin{array}{c}\text { Coarse } \\
\text { Aggregate } \\
(\mathrm{kg})\end{array}$ & $\begin{array}{c}\text { Fine } \\
\text { Aggregate } \\
(\mathrm{kg})\end{array}$ & $\begin{array}{c}\text { Cement } \\
(\mathrm{kg})\end{array}$ & $\begin{array}{c}\text { Silica } \\
\text { Fume } \\
(\mathrm{kg})\end{array}$ & $\begin{array}{c}\text { Max } \\
\mathrm{w} / \mathrm{c}\end{array}$ \\
\hline Ggregate & 751 & 848 & 415 & 41.5 & 0.36 \\
Limestone & 759 & 848 & 415 & 41.5 & 0.36 \\
Slag & 659 & 848 & 415 & 41.5 & 0.36 \\
\hline
\end{tabular}

- Air content of fresh SFMC of 6 to 10 percent and slump of 10.2 to $20.3 \mathrm{~cm} \mathrm{(4}$ to 8 in.);

- Application of bonding grout to prepared deck surface immediately before placement of SFMC overlay;

- Transverse texturing of overlay surface after finishing; and

- Continuous wet curing for $72 \mathrm{hr}$.

Field surveys include Visual inspections, Condition surveys and Groundpenetrating radar (GPR) surveys.

Laboratory tests include Testing of permeability to chloride ions (AASHTO T277-89, "Rapid Determination of the Chloride Permeability of Concrete.") and Testing 
of overlay bond strength (Figure 8 of ACI 546.1R-80, "Guide for Repair of Concrete Bridge Superstuctures.”).

In their study, percentage of laboratory-prepared SFMC overlay specimens for which overlay bond strength exceeded concrete strength under direct tensile loading were shown in the following table.

\begin{tabular}{lllll}
\hline Test & Grout & \multicolumn{3}{c}{ Surface Condition } \\
\cline { 3 - 5 } Age & Option & Dry & SSD & Wet \\
\hline 14 & Grout & $100 \%(4 / 4)$ & $67 \%(4 / 6)$ & $0 \%(0 / 4)$ \\
Days & No Grout & $100 \%(5 / 5)$ & $80 \%(4 / 5)$ & $0 \%(0 / 4)$ \\
56 & Grout & $100 \%(6 / 6)$ & $33 \%(2 / 6)$ & $67 \%(4 / 6)$ \\
Days & No Grout & $100 \%(6 / 6)$ & $50 \%(2 / 4)$ & $0 \%(0 / 6)$ \\
\hline
\end{tabular}

The tensile failure loads ranged from 930 to $2550 \mathrm{kPa}$ (135 to $370 \mathrm{psi}$ ) in cases in which failure occurred at the overlay interface and from 3090 to $3910 \mathrm{kPa}$ (448 to 567 psi) in cases in which failure occurred within the PCC or SFMC portions of the specimens.

They concluded that:

1. The overall performance of 145 SFMC overlays in Ohio was good, with none of the overlays showing spalling or patching at ages ranging from 1 to 6 years. However, instances of drying shrinkage cracking were noted.

2. In the evaluation of existing SFMC-overlaid decks, it was concluded that manual sounding methods per ASTM D4580-86 were considerably more successful than GPR in correctly detecting areas of horizontal cracking.

3. Inspection of the undersides of existing SFMC-overlaid decks indicated that in most cases, full-depth repair areas had been filled using SFMC at the time of 
overlay. It is our opinion that the practice of placing partial- or full-depth SFMC repairs simultaneously with the overlay should be avoided. Prior placement of variable-depth PCC with subsequent placement of an SFMC overlay of uniform thickness is referable.

4. Prevention of excessive moisture loss from the fresh SFMC overlay surface by following the evaporation rate guidelines presented in ACI 308-92 is considered to be essential.

5. Although there are products that are marketed for use as both an evaporation retardant and a finishing aid, it is our opinion that the application of any liquid material to the concrete surface while finishing is in progress should be avoided.

6. The results of small-scale testing of laboratory-prepared overlay bond strength specimens under direct tensile loading suggest that the use of bonding grout may be unnecessary.

7. Both the grouted and ungrouted sets of overlay specimens tested in this study clearly showed optimum SFMC bond strength when the substrate concrete was dry at the time of overlay.

Ozyildirim et al., 1996 investigated the properties of fiber-reinforced concretes (FRCs) with steel (hooked-end), polypropylene (monofilament and fibrillated), and polyolefin fibers (monofilament) for application in pavements and bridge deck overlays.

They used the same basic mixture proportion and added different fibers with different volume percentages. The specimens were tested in the freshly mixed state for 
slump (ASTM C143), inverted slump (ASTM C995), air content (ASTM C231), unit weight (ASTM C138), and temperature (ASTM C1064), and in hardened state for compression testing (ASTM C39), splitting tensile strength testing (ASTM C496), firstcrack strength and flexural toughness testing (ASTM C1018), and impact testing (ACI 544.2R).

They concluded that:

- The use of fibers reduces the workability of concrete. However, with the addition of HRWRAs, workability similar to that of concretes without fibers is achieved.

- Although the ultimate splitting tensile strength, compressive strength, and first-crack strength are higher in most FRCs, only a few demonstrate increased strength after adjustments for air content.

- The impact resistance of concretes is greatly improved with increases in fiber volume and length. Concretes with polyolefin and steel fibers have the highest impact resistance.

- The toughness of concretes improves with increases in fiber volume. The highest toughness values are achieved with steel fibers, followed by polyolefin fibers, and then polypropylene fibers.

- Field results are in accordance with laboratory results. After 1 year, crack propagation and widening appear to be controlled in FRCs in the field. 
Detwiler et al., 1997 evaluated overlays placed on IL 4 bridge, which was built in 1973 on State Route 4 near Staunton, IL. The bridge is approximately $300 \mathrm{ft}(91 \mathrm{~m})$ long with two traffic lanes separated by a median strip. In Oct. 1986 the southbound lane was repaired using a standard dense mix concrete; the north bound lane was repaired in March 1987 using a silica fume concrete. The mix proportions are given in the following table.

\begin{tabular}{|c|c|c|}
\hline & $\begin{array}{c}\text { Silica fume concrete (SFC) } \\
(\mathrm{w} / \mathrm{cm}=0.31)\end{array}$ & $\begin{array}{c}\text { Dense concrete (DC) } \\
(\mathrm{w} / \mathrm{cm}=0.32)\end{array}$ \\
\hline Water & $218 \mathrm{lb} / \mathrm{yd}^{3}\left(129 \mathrm{~kg} / \mathrm{m}^{3}\right)$ & $264 \mathrm{lb} / \mathrm{yd}^{3}\left(157 \mathrm{~kg} / \mathrm{m}^{3}\right)$ \\
\hline Cement & $630 \mathrm{lb} / \mathrm{yd}^{3}\left(374 \mathrm{~kg} / \mathrm{m}^{3}\right)$ & $823 \mathrm{lb} / \mathrm{yd}^{3}\left(488 \mathrm{~kg} / \mathrm{m}^{3}\right)$ \\
\hline Silica fume & $70 \mathrm{lb} / \mathrm{yd}^{3}\left(42 \mathrm{~kg} / \mathrm{m}^{3}\right)$ & 0 \\
\hline Coarse aggregate & $1590 \mathrm{lb} / \mathrm{yd}^{3}\left(943 \mathrm{~kg} / \mathrm{m}^{3}\right)$ & $1389 \mathrm{lb} / \mathrm{yd}^{3}\left(824 \mathrm{~kg} / \mathrm{m}^{3}\right)$ \\
\hline Fine aggregate & $1358 \mathrm{lb} / \mathrm{yd}^{3}\left(806 \mathrm{~kg} / \mathrm{m}^{3}\right)$ & $1410 \mathrm{lb} / \mathrm{yd}^{3}\left(837 \mathrm{~kg} / \mathrm{m}^{3}\right)$ \\
\hline \multirow{2}{*}{$\begin{array}{c}\text { Strength, } 7 \text { days } \\
14 \text { days }\end{array}$} & $5780 \mathrm{psi}(40 \mathrm{MPa})$ & $5660 \mathrm{psi}(39 \mathrm{MPa})$ \\
\cline { 2 - 4 } & $6950 \mathrm{psi}(48 \mathrm{MPa})$ & $6370 \mathrm{psi}(44 \mathrm{MPa})$ \\
\hline Air content & $6.0-8.4 \mathrm{percent}$ & $5.5-6.3 \mathrm{percent}$ \\
\hline
\end{tabular}

In their field survey, the silica fume overlay indicated good performance. The surface shows very little abrasion wear, with the tine marks clearly visible. The dense concrete overlay indicated a similar degree of cracking. The surface shows good resistance to abrasion and freezing and thawing and is well bonded to the concrete substrate. Chain dragging indicated delamination in 8 areas representing less than $1 \%$ of the total overlay.

In their laboratory investigation, a total of 10 numbers 4 in. $(100 \mathrm{~mm})$ diameter cores were taken from the silica fume concrete overlay and two from the dense concrete 
overlay. These were examined according to ASTM C 856-83, "Standard Practice for Petrographic Examination of Hardened Concrete." Properties of concrete that are important for durability were considered excellent in both SFC and DC.

Four cores of each concrete were tested according to ASTM C 1202-94, "Standard Test Method for Electrical Indication of Concrete's Ability to Resist Chloride Ion Penetration." Total charge passed, coulombs, in six hours (ASTM C 1202) were shown in the following table.

\begin{tabular}{|c|c|}
\hline Silica fume concrete & Dense concrete \\
\hline 240 & 1350 \\
\hline 330 & 2200 \\
\hline 250 & 2720 \\
\hline 140 & 2380 \\
\hline
\end{tabular}

They concluded that from the field survey and the perographic examination, it is clear that both the DC and the SFC overlay repairs were originally of high quality. And silica fume concrete to have very low chloride ion penetrability.

Sprinkel, 1998 evaluated the first two very-early-strength latex modified concrete (LMC-VE) overlays constructed for the Virginia DOT. One overlay was constructed on the bridge, which was constructed in 1945 and has 33 simple spans, concrete beams, and two lanes, one eastbound (EBL) and one westbound (WBL). The average daily traffic was 14,000 in 1997 . The other overlay was constructed on the WBL of a structure, which was a four-span, continuous steel beam structure with three lanes. The average daily traffic was 63,632 in 1997. 
The procedures for installing the LMC-VE overlays were the same as for installing an LMC overlay, although the time required for each step was less. Very early strength is achieved with the special blended cement because of the fineness and the high $\mathrm{Al}_{2} \mathrm{O}_{3}$ and $\mathrm{SO}_{3}$ content.

The following table shows mixture proportions of LMC-VE, LMC-HE, and standard LMC.

\begin{tabular}{|c|c|c|c|}
\hline Mixture & LMC-VE & LMC-HE & LMC \\
\hline Cement & $388(658)$ & $481(815)$ & $388(658)$ \\
Fine aggregate & $944(1600)$ & $827(1402)$ & $927(571)$ \\
Coarse aggregate & $689(1168)$ & $674(1142)$ & $728(1234)$ \\
Latex (includes 52\% water) & $121(205)$ & $129(218)$ & $121(205)$ \\
Water & $81(137)$ & $97(164)$ & $81(137)$ \\
\hline
\end{tabular}

Note: Units are $\mathrm{kg} / \mathrm{m}^{3}\left(\mathrm{lb} / \mathrm{yd}^{3}\right)$.

Cylinders of concrete, 4 in diameter and 8 in high, were fabricated and tested in compression using steel end caps and neoprene pads (AASHTO T22). During the first 24 hours of age, the specimens were cured in plastic molds with wet burlap on the surface. Then specimens were removed from the molds and air cured in the laboratory. Curing temperature is also a major factor in the development of compressive strength. The following figures show the compressive strength test results.

Cylinders prepared at the job sites, cured in cylinder molds for 24 hours, and cured in air thereafter until tested. The values for tests at 4 weeks of age are similar to those found for conventional LMC. The values for tests at 6 weeks, 5 months, and 12 months of age are lower than the 1000, 800, and 500 coulomb values, respectively, typically obtained for conventional LMC. The following table shows sprinkel's test results. 
The tensile strength test showed that LMC-VE provided high bond strength. The failures in the base concrete just below the bond interface typically indicated damage caused by concrete removal operations such as the use of milling machines. The cracks were typically near the outside edge of the WBL where the screed rollers reversed direction when striking off the overlay.

Sprinkel concluded that LMC-VE overlay could be placed and opened to traffic with as little as 3 hours cure time and that the initial condition of the overlays was as good as that of the more proven LMC-HE and conventional LMC overlays. LMC-VE overlays were an economical alternative to conventional concrete overlays. LMC-VE overlays should be used to reduce the cost of overlay construction and to minimize the inconvenience to motorists of overlay construction.

Sprinkel and Ozyildirim, 1998 evaluated sixteen high-performance concrete overlays with 13 concrete mixtures placed on two bridges. One overlay was constructed with concrete containing a new shrinkage-reducing admixture. The fresh (air content and slump) and hardened (strength, permeability, and drying shrinkage) properties are presented, with an emphasis on shrinkage characteristics. Based on a visual survey, all overlays were performing satisfactorily at 1 year after placement.

All material batches contained a Type I/II Portland cement and one or more pozzolanic materials, as shown in the Table. 


\begin{tabular}{|c|c|c|c|c|c|c|}
\hline \multicolumn{2}{|c|}{ Overlay } & \multirow{2}{*}{$\begin{array}{c}\text { Silica } \\
\text { Fume(\%) } \\
7\end{array}$} & $\begin{array}{c}\text { Fly } \\
\text { Ash }(\%)\end{array}$ & \multirow{2}{*}{$\begin{array}{l}\text { Slag } \\
(\%)\end{array}$} & \multirow{2}{*}{$\begin{array}{l}\text { Maximum } \\
(\mathrm{W} / \mathrm{CM})\end{array}$} & \multirow[t]{2}{*}{ Other } \\
\hline 1 & $\mathrm{~A}$ & & & & & \\
\hline 2 & $\mathrm{~B}$ & 5 & & 35 & 0.40 & \\
\hline 3 & $\mathrm{C}$ & 5 & 15 & & 0.40 & \\
\hline 4 & $\mathrm{D}$ & & & & 0.40 & $15 \%$ latex modified concrete \\
\hline 5 & $\mathrm{E}, \mathrm{F}^{\mathrm{a}}$ & 13 & 15 & & 0.25 & \\
\hline 6 & G & 7 & & & 0.40 & $5 \mathrm{~L} / \mathrm{m}^{3}$ Rheocrete 222 \\
\hline 7 & $\mathrm{H}, \mathrm{H}^{* \mathrm{~b}}$ & 7 & & & 0.40 & $\begin{array}{l}2.5 \mathrm{~L} / \mathrm{m}^{3} \text { Armatec } 2000 \text { and } \\
5.5 \mathrm{~m}^{2} / \mathrm{L} \text { topical application of } \\
\text { Armatec } 3020\end{array}$ \\
\hline 8 & $\mathrm{I}, \mathrm{I}^{* \mathrm{c}}$ & 7 & & & 0.40 & $\begin{array}{l}20 \mathrm{~L} / \mathrm{m}^{3} \mathrm{DCI}^{\mathrm{e}} \text { and } 3.1 \mathrm{~m}^{2} / \mathrm{L} \\
\text { topical application of Postrite }\end{array}$ \\
\hline 9 & $\mathrm{~J}$ & & & 40 & 0.45 & - \\
\hline 10 & $\mathrm{~K}$ & 7 & & & 0.40 & $7.4 \mathrm{~L} / \mathrm{m}^{3} \mathrm{SRA}^{\mathrm{d}}$ \\
\hline 11 & $\mathrm{~L}$ & 7 & & & 0.40 & $\begin{array}{l}14.8 \mathrm{~kg} / \mathrm{m}^{3} \text { polyolefin fibers } 50 \\
\mathrm{~mm} \text { long }\end{array}$ \\
\hline 12 & $\mathrm{M}$ & 7 & & & 0.40 & $\begin{array}{l}29.5 \mathrm{~kg} / \mathrm{m}^{3} \text { steel fibers } 25 \mathrm{~mm} \\
\text { long }\end{array}$ \\
\hline 13 & $\mathrm{~N}$ & 7 & & & 0.40 & $\begin{array}{l}3 \mathrm{~kg} / \mathrm{m}^{3} \text { polypropylene fibers } 19 \\
\mathrm{~mm} \text { long }\end{array}$ \\
\hline
\end{tabular}

${ }^{a}$ Overlays had a minimum thickness of $32 \mathrm{~mm}$ except $\mathrm{F}$, which had $19 \mathrm{~mm}$.

${ }^{\mathrm{b}} \mathrm{H}^{*}$ had only Armatec 2000.

${ }^{\mathrm{c}} \mathrm{I}^{*}$ had only DCI.

${ }^{\mathrm{d}} \mathrm{SRA}=$ shrinkage reducing admixture.

${ }^{\mathrm{e}} \mathrm{DCI}=$ inorganic corrosion inhibitor

Average air contents ranged from 3.5 to 9.8 percent. $G$ has the lowest air content, and $\mathrm{N}$ has the highest air content. Average slumps ranged from 50 to $210 \mathrm{~mm}$. The lowest value was obtained for $\mathrm{L}$, and the highest value was obtained for $\mathrm{H}, \mathrm{H}^{*}$. All mixtures, 
except L, were very workable. Concrete with the SRA required a high dosage of airentraining admixture.

The 1-day compressive strength of the SF and LMC concretes were in excess of $20 \mathrm{MPa}$, except the high-SF mix (E, F), which was delayed by the high dosage of highrange water reducing admixture (HRWRA). At 28 days, compressive strengths were satisfactory - the lowest was $31.4 \mathrm{MPa}$ for J, and the highest was E, F. Flexural strengths at 28 days were $4.8 \mathrm{MPa}$ or higher. The tensile bond strength exceeded $0.9 \mathrm{MPa}$ and was considered satisfactory. All concretes except J had very low permeability.

At 36 weeks, most of the shrinkage values were within the 0.05 and 0.06 percent range, and the concrete with SRA (K) had a lowest value 0.0397. The highest was obtained in D followed by I, I* and E, F. The mixture with SF (A) had a value of only $0.0536 \%$.

They concluded that:

1. High-performance concrete overlays that have low permeability to chloride penetration and satisfactory compressive, flexural, and bond strengths can be constructed with a variety of combinations of silica fume, fly ash, slag, latex, corrosion-inhibiting admixtures, SRA and fibers.

2. The concretes with the SRA have the lowest shrinkage values.

3. The overlays with the polyolefin fibers have a rough surface.

4. The overlays are in good condition after 1 year.

Fowler, 1999 reviewed polymers in concrete and studied benefits of them. 
He mentioned that polymers in concrete have received significant publicity over the past 25 years. Many optimistic projections were made as to the future widespread use of polymer-impregnated concrete (PIC), polymer concrete (PC), and polymer-modified concrete (PMC).

PMC and PC came into use in the 1950s, although the uses were very limited. It was only in the 1970s, after PIC was developed that concrete-polymer materials received significant publicity.

PIC was produced by impregnating hydrated Portland cement concrete with a low viscosity monomer, usually methyl methacrylate.

PC consists of aggregate with a polymer binder and contains no Portland cement or water. Polyester styrene, acrylics and epoxies have been the most widely used monomers/resins.

PMC using latexes has been in use since the 1950s. PMC consists of Portland cement concrete with a polymer modifier such as acrylic or styrene-butadiene latex (SBR), polyvinyl acetate, and ethylene vinyl acetate.

A fourth use of polymers is to seal cracks in concrete. Epoxy injection was developed to provide a structural repair, but has the disadvantage of being very expensive and slow. The development of high molecular weight methacrylate (HMWM) in the early 1980s for sealing cracks was a major development.

He concluded that PIC, PC and PMC have received considerable attention over the past 25 years. These materials have been used for repair of concrete, overlays, and precast components. Their limitations include cost, odor, toxicity, and flammability. 


\section{Appendix B}

\section{Experimental Data}

Free Shrinkage at Different Ages

\begin{tabular}{|c|c|c|c|c|c|}
\hline Days of Drying & NC & LMC & MMC & MMC-FA & FRC \\
\hline (After curing) & (micro strain) & (micro strain) & (micro strain) & (micro strain) & (micro strain) \\
\hline 3 & 123 & 0 & 171 & 147 & 211 \\
\hline 6 & 240 & 0 & 352 & 360 & 299 \\
\hline 9 & 320 & 91 & 392 & 363 & 491 \\
\hline 12 & 405 & 165 & 571 & 472 & 459 \\
\hline 15 & 485 & 208 & 496 & 539 & 573 \\
\hline 18 & 541 & 299 & 600 & 643 & 619 \\
\hline 21 & 579 & 347 & 616 & 536 & 712 \\
\hline 24 & 595 & 355 & 587 & 555 & 592 \\
\hline 27 & 560 & 360 & 584 & 557 & 589 \\
\hline 30 & 576 & 376 & 597 & 587 & 603 \\
\hline 33 & 563 & 387 & 605 & 616 & 640 \\
\hline 36 & 592 & 405 & 624 & 576 & 677 \\
\hline 39 & 621 & 429 & 651 & 547 & 624 \\
\hline 42 & 643 & 461 & 603 & 541 & 595 \\
\hline 45 & 643 & 464 & 573 & 544 & 595 \\
\hline 48 & 648 & 493 & 568 & 589 & 587 \\
\hline 51 & 635 & 475 & 571 & 619 & 648 \\
\hline 54 & 675 & 531 & 611 & 600 & 672 \\
\hline 57 & 691 & 552 & 643 & 613 & 656 \\
\hline 60 & 672 & 533 & 619 & 653 & 667 \\
\hline 63 & 648 & 515 & 637 & 589 & 715 \\
\hline 66 & 699 & 581 & 677 & 624 & 651 \\
\hline 69 & 720 & 605 & 621 & 653 & 680 \\
\hline 72 & 728 & 611 & 651 & 611 & 717 \\
\hline 75 & 725 & 615 & 660 & 670 & 660 \\
\hline
\end{tabular}

Note: The irregularities in the values of shrinkage was due to some fluctuations of

humidity and temperature of the environmental room where the specimens were stored.

However the values of humidity and temperature were within the limit as mentioned in the main text. 
Charge Passed with Time

\begin{tabular}{|c|c|c|c|c|c|}
\hline $\begin{array}{c}\text { Time } \\
\text { (Minutes) }\end{array}$ & $\begin{array}{c}\text { NC } \\
\text { (Coulombs) }\end{array}$ & $\begin{array}{c}\text { LMC } \\
\text { (Coulombs) }\end{array}$ & $\begin{array}{c}\text { MMC } \\
\text { (Coulombs) }\end{array}$ & $\begin{array}{c}\text { MMC-FA } \\
\text { (Coulombs) }\end{array}$ & $\begin{array}{c}\text { FRC } \\
\text { (Coulombs) }\end{array}$ \\
\hline 0 & 0 & 0 & 0 & 0 & 0 \\
\hline 30 & 259 & 62 & 46 & 37 & 55 \\
\hline 60 & 548 & 127 & 93 & 75 & 113 \\
\hline 90 & 871 & 191 & 140 & 114 & 173 \\
\hline 120 & 1230 & 258 & 189 & 154 & 235 \\
\hline 150 & 1626 & 325 & 237 & 194 & 298 \\
\hline 180 & 2059 & 394 & 286 & 236 & 362 \\
\hline 210 & 2531 & 463 & 335 & 278 & 427 \\
\hline 240 & 3038 & 534 & 384 & 321 & 491 \\
\hline 270 & 3595 & 605 & 434 & 364 & 557 \\
\hline 300 & 4187 & 677 & 484 & 408 & 623 \\
\hline 330 & 4815 & 749 & 533 & 453 & 690 \\
\hline 360 & 5477 & 822 & 583 & 497 & 757 \\
\hline
\end{tabular}


Data of Direct Shear Test

\begin{tabular}{|c|c|c|c|c|}
\hline $\begin{array}{c}\text { Overlay } \\
\text { Mixture Types }\end{array}$ & $\begin{array}{l}\text { Treatment on } \\
\text { Substrate }\end{array}$ & Max Load (Ibs) & $\begin{array}{l}\text { Interface } \\
\text { Shear } \\
\text { Strength } \\
\text { (psi) }\end{array}$ & Failure Description \\
\hline LMC (1) & Acid Etching & 3574 & & Substrate \\
\hline LMC (2) & Acid Etching & 3818 & & Substrate \\
\hline LMC (3) & Acid Etching & 3447 & & Substrate \\
\hline LMC (4) & Acid Etching & 3681 & & Substrate \\
\hline LMC (5) & Acid Etching & 4248 & & Substrate \\
\hline LMC (6) & Acid Etching & 3926 & & Substrate \\
\hline LMC (7) & Acid Etching & 3330 & & Substrate \\
\hline LMC (8) & Acid Etching & 4189 & & Substrate \\
\hline LMC (1) & Mech. Abrasion & 4014 & & Substrate \\
\hline LMC (2) & Mech. Abrasion & 4248 & & Substrate \\
\hline LMC (3) & Mech. Abrasion & 4209 & & Substrate \\
\hline LMC (4) & Mech. Abrasion & 3555 & & Substrate \\
\hline LMC (5) & Mech. Abrasion & 6563 & & Substrate \\
\hline LMC (6) & Mech. Abrasion & 4355 & & Substrate \\
\hline LMC (7) & Mech. Abrasion & 3779 & & Substrate \\
\hline LMC (8) & Mech. Abrasion & 2441 & & Substrate \\
\hline MMC (1) & Acid Etching & 1982 & 227 & Interface \\
\hline MMC (2) & Acid Etching & 2891 & 330 & Interface \\
\hline MMC (1) & Mech. Abrasion & 2471 & 282 & Interface \\
\hline MMC (2) & Mech. Abrasion & 2529 & & $60 \%$-Interface, $40 \%$-Overlay \\
\hline MMC (3) & Mech. Abrasion & 2021 & 231 & Interface \\
\hline MMC (4) & Mech. Abrasion & 2295 & 262 & Interface \\
\hline MMC (5) & Mech. Abrasion & 3320 & 379 & Interface \\
\hline MMC (6) & Mech. Abrasion & 2168 & 248 & Interface \\
\hline MMC (7) & Mech. Abrasion & 2246 & 257 & Substrate \\
\hline MMC (8) & Mech. Abrasion & 2852 & 326 & Interface \\
\hline MMC-FA (1) & Acid Etching & 2803 & 320 & Interface \\
\hline MMC-FA (2) & Acid Etching & 2158 & & 70\%-Interface, $30 \%$-Overlay \\
\hline MMC-FA (3) & Acid Etching & 2881 & 329 & Interface \\
\hline MMC-FA (4) & Acid Etching & 4150 & 474 & Interface \\
\hline MMC-FA (5) & Acid Etching & 2725 & 311 & Interface \\
\hline MMC-FA (6) & Acid Etching & 2236 & 256 & Interface \\
\hline MMC-FA (7) & Acid Etching & 4219 & 482 & Interface \\
\hline MMC-FA (8) & Acid Etching & 4277 & 489 & Interface \\
\hline
\end{tabular}




\begin{tabular}{|c|c|c|c|c|}
\hline MMC-FA (1) & Mech. Abrasion & 2969 & 339 & Interface \\
\hline MMC-FA (3) & Mech. Abrasion & 2852 & 326 & Interface \\
\hline MMC-FA (4) & Mech. Abrasion & 3252 & 372 & Interface \\
\hline MMC-FA (5) & Mech. Abrasion & 2832 & 324 & Interface \\
\hline MMC-FA (6) & Mech. Abrasion & 3398 & 388 & Interface \\
\hline MMC-FA (7) & Mech. Abrasion & 4658 & 532 & Interface \\
\hline MMC-FA (8) & Mech. Abrasion & 2549 & 291 & Interface \\
\hline FRC (1) & Acid Etching & 3975 & 454 & Interface \\
\hline FRC (2) & Acid Etching & 1836 & 210 & Interface \\
\hline FRC (3) & Acid Etching & 1709 & 195 & Interface \\
\hline FRC (4) & Acid Etching & 2129 & 243 & Interface \\
\hline FRC (5) & Acid Etching & 1162 & 133 & Interface \\
\hline FRC (6) & Acid Etching & 1787 & 204 & Interface \\
\hline FRC (7) & Acid Etching & 3574 & 408 & Interface \\
\hline \hline FRC (1) & Mech. Abrasion & 1992 & 228 & Interface \\
\hline FRC (2) & Mech. Abrasion & 2246 & 257 & Interface \\
\hline FRC (3) & Mech. Abrasion & 2773 & & Substrate \\
\hline FRC (4) & Mech. Abrasion & 2695 & 308 & Interface \\
\hline FRC (5) & Mech. Abrasion & 4209 & 481 & Interface \\
\hline FRC (6) & Mech. Abrasion & 2031 & 232 & Interface \\
\hline FRC (7) & Mech. Abrasion & 2715 & 310 & Interface \\
\hline FRC (8) & Mech. Abrasion & 2557 & & Substrate \\
\hline
\end{tabular}

